\title{
Unboxing the molecular modalities of mutagens in cancer
}

\author{
Smita Kumari ${ }^{1}$ - Sudhanshu Sharma ${ }^{1} \cdot$ Dia Advani ${ }^{1} \cdot$ Akanksha Khosla $^{1} \cdot$ Pravir Kumar $^{1} \cdot$ Rashmi K. Ambasta $^{1}$
}

Received: 24 April 2021 / Accepted: 22 September 2021 / Published online: 5 October 2021

(C) The Author(s), under exclusive licence to Springer-Verlag GmbH Germany, part of Springer Nature 2021

\begin{abstract}
The etiology of the majority of human cancers is associated with a myriad of environmental causes, including physical, chemical, and biological factors. DNA damage induced by such mutagens is the initial step in the process of carcinogenesis resulting in the accumulation of mutations. Mutational events are considered the major triggers for introducing genetic and epigenetic insults such as DNA crosslinks, single- and double-strand DNA breaks, formation of DNA adducts, mismatched bases, modification in histones, DNA methylation, and microRNA alterations. However, DNA repair mechanisms are devoted to protect the DNA to ensure genetic stability, any aberrations in these calibrated mechanisms provoke cancer occurrence. Comprehensive knowledge of the type of mutagens and carcinogens and the influence of these agents in DNA damage and cancer induction is crucial to develop rational anticancer strategies. This review delineated the molecular mechanism of DNA damage and the repair pathways to provide a deep understanding of the molecular basis of mutagenicity and carcinogenicity. A relationship between DNA adduct formation and cancer incidence has also been summarized. The mechanistic basis of inflammatory response and oxidative damage triggered by mutagens in tumorigenesis has also been highlighted. We elucidated the interesting interplay between DNA damage response and immune system mechanisms. We addressed the current understanding of DNA repair targeted therapies and DNA damaging chemotherapeutic agents for cancer treatment and discussed how antiviral agents, antiinflammatory drugs, and immunotherapeutic agents combined with traditional approaches lay the foundations for future cancer therapies.
\end{abstract}

Keywords Mutation $\cdot$ DNA damage $\cdot$ DNA repair mechanism $\cdot$ Inflammation $\cdot$ Immunotherapy

\section{Introduction}

Genomic integrity is an essentiality that needs to be maintained and assured. Alterations arising from various genotoxic factors like stress induced due to environmental agents and toxins, exposure to ionizing radiations, DNA replicative errors, and various endogenous and exogenous metabolites thus hamper the cellular deoxyribonucleic acid (DNA). As these mutagenic factors affect the molecular signature of DNA, they exert different mutational signatures, which helps predict the extent of damage caused to the complex cellular machinery comprising DNA. These environmental mutagens also affect

Responsible Editor: Lotfi Aleya

Rashmi K. Ambasta rashmiambasta@gmail.com

1 Molecular Neuroscience and Functional Genomics Laboratory, Department of Biotechnology, Delhi Technological University, Shahbad Daulatpur, Bawana Road, Delhi 110042, India at the level of metabolism by interrupting the metabolites involved in maintaining the state of various enzymes (for example, cyclooxygenases and oxygenase) involved in commanding multiple pathways (Volkova et al. 2020). Ubiquitination plays a prominent role in cancer. Evident studies suggest that ubiquitin E3 ligases such as the expression murine double minute 2 (MDM2) are highly upregulated in various cancers that affect various downstream targets like $\mathrm{p} 53$. These mutagens distort the regulatory machinery of these ligases, thereby causing progression in cancer (Gupta et al. 2019). The extent of the damage caused depends on the mutagens' structural and molecular capabilities to which the DNA is exposed. Studies predict that these environmental mutagens are highly damaging as these can lead to carcinogenesis and aging of the affected cells. Therefore, this level of damage is caused via chromosomal instability, modification in the sequence of bases of DNA, and aneuploidy (Karthika et al. 2021). Mutagens that cause this variable damage can be physical, biological, and chemical in nature (Temko et al. 2018). Physical mutagens such as lead, arsenic, cadmium, and mercury are known to be associated with cancer and are potent carcinogens. These 
mutagens bind and cause mutation in the sequence of DNA bases either by interacting with proteins that bind to the DNA or by halting the repair machinery of DNA, thereby increasing the level of mutations and prompting carcinomas of various origin (Kabir et al. 2021). Evident studies suggest cadmium's role in inducing non-small cell lung carcinomas (NSCLCs), prostate, and cancers of biliary regions (Hartwig 2013). Exposure to radiations of ionizing nature such as UV and gamma also causes denaturation that further leads to spontaneous mutagenesis (Toxicology 1992). These mutagens increase reactive oxygen species (ROS) aggregation level that binds with the nucleic acid, enhances apoptosis and oxidative stress, causing tumor loading and unclear abnormal cellular check.

Similarly, various classes of chemical mutagens (alkylating agents, DNA intercalating agents, and deaminating agents) such as melphalan, benzidine, and diethylstilbestrol mediate base-analog and cause pyrimidines to shift, leading to mutagenesis in healthy cells (Weber et al. 2002). Studies also define the role of various infectious mutagens (bacteria and virus) that also interferes with the biological integrity of cells. Viruses of various modalities like the Epstein-Barr virus, hepatitis $\mathrm{B}$, and $\mathrm{C}$ elevate the cellular damage and are known to be linked with carcinogenesis ( $\mathrm{Li}$ et al. 2004). Another interesting character that comes into foreplay is hypoxia, being heterogeneous in nature, causes a metabolic shift in DNA stability by being linked with ROS generation causing oxidative stress and death of cells. Hypoxia-inducible factor (HIF-1 $\alpha$ ), a major transcription factor in hypoxia, is also somewhere known to be linked to promoting carcinogenesis in healthy cells (Jun et al. 2017; Kaplan and Glazer 2020). Epigenetic and genetic mechanisms are also known to be associated with the growth and development of various tumors (Rahman et al. 2021). Mutagens that interfere with the pathways associate with these mechanisms, such as differentiation, histone modifications, acetylation, methylation, etc., also degrades the DNA quality, causing cancer. Mutagenic agents of this class are also known to be activation-dependent and activationindependent mutagens. Examples of these DNA-damaging carcinogens include mycotoxins, polycyclic aromatic hydrocarbons, forms DNA adducts. Studies that govern the role of mutagens being the associator in the formation of DNA adducts are extensively described (Arlt et al. 2005; Totsuka et al. 2021). Also, how these DNA adducts are identified using sophisticated molecular techniques such as gas chromatography, liquid chromatography/mass spectroscopy (LC/MS), and fluorescent methods in the measurement of DNA adducts is an important concept, preventing adduct formation and cellular damage. Many studies have explored the therapeutic potential of natural compounds and phytochemical extracts in reducing the countereffects of these mutagens in various carcinomas (Grover et al. 2021).
Evident studies prescribe the role of environmental mutagens (endogenous and exogenous) in mediating inflammation-associated pathways. As these pathways help in mediating DNA damage and play a key role when talking about carcinogenesis, it is important to explore these associations (Bhattacharya et al. 2021; Piotrowski et al. 2020). Downregulation elements in these signaling like the nuclear factor- $\mathrm{KB}(\mathrm{NF}-\mathrm{KB})$, signal transducer and activator of transcription 1 (STAT1), interferon regulatory factor 3 (IRF 3), and activation of caspases and bridging with mutagens opens up a window how these mutagens guide inflammation, ultimately leading to cancer, the chunk of which is described in detail in this review (Preventive 2018). The release of various inflammatory cytokines like the IL-2, IL-10, and TNF- $\alpha$ and their secretions influence DNA-damage response and activation of pathways such as the JNK/STAT1, which can act as a therapeutic possibility targeting inflammation in cancer (Sandhir et al. 2017; Fadriquela et al. 2021). In order to achieve stable, and functional DNA integrity, a certain DNA-repair mechanism comes into action when struck by the effect of any exogenous and endogenous mutagens. These DNA-repair mechanisms include single-strand break repair (SSB) comprising the base-excision repair (BER), nucleotide-excision repair (NER), and mismatch repair. For more severe damage (double-stranded DNA break), homologous recombination (HR) and non-homologous end-joining (NHEJ) commands the repair machinery that is affected by these environmental mutagens(Chatterjee and Walker 2017). Deformity in the repair mechanism affects the cellular machinery that ultimately leads to the formation of an abnormal mass of cells, causing cancer. Therefore, targeting these repair mechanisms can be an asset to how these mutagens affect the cellular DNA and in the prevention of carcinomas. Also, it is necessary to explore inhibitors that could potentially target these damages caused by various environmental mutagens, as an early detection and prevention can be a game-changer when talking about how these environmental modulators impact the DNA and lead to the establishment of a deadly disease so-called cancer.

\section{Environmental mutagens as DNA damage activators enhancing carcinogenesis}

Any environmental substance that causes a mutation is known as a mutagen, and these agents are called mutagenic agents. Cancer-causing mutagens are known to be carcinogens, but not all mutants are necessarily carcinogenic in nature (Griffiths et al. 2000; Errol 2001). Every single mutant knows to characteristic mutational signatures (combinations of mutation types arising from specific mutagenesis processes such as DNA replication infidelity, exogenous and endogenous genotoxins exposures, defective DNA repair pathways, and 
DNA enzymatic editing) (Kaoru 2016). Some mutation is known as "spontaneous mutations" due to spontaneous hydrolysis, DNA replication errors, repair, and recombination (Ripley 2013). Some mutants are known as promutagens that exert their effect through their metabolites, and conversion of these metabolites into carcinogenesis depends on the metabolic process of an organism, for example, through the activity of the cytochrome P450 system and other oxygenase such as cyclooxygenase (Kim and Guengerich 2005; Martín-Sanz et al. 2017). Different mutagens act differently on DNA, for example, some mutagens induce chromosomal instability, including chromosomal breakages and rearrangement of the chromosomes such as translocation, deletion, and inversion (Mishima 2017). In the same way, some mutagens modify DNA sequence involving the substitution of nucleotide basepairs, insertions and deletions of one or more nucleotides in DNA sequences and others lead to aneuploidy (Mandrioli et al. 2016). The complicity of environmental mutagens (DNA damaging agents) in biological processes and how it is linked to cancer has been shown in Figure 1. The role of mutagens has also been briefly described below.

\section{Physical mutagens triggered mutagenesis}

Environmental agents (physical, chemicals, radiation, and biological) can be mutagens (mainly that alter DNA) or carcinogens (cancer-causing substances). The steps involved for a mutagen to become a carcinogen to cause cancer involve the metabolic activation, reaction with DNA to form DNA adduct, and then DNA replication of this adduct, subsequently resulting in a mutation. This mutation (in a cancerous gene) results in enhanced growth potential and ultimately induces tumor. The physical mutants are present in our surroundings, possessing mutational signatures that alter the genetic information or change an organism's DNA sequence. These primarily include heavy metals and heat. In the current scenario, many heavy metals are known to be contagious to well-being, and studies suggest some acts as potential carcinogens too. The metals can either endogenously or exogenously damage the DNA by producing ROS, thereby impairing the repair mechanisms. Additionally, comprehensive studies have revealed that heavy metals can cause various diseases like cardiovascular diseases, autoimmune disorders, neurodegenerative disorders, etc. The damage caused by arsenic (As), lead $(\mathrm{Pb})$, cadmium $(\mathrm{Cd})$, chromium $(\mathrm{Cr})$, and mercury $(\mathrm{Hg})$ has a long history as a carcinogen. There are multiple mechanisms by which these metals can induce carcinogenesis, as the exposure of these heavy metals directly or indirectly disrupts the intracellular processes. And thus, these processes have potential candidature for acting as markers of heavy metal-induced carcinogenesis.

As is known to be one of the most common mutagenic agents that is also a potential class I human carcinogen.
There is an enormous collection of writing supporting Asrelated carcinogenesis (Vega et al. 1995; Salazar et al. 2010; Tokar et al. 2010). Being a toxic semi-metal, As exists in mainly inorganic form as arsenate and arsenide in nature. These inorganic forms are highly hazardous to health as they can cause skin, lung, and liver cancers (D'Souza and Peretiatko 2002; Martinez et al. 2011). Also, As residues interact with DNA-binding proteins and disrupt the DNA repair machinery and increase the risk of carcinogenesis. The studies have also stated that exposure to As alone is not satisfactory enough to cause cancer, it just acts as a co-carcinogen whose effect is enhanced when combined with the other mutagenic agents like UV radiations or Benzo(a)pyrene diol epoxide (BPDE), which give rise to high genomic instabilities and finally results in tumorigenesis (Rossman et al. 2004), which is beneficial for the evaluation of its bioeffect. The comprehensive studies suggest that As (III) and BPDE synergistically lead to genotoxicity, DNA strand break damage, and causes carcinogenesis. The plausible mechanism of action is by inhibiting As metal methylation, in return As(III) inhibits nucleotide excision repair (NER) of the DNA adduct damage caused by BPDE(Li et al. 2019).

Also, occupational exposure to another heavy metal, $\mathrm{Cd}$, is concerned with toxicity and carcinogenesis as evidence suggests it to be a prime suspect causing lung cancer(Nawrot et al. 2006). However, exposure to cadmium is equally responsible for causing tumors in other organs like the kidney, breast, and prostate (Nordberg et al. 1975; Dudley et al. 1985; Lauwerys and Bernard 1986; Itoh et al. 2014). In general, the cadmiuminduced carcinogenicity triggers the proteins involved in DNA damage and results in cellular growth deregulation and apoptotic resistance of cells (Hu et al. 2002).

On the other hand, lung cancer is also diagnosed in people working in the chromate-producing industry, indicating that $\mathrm{Cr}$ is also a primary cause (Langård and Vigander 1983). The Cr dust is highly insoluble in water; after entering the body, it settles down in blood vessels and produces ROS. These ROS then bind with DNA, causes cellular damage, further inducing apoptosis, oxidative stress, and cancer in the lungs and kidneys. In addition to above mentioned, other prevailing mutagenic metals known to provoke carcinogenesis are listed in Table 2, along with the cancer they cause and current medications used.

The shifting temperature has been quite long known to cause mutations in various organisms (Waldvogel and Pfenninger 2020). These mutations are caused by a raised weather that does not directly affect the DNA but results from perturbations of the enzymes involved in DNA synthesis. The heating of DNA over $95{ }^{\circ} \mathrm{C}$ leads to denaturation and breakage of phosphodiester bonds, while heating to $36{ }^{\circ} \mathrm{C}$ is known to cause spontaneous mutagenesis. From the studies, it has been found that the rate of heat-induced mutation in T4 is nearly $4 \times 10^{-8}$ at $37^{\circ}$ per G-C base pair/day. While for the 
Fig. 1 Model for environmental risk factor, DNA damage, and its response in biological processes linked to cancer: Repetitive exposure of cells to intrinsic and extrinsic carcinogens may result in accumulation of free radicals such as ROS, which leads to oxidative stress and DNA damage and together with all results into inflammation. These generate various growth factors (VEGF), cytokines (TGF- $\beta$, TNF- $\alpha$, IL-6, etc.), transcription factors (c-Myc, NF-kB, STAT3), HIF- $1 \alpha$. Elevation ROS upregulates the expression of MMPs through TGF $\beta$. Furthermore, ROS also mediates the expression of vimentin and VEGF, which increases EMT (promotes cancer cell migration) and angiogenesis, respectively. DNA damaging agents also generate a variety of lesions, such as mismatched nucleotides, base lesions, bulky (helix-distorting) adducts, SSBs, or DSBs, which causes mutations that have specific cellular consequences, including transformation or cell death. Cellular events lead to genomic or microsatellite instability, which causes cancer. The dysregulated DNA repair mechanism is unable to recognize DNA lesions and which may subsequently lead to carcinogenesis. AID, activationinduced cytidine deaminase

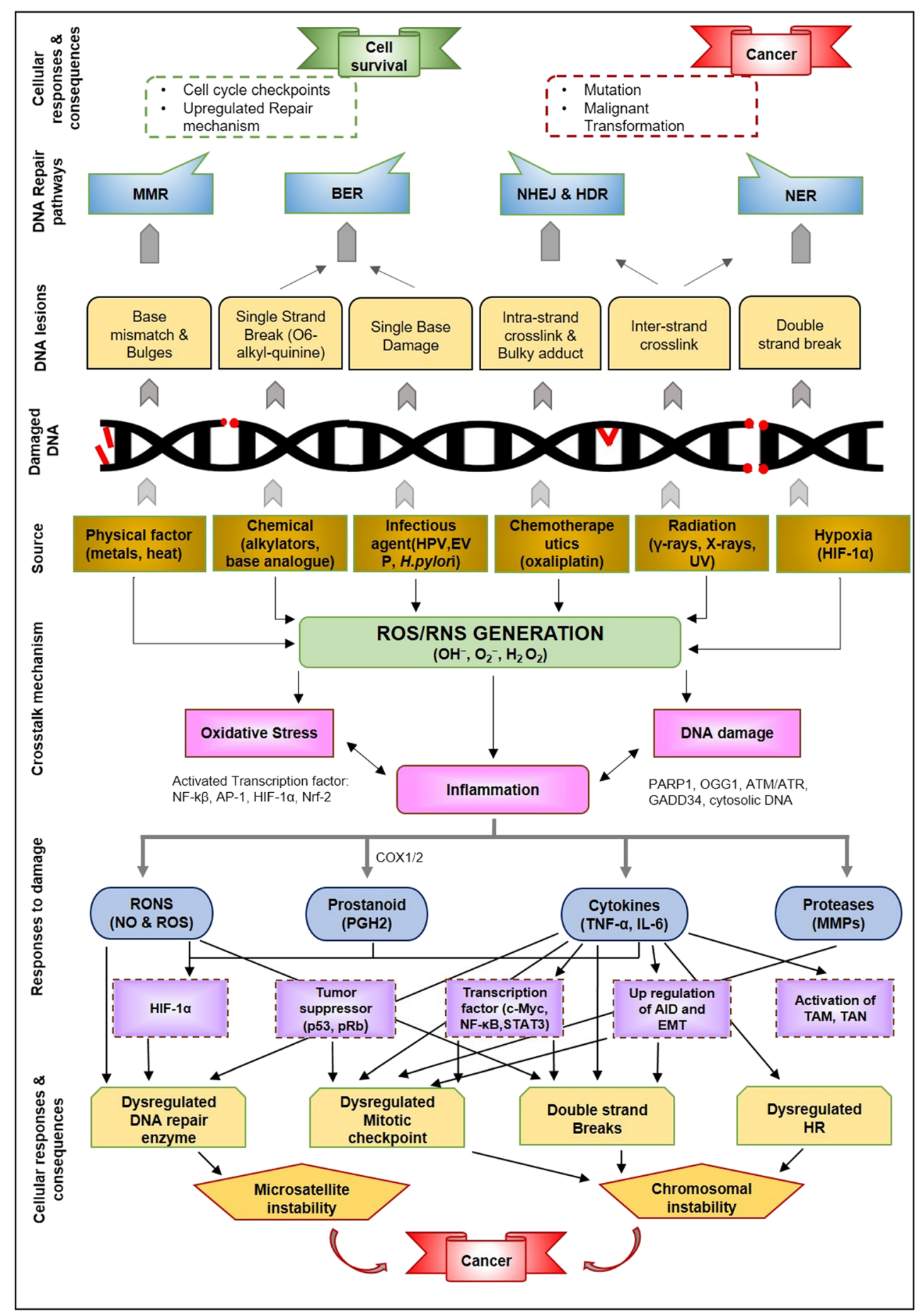

human genomes, this value accounts for 100 per diploid cell/day(Siddiqui and Khan 1999). Thus, all the evidence advocates that heat can also act as a common physical mutagen.

\section{Congeneric series of chemical mutagens}

Percival Pott, in 1775, was the first one to report a case of occupational cancer caused by the mutagens present in a work environment. He observed that prolonged exposure to chimney sweeps was a major contributory factor towards the development of scrotal cancer in men. These sweeps contain potential DNA-damaging agents, polycyclic aromatic hydrocarbons, which cause mutations and lead to cancer development (Androutsos 2006). Thus, chemicals that alter the DNA are known as chemical mutagens. These include alkylating agents, hydroxylation agents, deaminating agents, intercalating agents, base analogs, etc. Most of these are mutagens, and some of them even act as potential carcinogens. 
Interestingly, International Agency for Research on Cancer (IARC) has listed 88 chemical agents as human carcinogens based on animal bioassays (generally conducted in rats and mice). These animals were exposed to high doses of these agents, typically for two years. These agents include organic compounds (Naphthalene, 4-Aminobiphenyl, Benzidine, Chlornaphazine, Diethylstilbestrol, Melphalan, and many others), hormones (Estradiol), fibers (Asbestos, Erionite), components of soot, tar, etc.(Little et al. 2009; Botelho et al. 2014). These mutagens are present abundantly in our surroundings, like in tobacco smoke, air pollution, and even are generated by processes involving the peroxidation of lipids. Mostly these chemical agents are potential carcinogens that react with bases of the DNA to form mutagenic adducts and are used as a biomarker for diseases related to neurodegeneration, metal storage disorders, and may even cause inflammation or cancer, etc. (Sanchez et al. 2021a; Kaur et al. 2021). Even alcohol consumption is a prime factor related to inducing carcinomas of the head, neck as well as esophagus. The mechanism of alcohol-induced cancer is not known, but the aldehyde products of alcohol oxidation interfere with DNA, resulting in adduct formation, which can lead to several mutations. Importantly, past studies have shown that aldehydederived DNA adducts like $N^{2}$-ethyldeoxyguanosine, $N^{6}$ ethyldeoxyadenosine, and $N^{4}$-ethyldeoxycytidine are known to have genotoxic effects in humans(Guidolin et al. 2021). Thus, performing high-performance liquid chromatographytandem mass spectrometry (HPLC/MS/MS) for the detection of exocyclic DNA adducts confirms about the DNA damage caused due to alcohol exposures play a critical role in cancer etiology. These chemicals, their mechanism of action, and cancer they induce have been summarized in Table 2 .

Generally, the chemical mutagens are classified into different categories (base analogs, intercalators, alkylating agents, etc.) based on their mode of action. Base analog mutagens are the chemicals that resemble normal bases structurally; they take part in DNA replication as these are misread by repair mechanisms as normal bases only. The 5-bromo-deoxyuridine (5BU), a synthetically synthesized compound that resembles the thymine, is the most studied base analog whose keto form (T mimic) and pairs with "A" typically (CASPARI et al. 1965). This potent mutagen is capable enough to cause point mutations resulting in deleterious alterations in genetic information. Certain other chemicals such as Azidothymidine (AZT) and 2-aminopurine (2- AP) also belong to the category of base analogs (Ma et al. 2017.; Persing et al. 1981), and each of these chemicals mutagenizes over time because of their resemblance with the normal bases. After undergoing multiple rounds of replication, these mutations are stabilized.

The chemical mutagens also comprise influential mutagens known as alkylating agents, deaminating agents, and DNA intercalating agents. The alkylators such as ethyl methane sulfonate (EMS) and nitrosoguanidine (NTG, NG, MNNG) are agents which cause alkylation of DNA by reacting with the nucleotide bases. These mutagens are inclined towards G-rich regions and react to form modified "G" residues, thereby undergoes depurination. Thus, the alkylation of DNA leads to many reactions like the formation of unstable triesters, which release the alkyl group and hinders the DNA replication machinery. Even these phosphate triesters, when hydrolyzed, lead to the breakage of the DNA backbone(Jones et al. 2010). Many other chemicals also act as mutagens like hydroxylamine, sodium azide, and nitrous acid, which cause oxidative deamination and cause fatal base pairing. Unlike other mutagens, nitrous acid directly modifies a base into a miscoding form and converts adenine to hypoxanthine, cytosine to uracil, and finally guanine to xanthine(Hartman et al. 1994). Among others, DNA-intercalating agents include acridine orange, ethidium bromide (EtBr), and daunorubicin which lead to distort the DNA helix and cause frameshift mutations either by adding or deleting certain bases. These compounds seemingly mutagenize by intercalating between bases present adjacent to one other, conceivably making repair systems reflect as if there is an alternative base at that position. The heterocyclic nitrogen mustard gas is a well-known example of it. Even some dyes like acridine orange, proflavine, and acriflavine have structures similar to those of purines and pyrimidines, and thus, they insert themselves in DNA. These intercalating agents distort DNA structure, lead to wrong base pairing, and are associated with single nucleotide-pair insertions, frameshift mutation (deletions) (Hoffmann et al. 2003) soot. In contrast, some studies have shown the pharmacological effect of Proflavin as it inhibits human osteosarcoma via apoptosis and autophagy (Karthika et al. 2021; Zhang et al. 2015a). Similarly study by Lin et al. showed that Acridine orange exhibits photodamage via disrupting acidic organelles and induces bladder cancer cells death underneath blue light exposure (Lin et al. 2017).

\section{Radiation-induced mutation and DNA damage}

The U.S. Environmental Protection Agency (EPA) states that all radionuclides are carcinogens under the Comprehensive Environmental Response, Compensation, and Liability Act of 1980 (CERCLA). The carcinogenicity of radiations depends on their type, exposure, and penetration power. There are different types of radiation like (a) ionizing radiation such as X-rays, gamma rays, and alpha particles; (b) ultraviolet radiations (UV) with wavelength above $260 \mathrm{~nm}$; and (c) radioactive decay, such as the decay of ${ }^{14} \mathrm{C}$ incorporated in DNA into nitrogen. In a living cell, radiation can damage proteins, lipoproteins, DNA, carbohydrates, etc., either by directly ionizing or exciting or indirectly by generating highly reactive species by radiolysis of the cellular water. These radiations perpetuate genetic effects, and, thus, the cellular repair system is largely ardent to its well-being. The radiations 
are a type of environmental mutagen that leads to immediate changes in a cell's DNA like the ionizing radiation (i.e., $\mathrm{X}$ rays) break DNA sequences; UV rays (mainly UV-B 280$315 \mathrm{~nm}$ ), penetrate through cellular and nuclear membranes resulting in DNA damage, UV-radiation induced free radical generation, and formation of dimers. ROS leads to damage to lipids, proteins, and cell structure, and DNA, resulting in oxidative stress involved in many cancer (Rastogi et al. 2010).

Broadly, there are two types of ionizing radiation, and one comprises corpuscular rays like alpha, beta, protons, etc. The alpha particles are a type of low penetrating radiation that shall consist of two protons and two neutrons. Whereas the beta particles more penetrating and less ionizing, consisting of electrons or positrons. These beta rays, alpha rays, fast and thermal neutrons are also known to cause chromosomal breakage and gene mutations (Loucas et al. 2013; Roychowdhury and Tah 2013; Yusuff et al. 2015; Kumawat et al. 2019). According to the epidemiological evidence, there are many health risks associated, including cancer risks at several anatomical sites (lungs, bones, liver, etc.) with radionuclides emitting these particles (El Ghissassi et al. 2009; Graf et al. 2014). In contrast, the other type of ionizing radiation includes electromagnetic rays like X-rays, gamma rays. The mechanism of action of X-rays and $\gamma$ rays both are the same as they are penetrable, non-is particulate in nature, thereby causing double-strand breaks (DSBs) in DNA. These DSBs in the DNA lead to either deletion or rearrangement and may become lethal in some cases too, and every DSB possesses the same tendency of inducing a cell transformation, and each transformed cell has the potential to develop into cancer (Kirby-Smith and Daniels 1953). Simultaneously, it has also been observed that sometimes the bases get oxidized due to the ionizing radiations. For instance, guanine $(G)$ gets oxidized to form Oxo G, which can base pair with both $A$ as well as $\mathrm{C}$, and it pairs with $\mathrm{A}$ then it causes transversion mutation (GC base pair changes to AT).

Another common mutagen is UV radiation, responsible for transforming healthy cells into cancerous (especially skin cancers) as they inactivate apoptosis (Laikova et al. 2019). These UV radiations excite the DNA molecule and cause crosslinking, single-strand breaks (SSBs), leading to the formation of pyrimidine dimer. Generally, cytosine (C) and thymidine (T) are more vulnerable to UV radiations and form dimers. These dimers distort the helical conformation of the DNA, weaken H-bonds, and inhibit the advancement of the replication fork (Rastogi et al. 2010). Moreover, UV radiation's ability to induce and promote malignant melanoma was conjointly shown in many animal models. It also alters cytokines such as TNF- $\alpha$ and interleukins (ILs), which indirectly affects matrix metalloproteinases (MMPs) synthesis, thereby promoting melanoma metastasis and invasion (Anna et al. 2007).
The radioactive materials after undergoing the decay process also induce mutagenesis, for instance, Sulfur-35 decays into Chlorine, Strontium-90 decays into Yttrium-90, and Barium-140 decays into Lanthanum-140, all of them interact and bind with DNA and results in DNA damage as well as genetic mutations (Chen 2013). Also, some studies suggest that iodine-131 used to treat thyroid cancer may lead to leukemia (Carhill and Vassilopoulou-Sellin 2012; Gilabert and Prebet 2012; Alsaud et al. 2020). Thus, in different ways, radiations are known to cause mutations depending upon their penetration power, dosage, and energy it possesses.

\section{Infectious agents mediated mutagenesis}

Some mutagens of biological origin are also known to cause mutations. These agents are sources of DNA from elements like transposons, bacteria, parasites, and viruses. The transposons are commonly known as jumping genes. These are noncoding sequences of DNA that relocate and replicate autonomously. The insertion into a DNA sequence of transposons can disrupt traditional gene functions (Woodford and Ellington 2007). The transposable elements can act either as oncogenic factors (e.g., HRas proto-oncogene, Myc oncogene, etc.) leading to genomic instability (deletions, insertions, Chromosomal mutations), or interfere with transcription factors and non-coding RNAs whose dysregulation further leads to carcinogenesis (Anwar et al. 2017). Lately, scientists have found on comparing adenomatosis polyposis coli tumor suppressor (APC) genes in healthy and colon cancer suffering cells on later consists of transposes. This further testifies the fact that transposes in somatic cells in mammals have some role in the development of colorectal cancer (Miki et al. 1992; Chenmala et al. 2021). Viruses are a common infectious agent that can induce mutagenesis as they can insert their DNA into the host genome and disrupt the gene functionality. Once inside the host, viruses use the host machinery to replicate, translate, and express their viral proteins. These viral mutations can be point mutations, including base substitutions and deletions and insertions(Shapiro et al. 1984). Some viruses are also known to cause cancers, and these are known as oncogenic viruses. These viruses' mechanism of action is that they insert a viral oncogenic gene into the host, which further augments already existing proto-oncogene, which becomes oncogene. Examples of such viruses include Hepatitis B, Hepatitis C, Kaposi sarcoma-associated herpesvirus (KSHV), EpsteinBarr virus, Human papillomavirus, etc. (Zur Hausen 1991). The viruses and their mechanism of action have been explained in detail further in this paper.

A few microscopic organisms like the bacteria Helicobacter pylori (H. pylori) can cause inflammation during which oxidative species are released, thereby leading to DNA harm and lessening the DNA repair system's productivity to a high mutational rate. H. pylori is a human carcinogen known 
to cause mutations in the gastric mucosa and finally leading to cancer (Rahman et al. 2019; Sheh et al. 2010). Some studies suggest $H$. pylori infection causes prolonged inflammation, and it is evident from the overexpression of cytokine (IL-1) in the stomach transgenic mice(Tu et al. 2008). These organisms later advance into erratic gastric inflammation and cancer as the inflammatory response may have predisposed cells in the stomach lining to become cancerous. The augmented cell turnover consequential due to the ongoing cellular damage possibly will increase the likability of harmful mutations. The other bacteria associated with causing cancer include Salmonella typhi (S. typhi), a potent agent for gallbladder cancer, Streptococcus bovis (S. bovis), a risk factor for colon cancer development, and Chlamydia trachomatis is known to cause cervical cancer(Mager 2006). Certain parasites like Opisthorchis viverrini $(O$. viverrini) and Clonorchis sinensis (C. sinensis) which reside inside the human body are also known to increase the risk of cancer. $C$. sinensis is a prime parasite with a $1.86 \%$ prevalence rate in Korean population, mainly linked to liver and biliary disorders, especially cholangiocarcinoma (CCA) (Kim et al. 2016). The exact mechanism contributing to cancer caused by $C$. sinensis is not clear but is analogous to carcinogenesis induced by $O$. viverrine. These parasites mainly cause inflammation, release parasite-derived products as well as ROS, which causes physical damage, adduct formation, and anticipate in carcinogenesis(van Tong et al. 2017). Another class of agents that can induce cancer is genotoxins released by certain strains of Escherichia coli (E. coli) known as colibactin. This colibactin induces tumor growth by regulating the SUMOylation process in the mice model, while colibactin damaged colorectal cells in humans by causing alkylation of DNA, leading to DSBs. These DSBs are hotspots of mutations involved in human carcinogenesis(Dalmasso et al. 2015).

Furthermore, food that we consume is also known to be carrying potential mutagens and accounts for over $99 \%$ of the carcinogenic and toxic chemicals to which humans are exposed. Likewise, the feeding onto the processed meat (Group 1 carcinogen) and red meat (Group 2A carcinogen) are also categorized as human carcinogens according to the International Agency for Research on Cancer. The epidemiological data has confirmed the same, but the underlying mechanism for mechanisms of genotoxicity and how cancer is induced is still unclear, particularly the extent to which DNA damage is caused. The literature studies suggest that meat consumption can cause DNA breaks, adduct formation (Pelland-St-Pierre et al. 2021).

Moreover, these mutagens are further classified as naturally occurring compounds, some formed during heating, and others include additives and contaminants (pesticides). The class of mutagenic plant-derived compounds includes pyrrolizidine present in some herbal teas and medicines. These indirect-acting mutagens and their interaction with other molecules induce DNA strand chromosomal breakage and mutations (Schoental 1968). PAHs are widespread chemical carcinogenic pollutants that are exposed to humans by consuming contaminated food. The dietary PAHs are known to induce colorectal cancer (CRC), but the underlying mechanism remains unclear (Poirier et al. 2019). Even the toxins produced by fungi growing on foodstuffs are also an essential source of mutagenic contaminants referred to as mycotoxins. Some examples of mycotoxins are fusarin, ochratoxin, deoxynivalenol, ochratoxin, etc. They are generally found growing on crops, meat products, milk and eggs, nuts and peanuts, fruits, and many other food items. These mycotoxins produced inhibit DNA and RNA synthesis and induce apoptosis (Ferrante et al. 2012). Also, some mycotoxins can intercalate between the bases of the DNA double helix, which hinders the replication process. As the replication of DNA is affected, it produces teratogenic and mutagenic effects. Furthermore, mycotoxins induce mutations in genes responsible for controlling the cell cycle, leading to cancer development (Claeys et al. 2020). In support of this, nearly ten investigations have found an association between aflatoxin (type of mycotoxin) and liver cancer (Rahman et al. 2020), while two studies reveal an association between ZEN (Zearalenone) and breast cancer (Pillay et al. 2002; Belhassen et al. 2015). Interestingly, the AFB1 itself cannot directly interact with DNA, only the bio-transformed version (AFB1-8, 9-epoxide via cytochrome $\mathrm{p} 450$ enzymes) is capable of generating highly mutagenic DNA adducts by irreversibly attaching to guanine residues. Thereby, most countries have put strict regulations about the levels of aflatoxin in food items as high amounts result in DNA adducts formation (Engin and Engin 2019).

\section{Hypoxia-induced DNA damage}

The hypoxia (a hallmark of cancer) is a sub-region in the tumor microenvironment (TME) along with nutrient deprivation, low extracellular $\mathrm{pH}$, and high interstitial fluid pressure. The hypoxic condition arises when oxygen consumption by cells exceeds that of supply (Vaupel and Harrison 2004). The hypoxic region is characterized as heterogeneous in nature, with regions of chronic and acute hypoxia, altered $\mathrm{pH}$, and immune infiltration (Hughes et al. 2019). In a hypoxic TME (e.g., 0.2 to $1 \% \mathrm{O}_{2}$ ), tumor cells slowly adapt to hypoxic conditions where they continue to grow and proliferate with altered/amended cellular biology. In contrast, another microenvironment is known as permanent anoxic (e.g., close to $0 \%$ $\mathrm{O}_{2}$ ). Tumor or normal cells are leading to cell death (Luoto et al. 2013). A multitude of researches has concluded intrinsic hypoxia biomarkers as HIF- $1 \alpha$, vascular endothelial growth factor (VEGF), carbonic anhydrase IX (CAIX), osteopontin and glucose transporters 1 and 3 (GLUT1, GLUT3), and the extrinsic biomarkers: drugs that specifically accumulate or 
become bio-reduced to form adducts within hypoxic cells such as pimonidazole (PIMO), EF5 and CCI-103 F (Ljungkvist et al. 2007; Le and Courter 2008). Hypoxia cells have defective DNA repair, increased mutation rate, and hypoxia has the capacity to accelerate genomic instability through increased chromosomal rearrangement and decreased centrosome function, increased unrepaired DSBs and replication errors, increased gene amplification, and inaugural of intrachromosomal fragile sites (Coquelle et al. 1998; Bristow 2008; Luoto et al. 2013). The study by Kumareswaran et al. found that under hypoxia state, aberrant or compromised DNA-DSB repair of G1-associated DNA-DSBs as a potential factor responsible for increased genetic and/or chromosomal instability (Kumareswaran et al. 2012).

Hypoxia instigates HIF and inducible nitric oxide synthase (iNOS), which results in upregulation of intracellular RNS and ROS, leading to DNA damage in progression with poor prognosis (Kawanishi et al. 2017; Rahman et al. 2020). A consequence of hypoxia in causing genomic instability has been shown beautifully in Figure 2. Still now, how hypoxia links with increases ROS production is still a matter of debate.
One theory supports this hypoxia act on complexes I, II, and III of the electron transport chain (ETC) in mitochondria which drive increased ROS production (Hamanaka and Chandel 2009). ROS plays a pivotal role in stabilizing and activating HIF $1 \alpha$, which activates survival, proliferation, metastasis, and a tumor cell's metabolic changes. ROS induces intracellular signaling mechanisms involving mitogen activated protein kinase (MAPK) that depends on nuclear factor kappa B (NF-KB). It can directly activate MMPs synthesis and tissue inhibitor of metalloproteinases (TIMPs), leading to proliferation and invasion of tumor cells( $\mathrm{Li}$ et al. 2011). This concludes that ROS continuously or perpetual assist directly or indirectly, to each step of carcinogenesis, from the initiation to the tumor transformation and progression (Singh et al. 2021.; Tafani et al. 2016). Moreover, when hypoxic cells acquire reoxygenated state, this results in further DNA damage due to a sudden burst of free radicals (Hammond et al. 2003). HIF $1 \alpha$ is crucial for tumor adaption to hypoxic, and it is also a key prognostic tumor factor (Fukushima et al. 2017; Han et al. 2019). Its overexpression has been linked with a poor disease outcome and increased patient mortality in

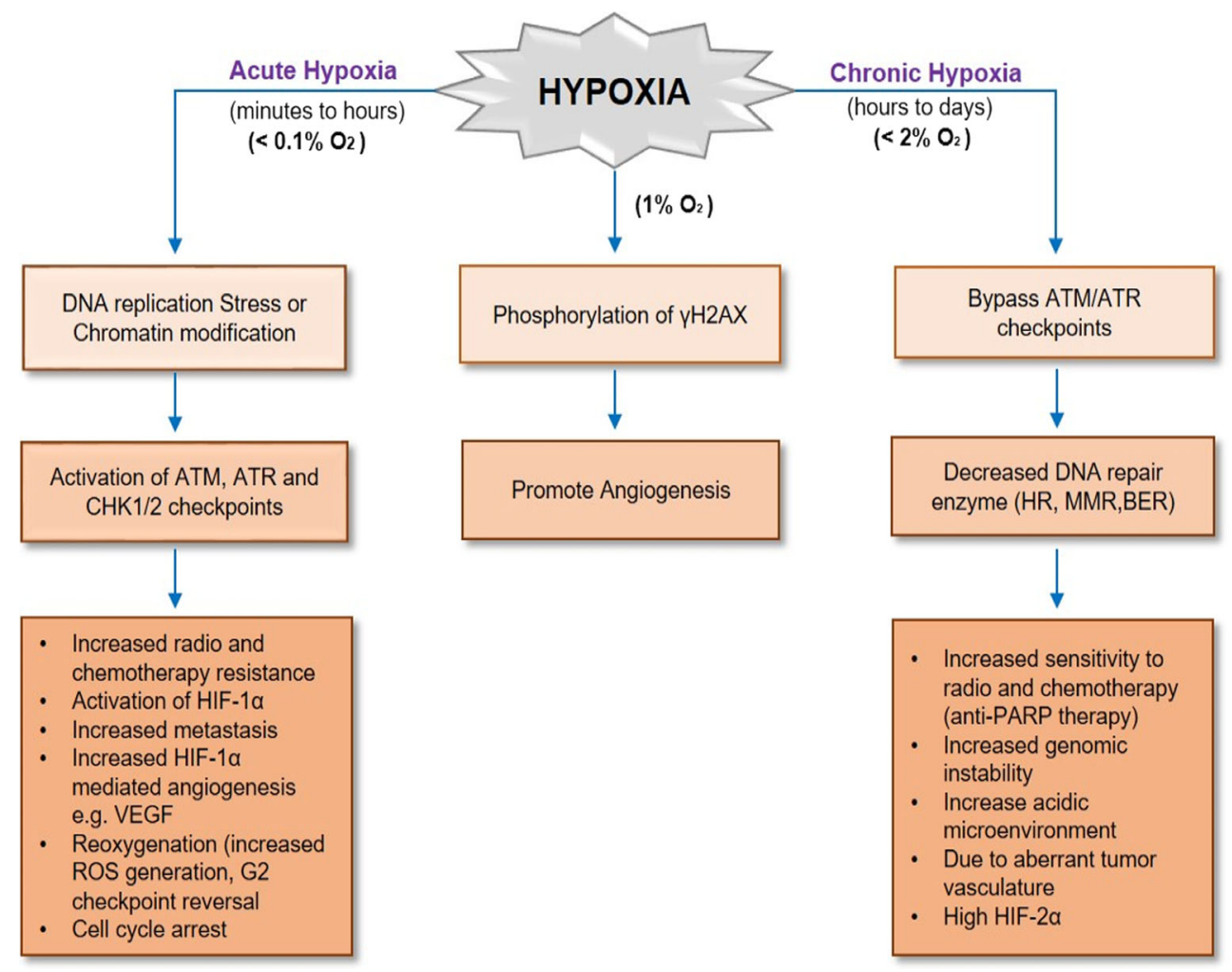

Fig. 2 Schematic of the hypoxia-mediated genetic instability: Cancer cell exposed to acute hypoxia causes DNA damage or compromised DNA replication also known as replication stress which activates ATM-ATRmediated cell cycle checkpoints to arrest the cell to repair any DNA damage caused by ROS. Due to impaired DNA repair enzyme or nonrepaired DNA breaks causes genomic instability, which results in tumorigenesis. Further acute hypoxia causes activation and stabilization of HIF- $1 \alpha$, promote angiogenesis and which results in radio and chemotherapy resistance. Whereas chronic hypoxia also gains genetic instability through decreased DNA repair enzymes, leading to increased mutation. It also upregulates the expression of HIF- $2 \alpha$. ATM, ataxia telangiectasia mutated; ATR, ataxia telangiectasia- and Rad3-related kinase; ROS, reactive oxygen species; BER, base-excision repair; CHK2, checkpoint kinase 2; HR, homologous recombination; MMR, mismatch repair; PARP, poly (ADP-ribose) polymerase 
various cancer such as bladder, brain, breast, cervix, colon, endometrium, lung, oropharynx, pancreas, skin, and stomach cancers (Semenza 2010; Wilson and Hay 2011; Jun et al. 2017; Barrak et al. 2020). Loss of HIF-1 $\alpha$ control can enhance tumorigenesis and genomic instability via cooperation with oncogene c-MYC (c-Myc expression is downregulated in low-oxygen regions of solid tumors) (Okuyama et al. 2010; Li et al. 2020). Moreover, the study by Wang et al. showed that HIF- $2 \alpha$, another transcriptional regulator of hypoxia, plays a crucial role in regulating the c-Myc expression in chronic hypoxia, and consequently influences 5-FU sensitivity in colorectal cancer by regulating or altering altered the G1/ S checkpoint (reason for chemoresistance) (Wang et al. 2016). Furthermore, DNA damage can also be induced by telomeric shortening, or replication stress instigated by oncogene activation and loss of function of tumor suppressor genes (Bartek et al. 2007).

A plethora of studies showed that chronic hypoxia leads to downregulation of DNA damage response (DDR) effectors proteins, such as RAD51 and BRCA1, in cancer. (Bindra et al. 2004, 2005; Meng et al. 2005). Hypoxia also induces replication arrest, which activates DNA damage response through ATR- and ATM-mediated signaling thus leads to induction of p53-dependent apoptosis (Olcina et al. 2010). Alteration in hypoxia affects DNA damage response pathways, including HR, NHEJ, miss-match repair(MMR), nucleotide excision repair (NER), base excision repair (BER), and the Fanconi anemia pathways (Begg and Tavassoli 2020; Kaplan and Glazer 2020). For instance, the downregulation of the NHEJ pathway could sensitize cells to DNA damage following ionizing radiation (IR). In contrast, the HR pathway's downregulation could sensitize cells to DNA crosslinking agents (Chan et al. 2009). Studies suggest that iNOS-dependent 8-nitroguanine formation by HIF- $1 \alpha$ and NF-KB plays an essential role in tumor progression, and 8nitroguanine can be a potential biomarker for inflammationrelated cancer (malignant fibrous histiocytoma) (Hoki et al. 2007). Furthermore, results show that HIF- $1 \alpha$ and iNOS have the probability of activating or influencing each other to handle fixed DNA damage, resulting in accumulation of mutation, acquiring tumor invasiveness, and poor prognosis (Kawanishi et al. 2017).

A study by Young and et al. found that hypoxia induces aberrant DNA synthesis, leading to DNA over replication and promoting metastasis (Young et al. 1988). Another study by Englander and his co-workers suggests that cerebral hypoxia causes mitochondrial and nuclear DNA damage in the rat hippocampus and cortex (i.e., rat brain) (Englander et al. 1999). Moreover, HIF-1 and HIF-2 in severe tumor hypoxia condition involved in the replication-associated generation of gamma- histone variant $2 \mathrm{AX}(\gamma \mathrm{H} 2 \mathrm{AX})$ in endothelial cells, which leads to neovascularization, and accumulation of $\gamma \mathrm{H} 2 \mathrm{AX}$ enhances a tumor cell's scope to repair DNA damage, contributing to chemoresistance (Economopoulou et al. 2009; Wrann et al. 2013). Recently, a study by Riffle et al. mentioned the involvement of ATM kinase, but not ATR responsible for $\gamma-\mathrm{H} 2 \mathrm{AX}$ formation (also known as DNA damage marker) in the hypoxic tumor spheroids, which mimic tumor microenvironments of A673 spheroids by hypoxiainduced phosphorylation of H2AX (Riffle et al. 2017). Indeed, hypoxic cells or cells growing in the hypoxic microenvironment acquire gene amplification, point mutations, and increased numbers of DNA strand breaks periodic hypoxia and reoxygenation cycle. These genetic changes cause further activation of oncogenes or inactivate tumor suppressor genes, resulting in a mutator phenotype (Chan et al. 2009)

\section{Mutagenic sensitivity: a biological marker of cancer susceptibility}

Comprehensive studies of tumor biology with different methods, including chemical carcinogenesis, molecular biology, developmental biology, biochemistry, and tumor virology, have highlighted the contributing role of genetic and epigenetic mechanisms in tumor development and progression. Carcinogens are the agents which promote cancer growth by altering and interfering with major cellular activities. Recent technological advancements, such as gene expression profiling, next-generation sequencing, and multi-omics analysis, are significant breakthroughs in the molecular characterization of tumors and associated mechanisms as modulated by the carcinogens (Perera and Weinstein 2000). Genetic and epigenetic alterations in the cellular pathways related to growth, differentiation, and death represent the fundamental cause of cancer. Interestingly, genetic and epigenetic mechanisms work sequentially to trigger tumorigenic processes, and these processes can be targeted therapeutically to suppress the cancerous affected region completely. The following sections will shed light on various genetic and epigenetic alterations induced by carcinogens.

\section{Genetic effect of environmental mutagens and carcinogens}

Cancer is characterized by continuous genetic alterations, including mutations, DNA damage, copy number variations, gene amplification, chromosomal abnormalities, and gene fusions (Adeola et al. 2021). These genetic aberrations can be specified to a particular segment of DNA or span the whole length of it and ultimately lead to either oncogene activation or tumor suppressor gene inactivation (Chakravarthi et al. 2016). Genetic and chromosomal stabilities are the characteristic features of most cancers, and progress has been achieved in investigating therapeutic options to cure cancer. Moreover, studies have revealed that genetic alterations in non-coding RNA 
also promote tumorigenesis by altering promoters' activities, enhancers, and other regulatory elements. MicroRNA (miRNA), the single-stranded RNA molecules, are extensively researched and known to be dysregulated in a variety of cancers (Melo and Esteller 2011). Both genotoxic and nongenotoxic carcinogens are responsible for gene expression changes and support tumor growth and proliferation.

Carcinogenic agents that do not require any modification or activation to cause genetic effects are termed activationindependent carcinogens. These agents, for instance, radiations, nitrosamines, and alkylating agents, can directly interact with DNA and induce disarrangement of genetic material and the formation of DNA adducts. On the contrary, activationdependent agents, such as, polycyclic aromatic hydrocarbons (PAHs), mycotoxins, and aromatic amines, require phase I or II type metabolic reactions to exert their genotoxic effects (Barnes et al. 2018). Several reactive oxygen species, like hydroxyl radicals and reactive nitrogen species like peroxynitrite, are known for their genotoxic effects. ROSinduced damage is the major contributing factor to base modifications, generation of apurinic/apyrimidinic sites, and production of single-strand DNA breaks. Interestingly, ROSinduced damage produces various modified bases, which gets accumulated and promote genetic defects and instability (Kryston et al. 2011). Oxidative damage generated by reactive free radicals further induce DNA-crosslink (DPCs) formation. A couple of studies have confirmed that environmental exposure to ROS/RNS developing substances, such as $\mathrm{NiCl}_{2}$, sulfur dioxide, arsenite, and benzopyrene, triggers DPCs formation, which further causes interruptions in DNA replication and transcription processes (Kojima and Machida 2020).

Heavy metals like Cr, As, nickel, mercury, and aluminum are considered the ambassadors of mutagenic changes. For instance, pentavalent $\mathrm{Cr}$ makes a complex with a guanine base and induces conversion of the base to 8-Oxoguanine that will further cause $\mathrm{G}$ to $\mathrm{T}$ transversions (Jadoon and Malik 2017). In a study in human recombinant hepatoma cells, chromate (VI) was found to induce transcriptional activation of 13 different promoters that ultimately caused activation of various signal transduction pathways (Tully et al. 2000). Besides this, the carcinogenic effect of nickel was established by many studies as the metal induces DNA damage through DNA binding and production of ROS. The metal also interferes with DNA repair mechanisms, including nucleotide repair, BER, mismatch repair, and homologous and nonhomologous recombinational repair pathways (Guo et al. 2019). Surprisingly, nickel was found to regulate the gene expression of various genes such as telomere marker gene, hypoxia-regulated gene Cap43, and several other genes related to mitogenesis (Beyersmann 2002). Additionally, As has also been investigated for its carcinogenic and cytotoxic effects. As is known to promote mutations in tumor protein p53 (T53), interference with DNA repair activities, inhibition of poly ADP-ribosylation, suppression of the transcriptional activity of zinc finger proteins, such as XPA and PARP1, and ubiquitin-mediated proteolysis of DNA repair enzymes (Muenyi et al. 2015).

\section{Epigenetic effect of environmental mutagens and carcinogens}

Epigenetic alterations have a prominent role in triggering cancer-specific characteristics and acquisition of tumor development. Genomic hypo-methylation, hyper or hypomethylation of DNA, and histone proteins' modifications are the major epigenetic features associated with neoplastic cells (Jones and Baylin 2007). Studies have revealed that tumorigenesis is the result of the cumulative effect of various epigenetic modifications. For instance, acetylation of histone proteins H3, $\mathrm{H} 4$, methylation of $\mathrm{H} 3 \mathrm{~K} 9$, and cytosine methylation are observed during gene silencing (Richards and Elgin 2002). DNA methylation, histone methylation, and histone acetylation are reported as the major epigenetic regulatory mechanisms associated with cancer. DNA methylation is a unifying feature of cancers and contributes to the inactivation of transcriptional events and chromatin architecture (Klutstein et al. 2016). Similarly, histone modifications, including mainly acetylation and methylation and phosphorylation, glycosylation carbonylation, SUMOylating, and ribosylation, both at the promoter and targeted level, have a contributory role in tumor development (Kurdistani 2007).

Cumulating shreds of evidence have suggested that both genotoxic and non-genotoxic carcinogens contribute to epigenetic abnormalities associated with cancer (Pogribny and Rusyn 2013). The carcinogenic potential of heavy metals such as aluminum, $\mathrm{Cr}$, nickel in inducing epigenetic changes like the silencing of DNA and tumor suppressor genes have been reported in many studies. Both short and long exposures to arenite cause modifications in DNA methylation patterns. Research with mice exposed to arenite has shown that the increased metal concentration was associated with altered DNA methylation, silencing of cytochrome P450 family members, and upregulation of glutathione S-transferase family members(Xie et al. 2007). Likewise, in lung cancer cells, nickel transformation was linked with the silencing of DNA repair gene $\mathrm{O}^{6}$-methylguanine DNA transferase (MGMT) correlated with hypermethylation of MGMT promoter along with chromatin condensation (Ji et al. 2008). Furthermore, the epigenetic potential of trivalent chromium is validated by a study where the metal has induced hypermethylation of CYP1a1 promoter and also silencing of CYP1a1 gene expression by recruiting histone deacetylase 1 (HDAC1) and DNA methyltransferase (DNMT) enzyme (Wei et al. 2004).

Besides heavy metals, gaseous olefin 1,3-butadiene, a monomer used in rubber production, is also known for its carcinogenicity and induced epigenetic alterations. The gas induces genomic instability, chromatin de-compaction, and activation of transposons. Interestingly, it was found that the 
loss of methylation at $\mathrm{H} 3 \mathrm{~K} 9$ and $\mathrm{H} 4 \mathrm{~K} 20$ was the primary factor responsible for chromatin de-compaction and transcriptional repression (Koturbash et al. 2011). In addition to this, several pharmaceutical compounds, for instance, diethylstilbestrol, a synthetic nonsteroidal estrogen, is a known human carcinogen that causes demethylation and transcriptional silencing of several critical genes related to tumorigeneses such as lactoferrin (Lf), c-fos, and nucleosomal binding protein 1 (Nsbp1) (Pogribny and Rusyn 2013). In parallel, phenobarbital, a non-genotoxic carcinogen, also induces epigenetic abnormalities. It has been reported that the compound induces DNA methylation in genes related to the cytochrome P450 family in experimental tumor mice model (Lempiäinen et al. 2011).

Moreover, many biological carcinogens, such as aflatoxins isolated from Aspergillus flavus (A. flavus) and Aspergillus parasiticus (A. parasiticus), are also potent epigenetic regulators. In a study, Zhang et al. demonstrated that exposure to aflatoxin B1 (AFB1) is responsible for hypermethylation mediated inactivation of several tumor suppressor genes RASSF1, MGMT, and p16. They validated their hypothesis by showing a positive correlation between AFB1-DNA levels and methylation patterns of associated genes (Zhang et al. 2002). Similarly, several epigenetic modulations caused by $H$. pylori have been disclosed in gastric cancer studies. H. pylori infection is the source of aberrant DNA methylation of several cancer-related genes, including lipoxygenase (LOX), thrombomodulin (THBD), actin-related protein $2 / 3$ complex, subunit $\mathrm{p} 41$ (p41ARC), and tumor suppressor p16 ${ }^{\text {INK4A }}$ (Nakajima et al. 2009)

\section{Relationship between DNA adduct and tumor occupation}

DNA adduct is a small piece of DNA that binds to a chemical covalently and causes DNA damage and abnormal DNA replication. The process of adduct formation is considered the initiation of mutational events, and thus DNA adducts serve as potential biomarkers for cancer diagnosis(Rajalakshmi et al. 2015). Early studies in cell culture models have explained that many chemical carcinogens generate DNA adducts and induce mutagenesis. Further, Maher and Mccormick's study validated the hypothesis of DNA adducts as they found a strong correlation between the concentration of carcinogens, DNA adduct formation, mutagenesis, and tumor formation (Maher and Justin McCormick 1984). Several studies are available in the literature to define the role of DNA adducts in tumorigenesis. One of the notable examples is aristolochic acid. This chemical induces DNA damage by 7-(deoxyadenosine-N6-yl)-aristolactam I (dA-AL-I) adduct formation as measured in the urothelial tissues of the exposed individuals (Chen et al. 2012). Similarly, UV irradiation- induced DNA damage in human cancers is another example highlighting the role of DNA adducts. UVinduced damage results in the production of cyclobutane pyrimidine dimers and 6-4 photoproducts that induce CC to TT mutations (Cadet and Douki 2018). Besides, methylating agents, Cisplatin, cigarette smoke, aflatoxin, malondialdehyde, and 4-hydroxynonenal are the wellknown DNA adducts (Garner 1998).

The human diet contains several mutagenic and carcinogenic ingredients; therefore, several research groups are interested in investigating the process of DNA adduct formation in diet-related carcinogenic pathways (Hemeryck and Vanhaecke 2016). Mycotoxins, including aflatoxins, fumonisin, sterigmatocystin, and others, have been studied for their carcinogenic potential; however, only AFB1 has been categorized as a human carcinogen. Exposure to AFB1 causes the formation of DNA adducts like AFB1-N7-G through lipid peroxidation, as revealed from studies in hepatocellular carcinoma (Wogan et al. 2004) (Wang and Groopman 1999). AFB1 first transformed itself into carcinogenic AFB1-8,9-epoxide and AFB1-Fapy-Dg, which further reacts with guanine residues to produce mutagenic DNA adducts, which in turn induce cell cycle checkpoint deterioration (Engin and Engin 2019)

Moreover, ptaquiloside found in bracken fern has been associated with the occurrence of bladder and gastrointestinal tumors. Exposure to this carcinogen leads to the formation of DNA adducts ptaquilosin and ptaquilosin dienone with alkylating properties (Hodge 1973). Like so, flavoring substances estragole and methyleugenol are also linked with DNA adduct formation and carcinogenesis. 18 N2-(transisoestragol-3'-yl)-G, N2-(estragole-1'-yl)-G, 7-(transisoestragol-3'-yl)-G, and 8-(trans-isoestragol-3'-yl)-G are the DNA adducts generated from estragole (Paini et al. 2012) while [N6-(transmethylisoeugenol-3'-yl)-A and N2-(trans-methylisoeugenol-3'-yl)-G are DNA adducts resulted from methyleugenol (Smith et al. 2002b).

DNA adducts can be analyzed and measured with different methods, and in the past three decades, various everimproving ways have been documented. The classical approach is the use of radioactive carcinogens. The method uses either carbon-14 or tritium-based labels and can measure 1 DNA adduct per $10^{6}$ or $10^{7}$ nucleotides. The most sensitive physio-chemical method of adduct detection is ${ }^{32} \mathrm{P}$-post labeling method/immunoaffinity method. The procedure does not require prior knowledge of the adduct structure and helps detect a wide range of high molecular weight chemical carcinogens such as polycyclic aromatic hydrocarbons, cigarette smoking, and dietary mutagens (Watson 1987). Gas or liquid chromatography-mass spectrometry, based on ionization techniques, is another specific method of adduct measurement. The technique requires hydrolysis or derivatization of carcinogen before quantifying the adduct levels (Gavina et al. 2014). 
For instance, a recent study has highlighted the relevance of the high-performance liquid chromatography-tandem mass spectrometry (HPLC/MS/MS) technique to quantify $1, \mathrm{~N}^{2}$ propanodGuo adducts generated by reaction between aldehyde and DNA bases (Sanchez et al. 2021b). Fluorescencebased methods have also been exploited as adduct measurement techniques to provide better specificity and sensitivity. A more sensitive version of the technique utilizes fluorescent dyes such as BODIPYFL, and the adducts are separated and then detected by laser-induced fluorescence (Jang et al. 2006).

Additionally, immunoassays with antibodies have been used widely as a method of DNA adduct quantification. Competitive quantitative assays and dot blot assays are the most commonly used immunoassays. A fascinating feature of immunoassays is their sensitivity as they can detect 1 adduct $/ 10^{8}$ nucleotide; sometimes, the detection will be as specific as 2-3 adducts $/ 10^{9}$ nucleotides. Another essential feature of these assays is their specificity as the antisera are designed to a particular adduct and can recognize structurally similar adducts related to the same or even different carcinogens classes. The technique has been used widely to measure adducts present in human tissues and blood samples (Brown 2012) (Santella 2018). Recent work described how technological advancements had improved the evaluation of DNA adducts. The advancement of next-generation sequencing (NSG) methods has significantly opened up new avenues for DNA adductome analyses. In this approach, the first step is LC-MSbased analysis followed by validation of biological activities and analysis of mutational signatures. The last step is to measure DNA adduct levels in blood or tissue samples (Totsuka et al. 2021).

\section{Crosstalk between DNA damage and inflammation in multiple steps of carcinogenesis}

Inflammation, including both acute and chronic, is induced by multiple factors, including environmental carcinogens (already explained above in review), infectious agents, TME components, and hypoxia. Abundance studies support that inflammation produces free radicals resulting in DNA damage, and free radicals damage healthy cells and causes inflammation (Pham-Huy et al. 2008). Inflammation also results in oxidative stress, which upregulates cancer developments in organs. 8-hydroxy-2-deoxyguanosine has the potential to be used as a biological marker for oxidative stress. Under the exposure of UV radiation or free radical damage, oxidative nucleotide such as glycol, dTG, and 8-hydroxy-2deoxyguanosine is found to be increased during oxidative damage to DNA (Hattori et al. 1996). In cancer, failed DNA repair mechanism causes unrepaired DNA lesion, which causes a mutation in the genome and further leads to microsatellite instability and genome instability (Negrini et al. 2010). Studies showed cancer cells, after undergoing apoptosis, release immunogenic cell death (ICD), which activates the host's immune systems (Pham-Huy et al. 2008). How inflammation mediates DNA damage and their crosstalk mechanism and the inflammatory microenvironment's involvement have been explained in upcoming subsections.

\section{Inflammation-mediated DNA damage}

Acute inflammation has been linked with a defense mechanism. In contrast, chronic inflammation has been associated with carcinogenesis, including cellular transformation, promotion, survival, proliferation, invasion, angiogenesis, metastasis, autoimmune, neurological disease, diabetes, etc. (Coussens and Werb 2002; Mantovani 2005). In 1987, the study by Lewis and et al. reported that inflammation and the release of genotoxic oxidants might be one mechanism for carcinogenesis (Lewis and Adams 1987). Under chronic condition not only epithelial cells but also inflammatory cells such as lymphocytes, macrophages, and plasma cells produces reactive oxygen/nitrogen species (ROS/RNS) or reactive oxygen and nitrogen species (RONS), which in turn causes (a) DNA damage including nucleobase oxidation, deamination, halogenation, and alkylation, as well as strand breaks of the phosphodiester backbone, (b) carbonylation (an irreversible and irreparable protein modification induced by oxidative stress) in organs, leading to cancer. A plethora of studies showed that numerous RONS is a potent oxidizing agent. RONS oxidized guanine (known to be the most easily oxidized DNA base) to produce mutagenic 8-oxo-guanine (8oxoG) and 8-nitro-guanine (which is unstable and quickly becomes an abasic site) (Steenken and Jovanovic 1997; Lonkar and Dedon 2011). Thus 8oxoG can lead to $\mathrm{G} \rightarrow \mathrm{T}$ transversions mutation, and this is more susceptible to oxidation than its parent guanine, leading to the production of various more stable and mutagenic secondary products such as spiroiminodihydantoin ( $\mathrm{Sp}$ ), guanidinohydantoin ( $\mathrm{Gh}$ ), oxazolone $(\mathrm{Oz})$, oxaluric acid $(\mathrm{Oa})$, and cyanuric acid $(\mathrm{Ca})$ (Cheng et al. 1992; Uppu et al. 1996). Murata's review talked about the presence of mutagenic DNA lesions, such as 8-oxo7,8-dihydro-2'-deoxyguanosine (8-oxodG) and 8-nitroguanine in inflammation-related Cancer (Murata 2018; Singh et al. 2019). In addition to oxidation, RONS can deaminate DNA bases, and deaminated products are mutagenic in nature. Spontaneous deamination of the methylated form of cytosine $(5 \mathrm{meC})$ leads to a change base into uracil or thymine (causing $\mathrm{C} \rightarrow \mathrm{T}$ transitions). This molecular signature has been found in many cancers. The amount of mutation correlates with the cancer diagnosis stage; thus, this supports cancerassociated inflammation causes deamination and accumulation of mutations (Marusawa et al. 2011). Further, inflammatory cells also secrete hypohalous acids, which react with 
DNA during inflammation to form the adducts. For example, neutrophils secrete the myeloperoxidase enzyme to produce hypochlorous acid $(\mathrm{HOCl})$, and eosinophils secrete eosinophil peroxidase to produce hypobromous acid ( $\mathrm{HOBr}$ ). Inevitable, the halogenated nucleobase, 5-chlorocytosine $(5 \mathrm{ClC})$, has a greater possibility to accumulates than oxidative deamination, and thus $5 \mathrm{ClC}$ has been assigned a biomarker for chronic inflammation (Kay et al. 2019). DNA damage causes inflammation contributes to genomic instability (a hallmark of cancer) (Negrini et al. 2010), and both inflammation and genome instability share a complex relationship. A positive feedback loop occurs where DNA damage can trigger cell cycle arrest, apoptosis, senescence, and necrosis, of which the latter two can aggravate inflammation (Aoshiba et al. 2013). This feedback loop is deliberately regulated by DNA repair pathways, transcription factors, and cellular signals. Failure of DNA repair mechanism or unrepaired DNA damage from inflammation helps develop cancer by increasing mutagenesis. A study by Jaiswal et al. reported that inflammatory cytokines (such as IL- $1 \beta$, IFN- $\gamma$, and TNF- $\alpha$ ) induce DNA damages and compromise DNA repair activity via a nitric oxide(NO)-dependent mechanism (Jaiswal et al. 2000). NO at a concentration less than $400 \mathrm{nM}$ act as signaling molecules, but innate immune cells produce high levels of superoxide $\left(\mathrm{O}_{2}^{*}\right)$ and enzymes that contribute to RONS production along with radicals (e.g., superoxide, hydroxyl radical $* \mathrm{OH}$, and nitrogen dioxide $\mathrm{NO}_{2}{ }_{2}$ ), anions (e.g., peroxynitrite $\mathrm{ONOO}^{-}$, and nitrosoperoxycarbonate $\mathrm{ONOOCO}_{2}^{-}$), anhydrides (e.g., nitrous anhydride $\mathrm{N}_{2} \mathrm{O}_{3}$ ), hypohalous acids (e.g., hypochlorous acid $\mathrm{HOCl}$ and hypobromous acid $\mathrm{HOBr}$ ), and hydrogen peroxide $\left(\mathrm{H}_{2} \mathrm{O}_{2}\right)$. Moreover, pro-inflammatory cytokines energizing intracellular RONS production (Kay et al. 2019). ROS (being secondary messenger), hypoxia, and DNA damage contribute to the signaling cascade of receptors (e.g., members of the Toll-like receptors (TLRs) or nucleotidebinding oligomerization domain (NOD)-like receptors (NLRs) that instigate pro-inflammatory innate immune response through an array of functionally diverse down-stream signaling elements (e.g., NF-kB, STAT1, IRF-3, and caspase1 activation) (Pálmai-Pallag and Bachrati 2014) also cytokines such as IL6, STAT3, and TNF- $\alpha$ (Kidane et al. 2014). Moreover, damaged DNA leads to upregulation of IRF7 and phosphorylation of IRF3, resulting in its translocation to the nucleus from the cytoplasm, where it functions as the transcription factor. IRFs lead to the production of type IFNs and pro-inflammatory factors (Brzostek-Racine et al. 2011). Besides this, DNA damage influences activation of ATM and a series of consecutive post-translational modifications such as SUMOylation, phosphorylation, and ubiquitination of NEMO in the nucleus, which are vital for signal transduction to activate NF- $\mathrm{kB}$ (McCool and Miyamoto 2012). Other studies show NF- $k B$ activates the human IFN- $\lambda 1$ gene, IRF-1, and IRF-7 that can further impact the expression of IFN- $\alpha$ and
IFN- $\lambda$ genes (Brzostek-Racine et al. 2011). NF- $k B$, transcription factor regulates expression of several pro-inflammatory gene products such as TNF and its family, IL-1a, IL-1b, IL-6, IL-8, IL-18, chemokines, MMP-9, VEGF, COX-2, and 5LOX, leading to tumorigenesis by inhibition of apoptosis, proliferation, angiogenesis, invasion, and metastasis. Numerous studies support tumor-producing inflammation can stimulate NF- $\mathrm{kB}$, resulting in iNOS -dependent DNA damage. Moreover, studies also showed that hypoxia induces hypoxia-iNOS, which increases intracellular RNS and ROS free radicals concentration, resulting in DNA damage with poor prognosis (Janssens and Tschopp 2006; Kawanishi et al. 2017). The growing evidence of studies in the inflammation area suggests that carcinogens (such as cigarette smoke), tumor promoters, carcinogenic viral proteins, chemotherapeutic agents, and $\gamma$-irradiation induces NF- $\mathrm{KB}$ (Aggarwal et al. 2006). Anti-inflammatory drugs have the ability to target NF-KB and its regulated genes, and thus have the potential for targeting cancer (Yu et al. 2020). A study by Sokolova and Naumann mentioned human pathogen H. pylori, immune cells, and epithelial cells create inflammatory environments by promoting oxidative stress (stimulate the production of RONS) that results in DNA damage, apoptosis and cell proliferation in gastric mucosa, which leads to intestinal metaplasia and gastric carcinogenesis. Further, bacteria $H$. pylori can stimulate RONS production in immune cells. RONS is toxic to mitochondrial DNA (mtDNA), causing genome instability and loss of homeostasis (CalvinoFernández et al. 2008; Sokolova and Naumann 2019). Released extracellular or intracellular oxidamaged mtDNA (mtDNAox) fragments released from cells act as mediators of immune response via DAMP that further activates TLR9 receptor signaling. Other researchers have also studied the relationship between DNA damage and chronic inflammation in human cancer (Kawanishi et al. 2017). Prolonged inflammation hampers the DNA repair mechanism (downregulates MMR and BER mechanism), which eventually leads to cancer.

\section{Tumor microenvironment-induced inflammation followed by DNA damage}

Tumor cells generate an inflammatory microenvironment that encourages tumor cell proliferation and survival, ECM degradation and remodeling, abnormal vasculature, immune cell infiltration. These collaboratively facilitate growth which enables cancer progression (Coussens and Werb 2002). The solid tumor shows inflammation in the inflammatory microenvironment; immune cells like neutrophils, macrophages release $\mathrm{NO}$, and superoxide $\left(\mathrm{O}_{2}^{-}\right)$. During injury or inflammation sites, neutrophils and macrophages migrate and produce extracellular ROS and RNS. Moreover, at the infection site, neutrophils and macrophages generate an array of including 
superoxide $\left(\mathrm{O}_{2}{ }^{-}\right), \mathrm{H}_{2} \mathrm{O}_{2}, \mathrm{HOCl}, \mathrm{NO} *$, and $\mathrm{NO} 2 *$ radicals (Mittal et al. 2014). ROS and RON are chemicals components of inflammatory with free radicals, containing one unpaired electron (Biswas et al. 2017). UV-A or $\gamma$-irradiation, drugs, heavy metals, etc., are the exogenous source and oxidative metabolism, apoptosis, bystander cells, or enzymatic activity are an endogenous source of oxidative stress mediating ROS production (Pálmai-Pallag and Bachrati 2014). NO is longlived free radicals that diffuse through the extracellular matrix (ECM). They enter the nucleus by crossing through the plasma membrane and the cytoplasm of epithelial cells; in contrast, $\mathrm{O}_{2}-$ is barely long-lived to react with DNA inside the epithelial cells' nucleus. Alternatively, inflammatory cells also secrete cytokines (TNF- $\alpha$ ) to induce $\mathrm{O}_{2}-$ accumulation in neighboring epithelial cells (Grivennikov et al. 2010).

Ning and a co-worker mentioned the presence of powerful DNA lesions in cancer and inflammatory cells in the stroma of nasopharyngeal carcinoma (NPC) patients. Further, iNOS expression was spot in the cytoplasm of cancer cells positive for 8-nitroguanine (Ma et al. 2008). Another essential component of TME is hypoxia, which is a characteristic feature of both tumors and inflammation. HIFs are the indispensable regulator of tumor inflammation (Mamlouk and Wielockx 2013; Triner and Shah 2016). The hypoxic condition leads to highmobility group box-1 protein (HMGB1) translocation of HMGB1 to the cytoplasm from the nucleus (Kang et al. 2013). HMGB1 also release in the extracellular environment by two mechanisms, including active and passive release. Activated immune cells (e.g., macrophage and monocytes) actively release, whereas damaged or necrotic cells participate in the passive release of HMGB1 in the environment. Active HMGB1 release encourages neutrophil recruitment, activation of dendritic cells, and the release of pro-inflammatory cytokines, such as TNF- $\alpha$ and IL-6, from macrophages (Yun et al. 2021). Extracellular secreted HMGB1 from cells encourage various cellular functions, including proliferation, inflammation, and angiogenesis, along with hampering host anti-cancer immunity, which together contributes to tumorigenesis (reviewed in (Wang and Zhang 2020)). Besides, HMGB1 activates the pro-inflammatory signaling pathway and is involved in forming an inflammatory bone-marrow microenvironment (Yuan et al. 2020). The interplay of HMGB1 with RAGE, TLR2, TLR4, and TLR9 (receptor for HMGB1 CpGDNA complex) transduces cellular signals through a customary pathway that instigate the NF- $\mathrm{KB}$ pathway, and it also interacts with CXCL12/CXCR4 to activate the NF-KB pathway and thus facilitating the adhesion and survival of malignant cells (Ibrahim et al. 2019). The CXCL12 (SDF-1)/ CXCR4 axis is associated with tumor progression, angiogenesis, metastasis, and survival by stimulating various signaling pathways, such as ERK1/2, Ras, p38 MAPK, PLC/MAPK, and SAPK/JNK (Zhou et al. 2017). Numerous studies showed that ROS and RNS induce ICDs in cancer cells, which further enhance HMGB1 expression and HMGB1-DNA forms a complex leading to NO generation 8-nitroguanine formation (Sokolova and Naumann 2019). Indeed, the HMGB1 and TIM-3 interaction promotes VEGF secretion and thus promotes tumor angiogenesis. This interaction can be a potential target for tumor immunogenic chemotherapy and development (Yasinska et al. 2018). Moreover, data by Parker et al. allude HMGB1 facilitates MDSCs differentiation in the bone marrow and hampers the activation of antigen-driven CD4+ and $\mathrm{CD} 8^{+} \mathrm{T}$ cells (Parker et al. 2014; Tachibana 2018). More importantly, NF- $\mathrm{KB}$ is an essential player in inflammation, which also regulates iNOS expression. Abundant published evidence suggests that pro-inflammatory cytokines such as TNF- $\alpha$ and IL-6 induce iNOS expression, leading to the formation of mutagenic DNA lesions and carcinogenesis under the inflammatory microenvironment (Sokolova and Naumann 2019).

Another type of inflammation developed in response to anti-cancer therapies (chemotherapy, radiotherapy, immunotherapy, targeted therapy, etc.) is therapy-induced inflammation. Dying cells release DAMPs such as ATP, calreticulin, and HMGB1, which stimulate immune-stimulatory cytokines and enhance the release of tumor neo-antigens which activate de novo anti-tumor $\mathrm{T}$ cell responses or may be responsible for immunosuppression. This response is context-dependent and varies with individual and cancer types. Different cells present in TME, such as myeloid cells and fibroblasts and infiltrating cells, produce cytokines and growth factors such as TNF, EGF, IL-6, Wnt ligands. These growth factors may lead to chemoresistance as they are responsible for therapy efficiency used for treatment (Greten and Grivennikov 2019). TNF- $\alpha$ is probably an essential EMT-promoting cytokine and contributes to invasion in many cancers (Sistigu et al. 2017).

A recent study by Srivatsa and co-workers suggested that enhanced expression of EGFR in myeloid cells from colorectal fibroblast is a significant factor in therapy resistance and linked with tumor progression and reduced survival time of colorectal cancer patients (Srivatsa et al. 2017). This is also supported by another study by Halbrook et al., where they have mentioned how the release of pyrimidines such as deoxycytidine from tumor-associated macrophage (TAM) inhibits gemcitabine therapy and is responsible for developing gemcitabine resistance in patients with pancreatic ductal adenocarcinoma (PDA) (Halbrook et al. 2019). Further, the plethora of studies showed that inflammation influences EMT on several levels (because the microenvironment is composed of inflammatory cells and inflammatory mediators, such as cytokines and chemokines, which strongly contribute to the EMT program) (Jing et al. 2011; Suarez-Carmona et al. 2017). Moreover, EMT has also been mediated and activated by (a) stimuli triggered by stromal cells and ECM components of the surrounding microenvironment, (b) soluble factors [epidermal growth factor (EGF), fibroblast growth factor (FGF), 
hepatocyte growth factor (HGF), PDGF, TGF- $\beta$ and VEGF, and (c) morphogens Wnt, Notch and Sonic hedgehog, and pro-inflammatory cytokines (i.e., IL-6, IL-8, TNF- $\alpha$ ) (Sistigu et al. 2017), also, inflammatory microenvironment (Sistigu et al. 2017). Various cytokines, such as TNF and IL-1 $\beta$, can alter the expression of transcription factors Twist and Slug involved in EMT (Ricciardi et al. 2015; SuarezCarmona et al. 2017). A study by Labelle and his colleague showed direct interaction of cancer cells with platelets, resulting in EMT and synergistically activating the TGF $\beta /$ Smad and NF-KB pathways in cancer cells, promoting invasion metastasis (Labelle et al. 2011).

In solid tumors such as breast, head and neck, pancreatic, lung, brain, prostate, and cervix, DSB repair mechanisms get profoundly influenced by TME cellular and non-cellular factors including hypoxia, inflammation, genotoxic stress, cellular metabolism, and the immune system. The role of the TME and its relationship with DNA damage is emerging as an essential consideration in developing anti-cancer therapy that targets DNA repair-deficient cancer cells. This tumor-TME-DNA damage relationship needs new insights. It is a critical area of investigation to treat cancer (Lama-Sherpa and Shevde 2020) effectively. The interrelationship between inflammation, ROS generation, cellular physiology, and pathology in tumor cells and their microenvironment is described in Figure 3.

\section{Expanding focus on DNA damage in cancer immunotherapy: a sting in a tail}

Numerous exogenous and endogenous insults result in DNA damage, and multiple DNA repair mechanisms are available in humans. DNA damage and repair mechanisms have been investigated in various cancers and play an essential role in carcinogenesis. Cancer cells have relaxed DNA repair mechanisms and are characterized by the property of resistance to cell cycle checkpoints that allow continuous proliferation and tumor formation. The concept of DNA damaging chemotherapeutics in various cancers has a long history. For example, the first compounds as DNA damaging agents that entered the market were DNA intercalating alkylating agents such as Carmustine, Lomustine, and Semustine, which modify DNA bases by forming cross-linkages (Nikolova et al. 2000). Similarly, other compounds inducing DNA damage effect are platinum compounds such as Carboplatin, Cisplatin, Oxaliplatin induce DNA damage by forming DNA crosslinks (Hato et al. 2014); antimetabolite DNA antagonists like 5Fluorouracil, Gemcitabine, Floxuridine, 6-mercaptopurine, Fludarabine, Cladribine induce DNA damage by generating replication interference (Tiwari 2012); and topoisomerase inhibitors such as Etoposide, Doxorubicin, Daunorubicin, interfere with DNA function by inhibiting the DNA-protein complex stability (Buzun et al. 2020) (Cheung-Ong et al. 2013).
Although chemotherapeutic DNA damaging agents have been investigated for their anti-cancer properties in various cancers, several adverse outcomes are also reported. The problems associated with chemotherapeutic agents have moved the focus of cancer therapy towards an immunotherapeutic approach.

Recent investigations have suggested an interplay exists between DNA damage repair and the immune system. This crosstalk has opened up the possibilities of modulating DNA by targeting immune system-related mechanisms, as explained in Figure 4. Studies have reported that DDR defects activate the host immune system by activating the STING pathway, which results in interferon production and amplification in $\mathrm{T}$ cell response. Studies in DDR-deficient breast cancers have found activation of cGAS/STING/TBK1/IRF3 pathway with enhanced interferon production, increased production of tumor-infiltrating lymphocytes (TILs), and upregulation in the activity of TANKbinding kinase 1 (TBK1) (Parkes et al. 2017). One of the essential mechanisms regulated by the DNA damage repair system in tumor cells is neo-antigen production. The mutations that arise due to failed DNA damage and genomic instability trigger the production of tumor-specific neo-antigens presented on cell surfaces that will be recognized by $\mathrm{T}$ cells and produce an antitumor response (Yarchoan et al. 2017). DDR deficiencies in cancers promote the frequency and occurrence of nonsynonymous mutations that lead to a new peptide formation. For instance, the high somatic mutational rates and abnormal chromosomal numbers promote neo-epitope formation in BRCA1/2 tumors (Strickland et al. 2016). Another crucial mechanism to be considered is the activation of immune responses by apoptotic signals produced by damaged cancer cells. The apoptotic cells secrete HMGB1 proteins, which in turn stimulate T cell immunity by promoting myeloid differentiation factor 88 (MyD88)/Toll-interleukin 1 receptor domain-containing adaptor inducing INF- $\beta$ (TRIF) signaling (Apetoh et al. 2007).

Furthermore, the cellular DDR machinery also induces the release of pro-inflammatory cytokines within the tumor microenvironment. A study has shown that DNA damage causes the release of pro-inflammatory cytokines TNF- $\alpha$ and IL-6 (Karakasilioti et al. 2013). Studies in DDR-deficient breast cancer cells have also shown enhanced production of chemokines CXCL10 and CCL5, creating a proinflammatory environment in cells (Parkes et al. 2017). Additionally, DNA repair also regulates the expression of programmed death-ligand 1 (PD-L1) through the STATIRF1 pathway. For instance, loss of DNA repair proteins was associated with increased PD-L1 expression after radiotherapy and chemotherapy treatment. Similarly, activation of the STING pathway after DNA damage has also been associated with increased PD-L1 expression. STING pathway activation increases the transcriptional activity of type-I IFN and other cytokines after DNA damage (Grabosch et al. 2019). A study has also demonstrated the role of DSBs in 


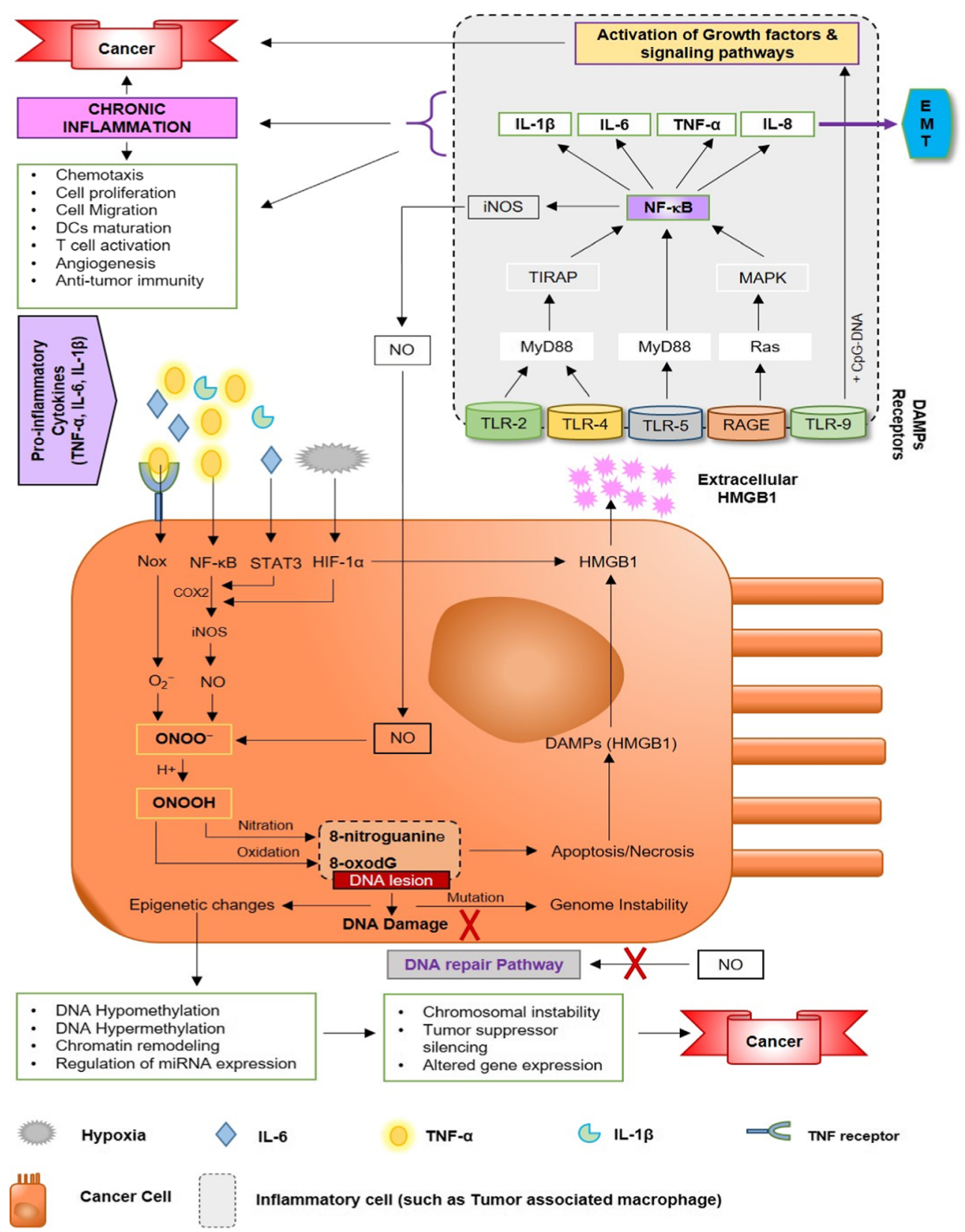

Fig. 3 Schematic presentation of interrelationship between inflammation, ROS generation and cellular physiology and pathology in tumor cells and its microenvironment: Inflammatory cells (such as macrophage) secrete cytokines such as TNF- $\alpha$ in the tumor microenvironment to stimulate $\mathrm{O}_{2}{ }^{-}$ formation via Nox where it reacts with NO, which is generated by especially iNOS to form $\mathrm{ONOO}^{-}$. This causes DNA lesions (8nitroguanine, 8-oxodG) in epithelial cells, which damage DNA. NO and ROS suppress the DNA repair mechanism, which results in genetic alteration (i.e., genomic instability) and epigenetic changes. Moreover, the epithelial cell containing damages DNA undergoes apoptosis, where HMGB1 (a nuclear protein), act as DAMPs translocate to extracellular space from nucleus. It is a crucial pro-inflammatory cytokine in its

regulating PD-L1 expression in cancer cells in an ATM/ ATR/Chk1-dependent manner, and activation of Chk1 is the critical step in regulating PD-L1 expression. The secretory form. Extracellular HMGB1 binds to different receptors include RAGE and TLRs. The effects of HMGB1 are executed through multiple signaling pathways, including NF- $\mathrm{KB}$ (p65) and MAPK. Various cytokines IL-8, IL-6, IL-1 $\beta$, TNF- $\alpha$ release in environment and resulted in tumorigenesis and chronic inflammation. Moreover, macrophage also produces NO (sufficiently long-lived to diffuse through the extracellular matrix) and enter epithelial cells to mediate DNA damage. In addition, IL-8 mediates HMGB1-induced tumor angiogenesis and EMT. Together all lead to cancer. iNOS, inducible nitric oxide synthase; DAMPs, damage-associated molecular patterns; HMGB1, high mobility group box 1 protein; EMT, epithelialmesenchymal transition

study has also reported that activation of canonical STAT1/STAT3 and IRF1 pathways are associated with DSB mediated PD-L1 upregulation (Sato et al. 2017). 
Fig. 4 Role of DNA damage in anti-tumor immune response. (A) DNA damage leads to abnormal transcription and translation that leads to the formation of peptides known as neoantigens. The neoantigens, after their synthesis, are transported to the cell surface and are presented in the HLAneoantigen complex. This complex interacts with $\mathrm{T}$ cell surface receptors and promotes $\mathrm{T}$ cell activity against tumor cells. (B) The double-stranded breaks produced during DNA damage regulate PD-L1 expression in ATR/Chk1/STAT/IRF1dependent manner. The PD-L1 expresses on tumor cells and interacts with PD-1 on the surface of $T$ cells, and induces $T$ cell anergy. (C) In response to DNA damage events, the DNA sensor cGAS binds to the DNA encapsulated in micronuclei and catalyzes the synthesis of cGAMP from ATP and GTP. cGAMP then activates the STING pathway and induces IRF3 expression by regulating TBK1 kinase. This leads to the synthesis of Type-I interferons (IFN-1). This further improves dendritic cell (DC) cross-presentation to enhance $\mathrm{T}$ cell activation
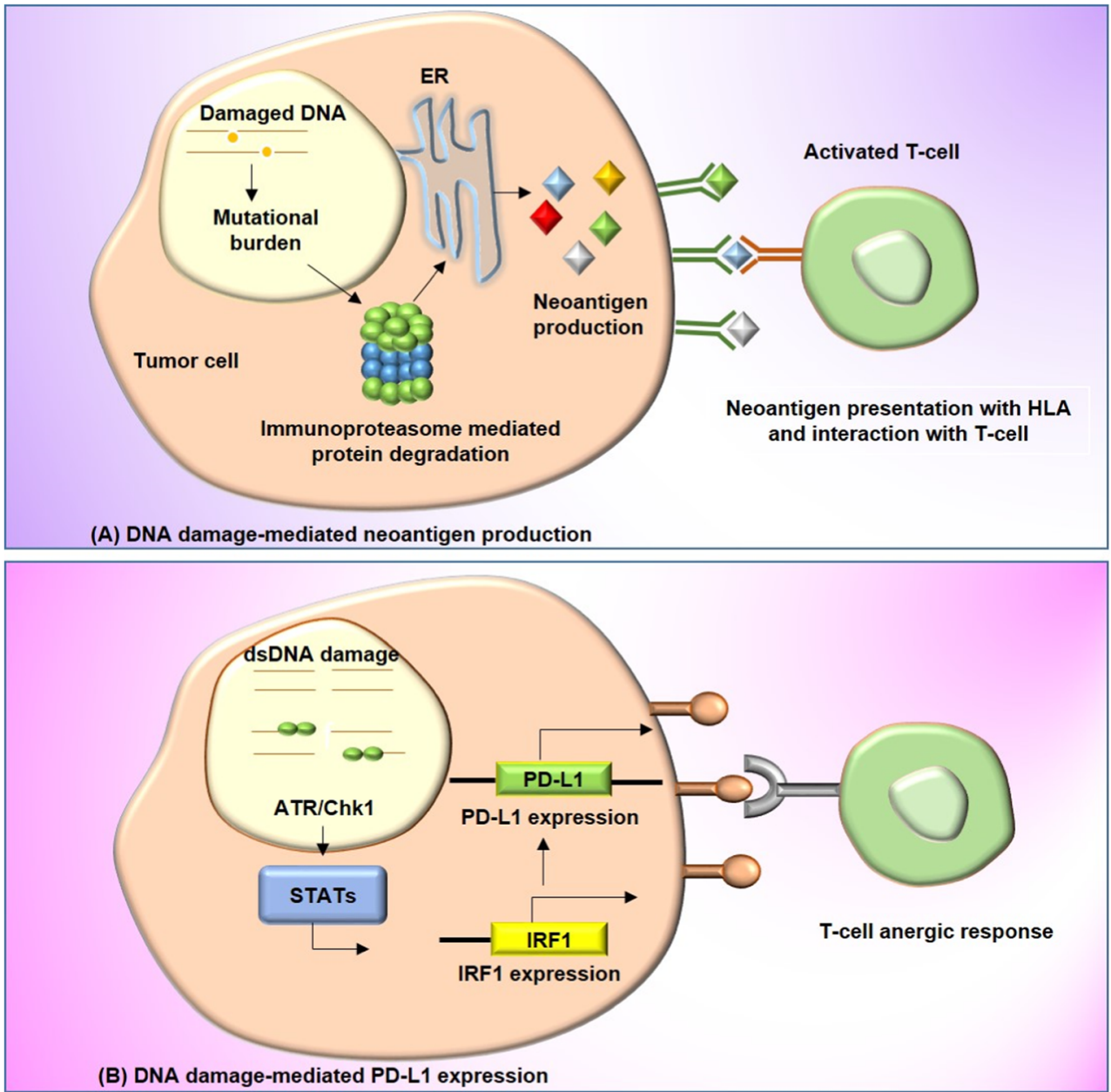

(B) DNA damage-mediated PD-L1 expression

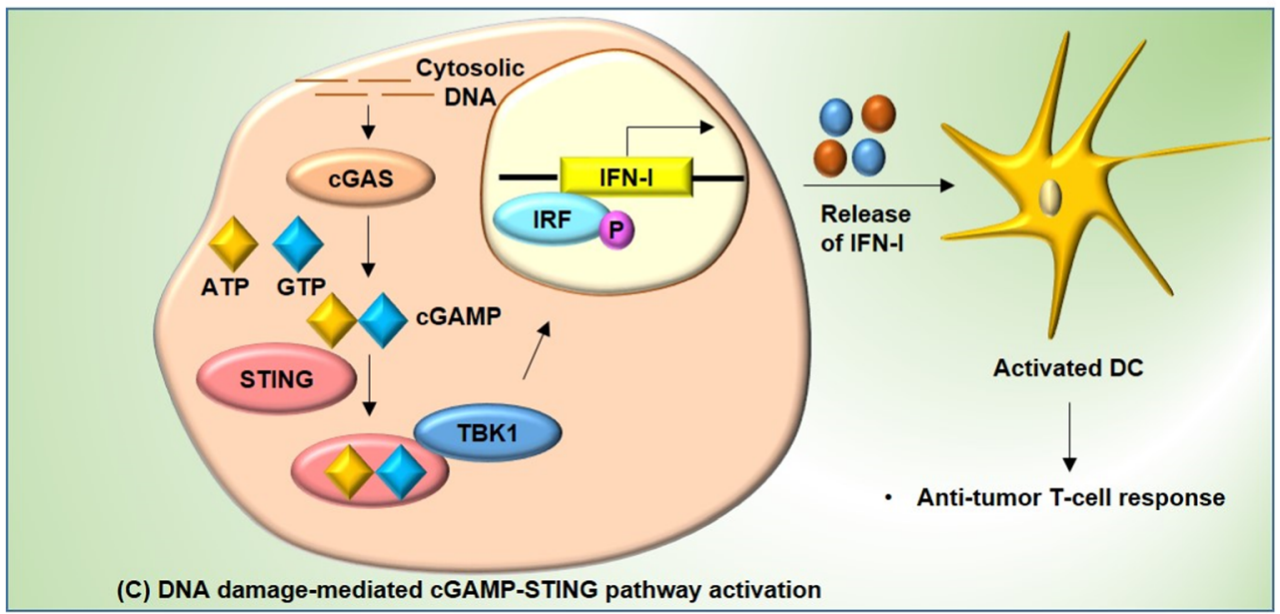

The immune mechanisms governed by DNA damage and associated mechanisms have developed a recent interest in developing immunotherapeutic anti-cancer agents. Several combinatorial therapeutic regimens involving DNAdamaging agents and immune-checkpoint inhibitors (ICIs) are being developed. This strategy may help to enhance genomic instability and immune system activation. As per the work published by Brown et al., about 200 clinical trials are ongoing for various cancers with DNA damaging agents and ICIs (Brown et al. 2018). Some studies have shown that deficiency in DNA repair pathways is associated with immune checkpoint blockade (ICB) response. Similarly, studies have shown that tumors with mismatch repair deficits have shown enhanced neo-antigen production and immune system activation when treated with PD-1 inhibitors (Le et al. 2017). Various poly adenosine diphosphate-ribose polymerase 
(PARP) inhibitors have been investigated in experimental and clinical studies to show the PD-L1 inhibitory effect. For example, Olaparib, a PARP inhibitor, has increased PD-L1 blockade in BRCA-deficient tumor cells, and Rucaparib also improved anti-PD-L1 treatment in BRCA mutant tumors (Lamberti et al. 2020). In a recent clinical study named KEYNOTE-365, the efficacy of DDR inhibitor combined with immunotherapy has been explored. The study was based on the intervention of Pembrolizumab, a PD-1 inhibitor, along with Olaparib, a PARP inhibitor. The therapy's primary response reduced serum prostate-specific antigen (PSA) levels (Yu et al. 2019). Besides PARP inhibitors, several other DDR inhibitors, such as ATM, ATR, CHEK, and WEE1, have also been studied in combination with immunotherapeutic agents. A summary of various ongoing clinical trials has been provided in Table 1.

\section{Impact of DNA repair on mutational signatures of environmental mutagens}

\section{Base excision repair in mammals and related signaling}

DNA lesions arising from various endogenous and exogenous mutagens in the environment cause loss of DNA bases due to hydrolytic cleavage, modification of the bases due to oxidation, methylation of non-enzymatic origin, leading to chemical alteration in the integrity of nucleic acid (Nature 2003). Frequent alteration in the DNA is necessary to be rectified, therefore, achieved using base-excision repair pathway BER. BER is an important asset in governing genomic stability and embroils various diseases such as cancer, aging prompting the establishment of various neurodegenerative disorders ([CSL STYLE ERROR: reference with no printed form.]). Purified enzymes such as DNA-glycosylase specific to DNA recognize the damaged DNA bases and cause cleavage of the glycosylic bond (linking DNA bases to the phosphate backbone) (Lindahl 1979). Another enzyme that adds to the repairment machinery of BER includes a DNA polymerase, AP endonuclease1 (APE1), and a ligase (Mitra et al. 1997). AP endonucleases' activity generates a 3-OH and a 5' terminus containing a deoxyribose phosphate (deoxyRP) to 5'-to the abasic site, resulting in a DNA single-strand break (SSB). Further, DNA polymerase $\beta$ (Pol $\beta$ ), XRCC1, and DNA ligase III $\alpha$ (Lig III) add up by filling the gap generated in between the nucleotide due to the removal of the base that was affected with a lesion (Dianov 2011). In short, patch BER (single nucleotide BER), DNA Pol $\beta$ embeds the missing base with the subsequent nick fixed by DNA ligase III complexed to $\mathrm{XRCC} 1$, therefore accomplishing DNA repair.

In contrast, in long patch BER, a polymerase $(\beta, \delta, \varepsilon)$ fills within a base gap. It keeps synthesizing DNA, whereas replacing the DNA downstream of the initial damage site produces a flap (2-13 nucleotides gap) of DNA removed by flap endonuclease-1 (FEN-1) in a PCNA-dependent manner. This long patch BER is sealed by DNA ligase I. The choice of whether or not repair is accomplished via short, or long patch BER chiefly depends on whether or not the abatic sugar is altered or reduced, as Pol $\beta$ cannot eliminate a changed sugar. If the $5^{\prime}$ sugar is modified, it is not removed by Pol $\beta$, and a long patch BER is initiated (Dianov 2011; Torgovnick and Schumacher 2015). OGG1 (8-oxoGuanine DNA glycosylase 1) and MYH (MutY DNA glycosylase) are most studies of nuclear glycosylases because of their involvement in recognizing and removing ROS-induced oxidative DNA lesions (8oxoGuanine) (Fayyad et al. 2021). Loss of OGG1 protein has been linked with lung, ovarian, and skin cancer. Missense mutation and a nonsense mutation in OGG1 have been reported in lung and breast cancer, respectively. Whereas increased expression of APE1 and XRCC1 has linkage with solid tumor and poor survival (Yuan et al. 2017). Methoxyamine, a small molecule that targets AP-site and blocks repair by APE1 enzymes, leads to the accumulation of DNA damage, hence introducing apoptosis.

Similarly, E3330 and Gossypol/AT101, NF-kB, and BCL2 inhibitors bind to APE1 and use alone or in combination with other chemotherapeutic agents for patients with lymphoma, prostate, lung, and glioblastoma cancers (Grundy and Parsons 2020). Moreover, Jones et al. study showed that biallelic mutations in the BER DNA glycosylase "MYH" result in adenomatous colorectal polyposis with substantial-high colorectal cancer risk (Oishi et al. 2002). Several research showed dysfunctional BER mechanisms linked with cancer (Maynard et al. 2009). On the same note, Lee et al. reported a deficiency in XRCC1 enzyme in breast cancers and studied DNA damaging agent's involvement in causing malfunctioning of BER enzyme, which proposed defects in BER as targets for therapeutic intervention in TNBC (Lee et al. 2019). In summary, the BER repair pathway components have been progressively recognized as promising and potential surrogate biomarkers, therapeutic cancer targets (Kumar 2020).

\section{Environmental mutagens and DNA mismatch repair}

Inadvertent incorporation of a nucleotide during the DNA replicative machinery despite the precise functioning by various DNA polymerases $(\varepsilon$ and $\delta$ ) leads to a mismatch in DNA bases. DNA proof-reading being the first line of defense when unable to rectify the mis-incorporated base sequences then causes the activation of the mismatch repair (MMR) pathway. Inactivation of genes involved in MMR due to interaction of mutagenic factors then leads to the occurrence of various mutator phenotypes (Zhang et al. 2005). Mismatch repair is also known to be associated with mutagenic insults induced 


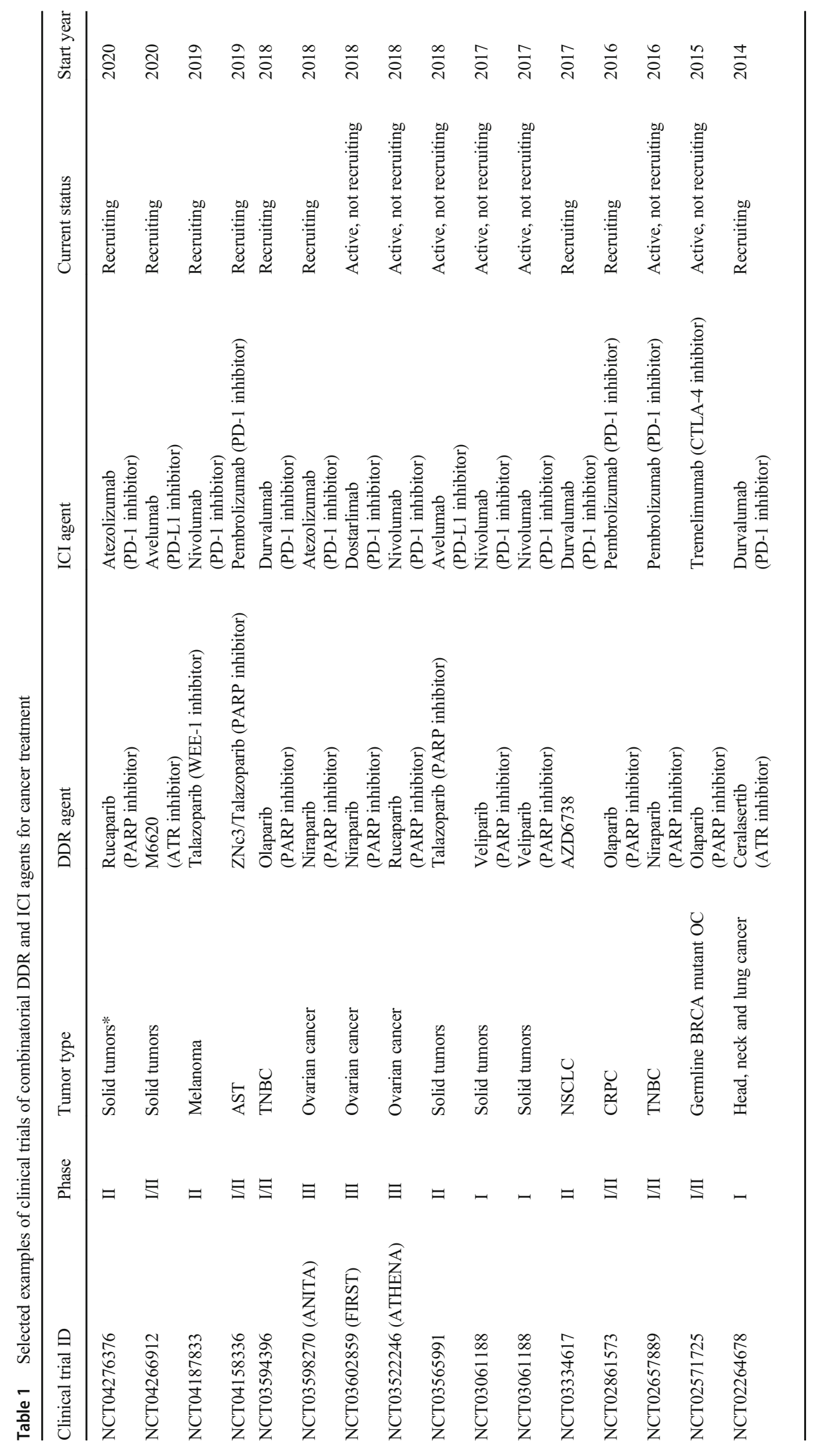


during DNA damage. These comprise lesions generated due to oxidative DNA, lesions affecting nucleotides arising from helix distortion, and nucleotides' synthesis due to methylations. Six MMR proteins are generally required in the proper functioning of this repair machinery. Studies have shown that endogenous mutagens, when they interfere with either of these MMR-related proteins (MSH6, PMS1, MLH1, MSH2, PMS2), lead to hereditary nonpolyposis colon cancer (HNPCC) (Vasen et al. 1996; Aarnio et al. 1999). Mismatch occurring in any nucleotide sequence is identified by the formation of a heterodimer comprising of $\mathrm{MSH} 2$ protein and MSH3/ MSH6 (Kolodner 1999). The occurrence of mismatch in the DNA causes a metabolic shift from ADP to ATP that causes a change in the confirmation of nucleotides, thereby converting MSH2/MSH6 assembly to a sliding clamp, further diffusing with the phosphate backbone of DNA in hydrolysisindependent manner.

Further, heterodimer complex (MLH1 and PMS2) or MLH1 and PMS1 mediates the foreplay between recognition of mismatched bases and proteins crucial for MMR. This assembly then binds with the complex containing DNA polymerases $(\delta$ and $\varepsilon$ ), proliferative cell nuclear antigens (PCNA), replication factors (SSD-binding proteins), and a helicase. MMR is known to be the suppressor of mutagenicity and elevates the level of checkpoint activation and induction of apoptosis by various ionizing radiation such as UV. Sites, where damage due to UV radiation occurs, are then occupied by the MMR heterodimers (MSH2-MSH6) that selectively bind to the mismatched bases and not binding with the matched nucleotides adjacent to the photolesions (Hong et al. 2008). Other metabolic components of mismatch repair machinery include SSD-binding protein RPA, HMGB1, and the RCF protein. RPA seems to be involved in every MMR stage as it binds with the nicked heteroduplex DNA much before the mismatched-provoked excision is stimulated by the Mut-S $\alpha /$ Mut- $\mathrm{L} \alpha$. This stimulation protects the ssDNA gapped sequences from excision and thus facilitates the resynthesis of DNA. Studies have shown that phosphorylation reduces the RPA for DNA, unphosphorylated RPA causes stimulation of DNA excision more efficiently as compared to phosphorylated RPA (Dzantiev et al. 2004; Ramilo et al. 2002).

Damage to the DNA by various alkylating agents such as N-methyl-N'-nitrosoguanidine (MNNG), procarbazine, and temozolomide are cytotoxic in nature that can kill cells that are replicating. As these cells progressively acquire resistance hence, they become deficient in MMR. Studies have shown that human colorectal cell lines are resistant to various alkylating agents and show associated MMR defects. Further, defects in MMR-related proteins MSH2 and PMS2 lead to resistance from alkylating agents (Hassen et al. 2016; Peltomäki 2016). Mutagens that cause damage to MMR proteins also impair various activities such as homologous recombination, somatic hypermutation, immunoglobin class switching, and trinucleotide repeats expansion (TNR). MMR mechanism is an important asset in maintaining the fidelity and integrity of DNA molecules; therefore, MMR-mediated DNA damage response can be an effective therapeutic target. A schematic representation is shown in Figure 5 about various DNA repair mechanisms activated during exposure to environmental mutagens (exogenous or endogenous mutagens).

\section{Nucleotide-excision repair mechanism in mammals and related signaling}

Distortion in the helical structure of DNA by various lesions caused due to various environmental mutagens like exposure from UV irradiations and various chemical toxins is generally eliminated using nucleotide excision repair (NER) (Gillet and Schärer 2006). This repair mechanism plays a pivotal role in maintaining genomic integrity; therefore, defects in this repairment machinery led to the establishment of different cancers. Two major pathways that govern that induced as a result of UV-irradiation (Hart et al. 1978). NER is initiated by recognizing the affected site by DNA lesion, which is generally recognized by XP-related proteins (DDB2 and XPC). After successfully identifying lesions on the template strand, TFIIH and proteins such as S XPA come under action (Repair 2016). XPC-RAD23-CETN2 heterodimers are important in recognizing DNA lesions when discussing the GG-NER mechanism in mammals (Volker et al. 2001). GG-NER employs the XPC-RAD23-CETN2 heterodimer complex that plays a prominent role in the recognition of lesions that detects and binds to the DNA sites.

Fig. 5 Schematic representation of various DNA repair mechanisms activated during exposure to environmental mutagens that can be either exogenous or endogenous. (a) Mismatch repair mechanism. Lesion that arises on the template strand and excision occurs followed by the binding of various DNA-binding proteins (MUTS $\alpha$ ), replication protein A (RPA). Recognition of the lesion and after excision, the machinery is taken up by exonuclease 1 (Exo1), Polymerase $\delta$ (Pol $\delta$ ), ligase I, and ATM or ATR. These proteins then cause synthesis of the repaired base sequence. (b) Nucleotide excision repair that occurs either in a transcription-coupled manner and global excision repair. DNA binding proteins such as DDB2, XPC, and DDB1 bind for damage recognition, followed by loading of $\operatorname{Rad} 23$ and Rad4 proteins. Attachment of RPA protein then generates nucleotide excision product. (c) Non-homologous end joining (NHEJ) in which loading of Ku70/80 complex proteins occurs on the lesion affected region, carried forward by end-processing by the assembly of artemis and ligation of the processed region by Ligase XRCC4/XLF/PAXX proteins. These ligand proteins, after excision cause the synthesis of intact DNA. (d) Mechanism of homologous recombination after mutagenesis causes recognition of the lesion on the double-stranded DNA (dsDNA), attachment of the RPA protein to the lesion binding site proceeded by insertion of RAD51 on the unwounded region. Formation of a D-loop occurs, and attachment of new repaired sequence within the D-loop causes successful synthesis of repaired DNA sequence 
Further, the double helix is distorted, leading to the destabilization of bases (Min 2007). During the occurrence of indirect damage to the DNA, XPCs bind to the DNA region where there is a presence of mismatched bases and no presence of any lesions. To avoid any erroneous breakdown at the bases, GG-NER needs to verify that the existence of lesion at that particular binding region occurs, and to execute this step, DNA-dependent ATPase/helicase activity of TFIIH is required (Sugasawa et al.
2009). TFIIH is a complex assembly made up of two ATPase helicase subunits (XPD and XPB), from which XPB is required during NER and in the transcription mechanism (Oksenych et al. 2009). XPD proteins, on the other hand, have dual activity (ATPase activity and a 5' to 3' helicase activity), important for NER but not required during transcription. Mutagens targeting and disrupting the sequence of nucleotides are taken care by the GG-NER pathway of DNA damage repair.

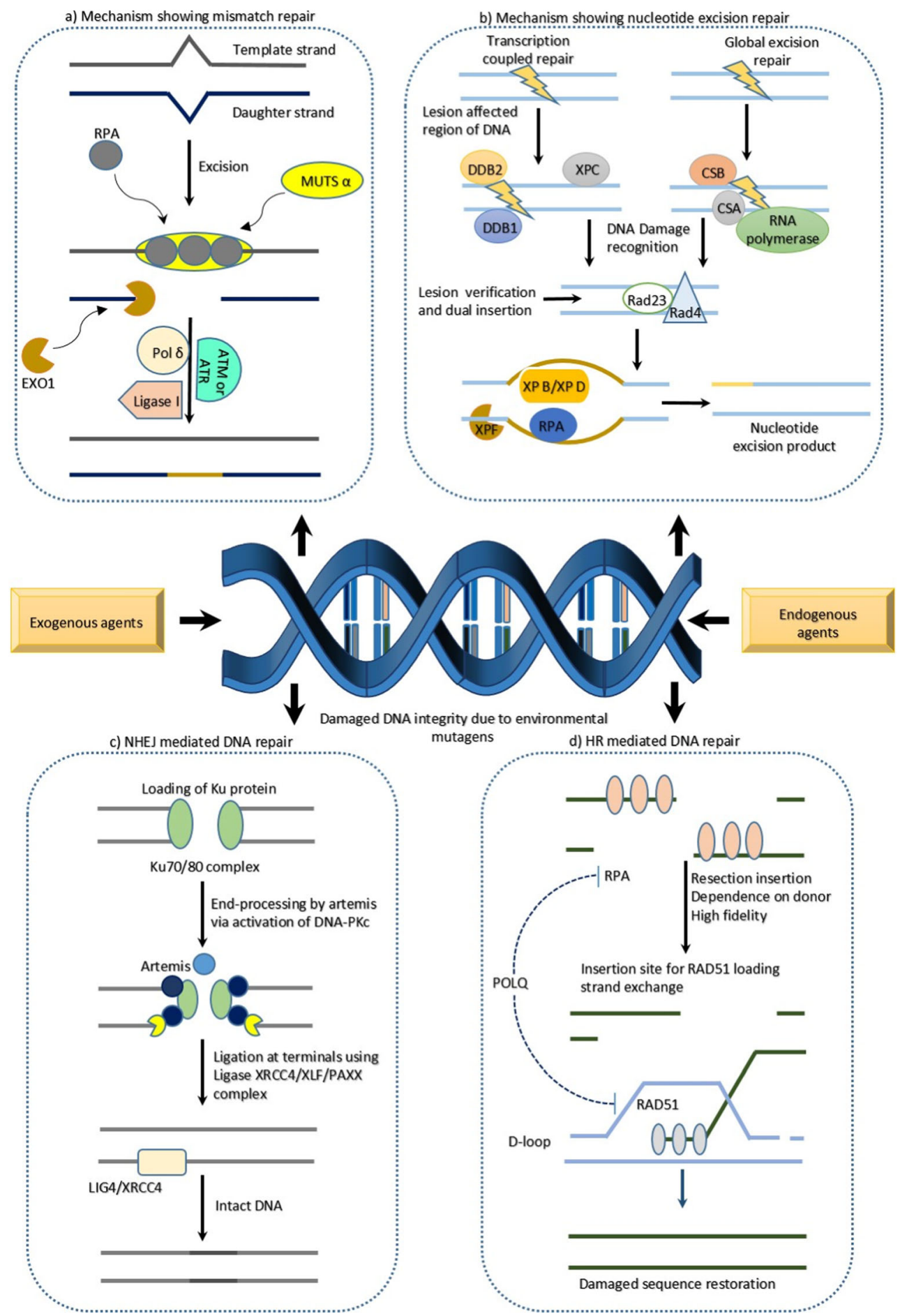


Genomic DNA is considerably larger, and the lesion's probability of occurrence is unexpectedly higher, causing an urgent need for a cell-free system. Assuming that there is a presence of a specialized mechanism assisting XPCs to identify lesions affected sites apart from whole naked DNA, different mechanisms are proposed. One such mechanism employs UV-damaged DNA damage binding protein complexes (UV-DDB). UV-DDB is known to be the assembly of DDB1 and DDB2, shows strong binding affinity and specificity to UV-damaged DNA (Fujiwara et al. 1999). These factors presumably bind to the pyrimidine photoproducts, attaching directly to the photolesions induced by UV and encounters for the presence of any lesion. But the base adducts that are bulky in nature, formed by chemical mutagens, are known to be the poor substrates for these UV-DDBs (Joon Hwang et al. 1999). Hence, UV-DDB repair mechanisms act to be more preferred when talking about the CPDs due to the poor recognition capability of XPCs. Mutagens that are crucial and cause these types of DNA damage, majorly photolesion due to exposure to radiations of ionizing origin, NER acts to be the line of defense and comes into roleplay as soon as a lesion is detected. Therefore, NER is an important repair mechanism in handling these types of lesions, and from the therapeutic prospect can be traced when talking photolesion induced DNA damage caused due to environmental mutagens.

\section{DNA- DSB repair and related signaling cascades:}

DSBs induced in DNA as a result of exposure from environmental mutagens such as the use of radiomimetic medicines such as neocarzinostatin and bleomycin, ionizing radiations (IR), use of cytotoxic agents such as camptothecin, doxorubicin, and etoposide appears to be the most lethal form of DNA damage (Helleday et al. 2007). This class of DSBs is known to be biologically important in nature as repairment of this defect is extremely crucial compared to any other DNA damage (Ciccia et al. 2010). The mechanism that holds the repair machinery of DSBs is carried either by homologous recombination, which occurs during the G2 and S-phase of cell cycle, or by NHEJ that can happen during any phase of the cell cycle (Karanam et al. 2012). For efficient regulation and in the maintenance of genomic instability, a series of signaling cascades get activated during DSB (Huang et al. 1996). If the DNA damage is severe in the cellular machinery, then activation of The DNA damage response occurs, which includes activation of cell cycle checkpoint, DNA repair, or regulation at the transcriptional level, ultimately leading to apoptosis (Bao 2011; De Zio et al. 2013). DNA DSBs, if not considered for corrections at the right time, lead to the loss of chromosomal regions and chromosomal translocations, thereby causing tumorigenesis due to genetic fusion or due to functional alterations in proto-oncogenes (Nikiforova et al. 2000). Studies convicting the role of these chromosomal arrangements include cancer of lymphatic origin and various nonlymphatic cancers (Richardson and Jasin 2000). NHEJ acts to be the simplest form of DSB repair pathway, works by joining the two ends of DNA in a sequence-independent manner, and is the preferable form of repair in case of blunt ends, although sequence alteration may occur at breakpoints due to incompatibility. Proteins acting as the core of this machinery are DNAdependent protein kinases and XRCC4/ligase IV/XLF complex (van Heemst et al. 2004). A ring-shaped heterodimer $(\mathrm{Ku} 70 / 80)$ binds to this protein kinase, thereby binding to the ends of the DNA molecules (Weterings and van Gen 2004). This KuXRCC4-DNA ligase IV complex efficiently reconstituted the blunt ends through the NHEJ pathway. A large fraction of DSBs induced by different mutagens is repaired by homology-directed recombination-mediated repair (HRR). The process starts with resection of $5^{\prime}$ DNA ends catalyzed by a trimeric complex MRN comprising of MRE11, RAD50, and Xrs/NBS1. The process is assisted by endonuclease Sae2/Ctp1/CtIP (Mimitou and Symington 2009). Further resection is carried out by singlestrand endonuclease DNA2 or EXO, combined with Sgs1/BLM helicase. The next step is the formation of ssDNA binding protein RPA-RAD51 recombinase with 3' single-strand DNA filament. The mechanism is characterized by the synthesis of specific "double Holiday junctions" where the nicks are sealed by DNA ligase (Chang et al. 2017). An alternative pathway for DSB repair is alternative (microhomology-mediated) end-joining (alt-EJ/ MMEJ). The pathway initiates with resection of 5' ends flanking DSB, followed by DNA end synapsis induced by PARP1. The polymerization is carried out by DNA polymerase $\theta(\operatorname{Pol} \theta)$, while the DNA ligase III -XRCC1 complex is required for the final ligation step (Cannan and Pederson 2016).

A comprehensive investigation of DDR gene alterations across 33 cancer types has revealed that HR is the most frequently mutated repair pathway, while a few cancers are associated with alteration in the NHEJ pathway (Knijnenburg et al. 2018). Mutational signatures affecting BRCA1, BRCA2, RAD51 genes (RAD51B, RAD51C), and BLM are found to be associated with HR alterations in cancers. A study in solid tumors has revealed the potential of HRD-targeted therapies as HR-DDR mutations were seen in $17.4 \%$ of tumors (Heeke et al. 2018). Likewise, a study has identified the role of MRE11 gene mutations in primary tumors. The gene is involved in DSB repair through NHEJ and HR pathways, and three different missense mutations are found to be associated with tumor development (Fukuda et al. 2001). As the failure of DDR in response to DSBs triggers tumor development, therapeutics targeting the DSB repair pathway could provide new treatment opportunities for a wide range of cancers.

\section{Therapeutics avenues targeting cancer provoked by mutagens}

Environmental mutagens cause cancer in humans. A plethora of studies have been performed to discover treatment avenues 
for targeting cancer from therapeutics and prevention perspectives. Different areas have already been exploring, and still, new areas are being studied to expand current knowledge related to cancer. Recent innovations are focused on immune checkpoint inhibitor biologics, therapeutic vaccines, small drugs, and CAR-T cell injections (Alard et al. 2020). Different drugs like NSAIDs have been repurposed for the prevention and treatment of cancer (Zhang et al. 2018b; Turanli et al. 2018). On similar notes, infectious agents are also significant causes of causing cancer. To target cancer due to viruses and bacteria, anti-viral therapies are being discovered and used in clinics. In addition to therapeutics drugs, indicative of cancer disease and reason for cause is also essential. To understand this, the importance of biomarkers study is necessary to respect diagnostic, prognostic, and predictive cancer and its treatment (Califf 2018). Biomarkers related to DNA repairs have been explained in detail in this section.

\section{Inhibitor targeting DNA damage caused due to environmental mutagens}

The DNA damage response entails an orchestrated network signaling molecules and proteins involved in cell cycle arrest and repair mechanism. These are crucial for cell viability and avoid an accumulation of damaged DNA from one generation to another. In cancer, these responses are dysregulated, leading to either upregulation, downregulation, or loss of some other pathways and cause DNA damage, leading to cellular responses like inducing apoptosis and modulating cell cycle progression (Gavande et al. 2016). These pathways, being upregulated, can potentially be resistant to anticancer DNA damaging agents. Hence, key component inhibitors of the pathway being dysregulated are plausible to prevent this therapeutic resistance (Curtin 2013). Also, from a pharmacological aspect, the repair system's inhibition promises to enhance the cytotoxicity of a varied range of anticancer agents.

Moreover, defects in DNA damage responses are dependent on the complex pathways, the inhibition of which will initiate tumor-specific cell killing. Therefore, inhibitors targeting DNA damage can enhance the efficacy of chemotherapy as well as ionizing radiotherapy involved in DNA damage. Additionally, studies suggest that chemical inhibitors developed to exploit synthetic lethal interaction effectively and can pave the path for promising DNA repair targeted agents to be used in cancer therapy (Madhusudan and Hickson 2005). ROS generation commonly causes damage to nucleobases, spontaneous deamination, and aberrant methylation due to S-adenosyl methionine and methyltransferase enzyme activity. To repair this methylguanine DNA methyltransferase (MGMT) and prevents cell death caused by alkylating agents (Pegg 1990), many approaches have been worked upon to block MGMT using alkylating agents like temozolomide DTIC (dacarbazine), using pseudosubstrates [e.g., O6-benzylamine (O6-BG) (Dolan et al. 1990). Some have been futile to show any considerable activity in cancer patients and have not progressed clinical trials any further (Khan et al. 2008; Kefford et al. 2009).

The repair mechanism involved could vary depending on nature. For instance, the extent of damage, for instance, nucleobase damages, is frequently repaired by BER, resulting in removing the damaged base and further repairing SSBs single-strand break repair (SSBR) pathway. Many studies have suggested that Methoxyamine, a small molecule, potentiates cytotoxicity as it binds to AP sites and targets BER. This further impact and prevent APE1 processing. APE1 increases tumor resistance while treating with chemotherapeutic agents, making it a key target for cancer therapy (Abbotts et al. 2014). The next class involves PARP inhibitors which include PARPi are NU 1025, NU 1064, AG 14361, AG 14699, GPI 15427, they have shown to decrease the repair mechanism of SSBs and survival too after being exposed to DNA methylating agents (Durkacz et al. 1980; Madhusudan and Hickson 2005). Thus, preclinical studies have potentiated DNA methylating agents' antitumor activity (Madhusudan et al. 2005). Moreover, some FDA has approved drugs that also act as PARPi in treatments, like ovarian cancer, which can be treated using Olaparib, Niraparib, and other combinations (LaFargue et al. 2019). These PARPi not only inhibit proteins involved in various pathways but also increase tumor-killing abilities. On the other hand, some pathways are in the development phase, like nonhomologous end-joining inhibitors, among which phosphoinositide-3-kinase related protein kinases (DNA-PKcs) have the most promising candidature. They undergo rough complex autophosphorylations and govern DNA interaction with proteins involved in repairs like cAbl, HSP90, PARP1, and H2AX, protect telomere (Zhou et al. 2013). The overexpression of DNA-PKcs is associated with radio-resistance in various carcinomas such as lung, esophageal, oral squamous cell, and other carcinomas (Srivastava et al. 2012), signifying that the chemical inhibition of DNA-PK can boost homologous recombination. The molecules belonging to this class are NU7026 [2-(morpholin-4-yl)-benzo[h]chromen-4-one]; NU7441; IC87102 (Willmore et al. 2004; Mohiuddin and Kang 2019). Some of the other emerging targets involve Pentamidine (Chow et al. 2004), antisense RNA targeting the ERCC1 protein (Selvakumaran et al. 2003), FA proteins (Ferrer et al. 2004), small inhibitory RNA molecules (siRNAs), but the long-term safety of these still need to be proven. Thus, as mentioned above, be it inhibitor or modulator of DNA repair can target a broad range of interactions, thereby presenting a new scope for escalating therapeutics for cancer (Table 2).

\section{DNA damage and repair biomarkers in cancer therapy}

The DDR system encompasses eight pathways: MMR, BER, checkpoint factors, Fanconi anemia, HRR, NER; nonhomologous end-joining; and DNA translesion synthesis. 


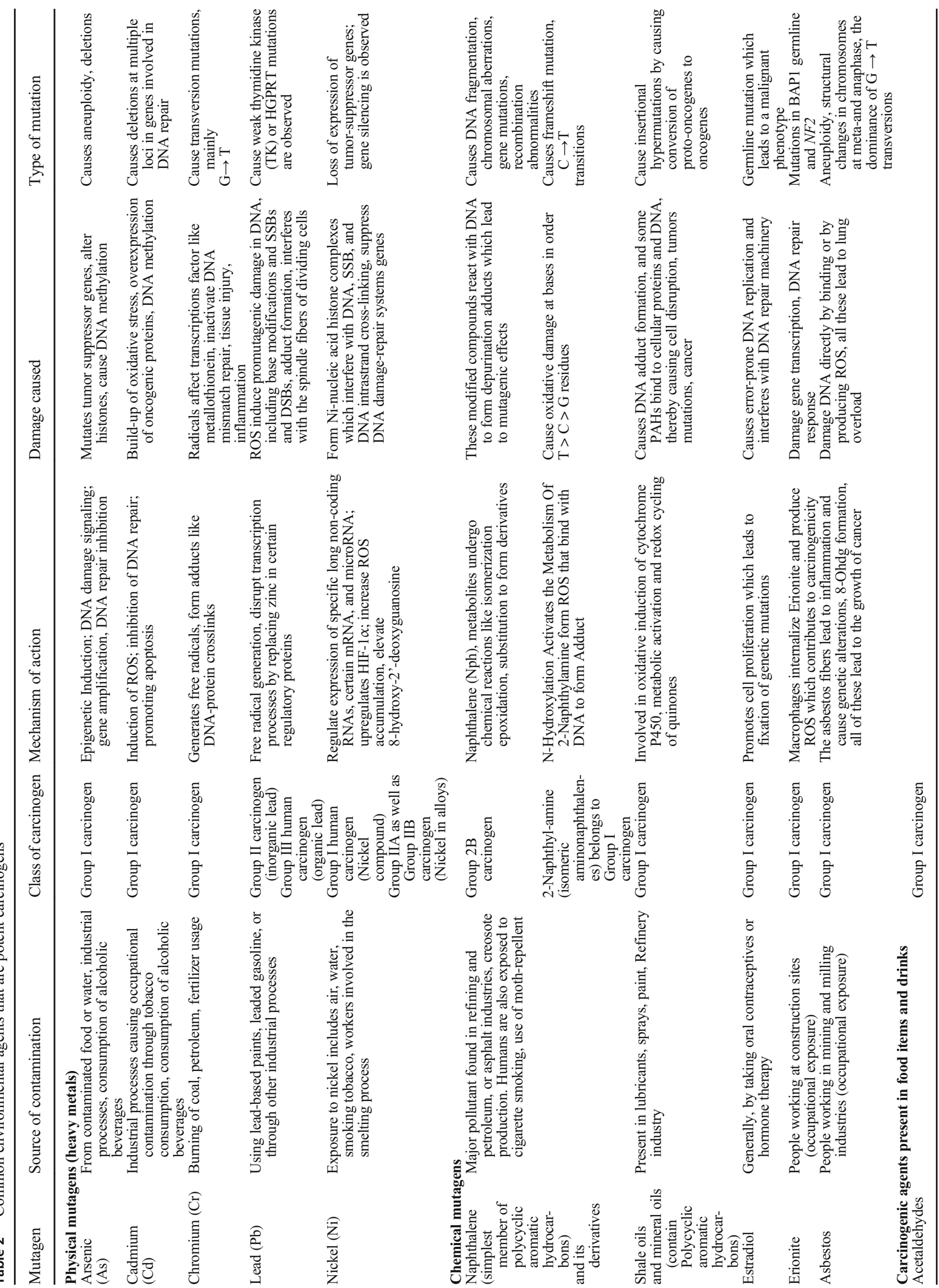




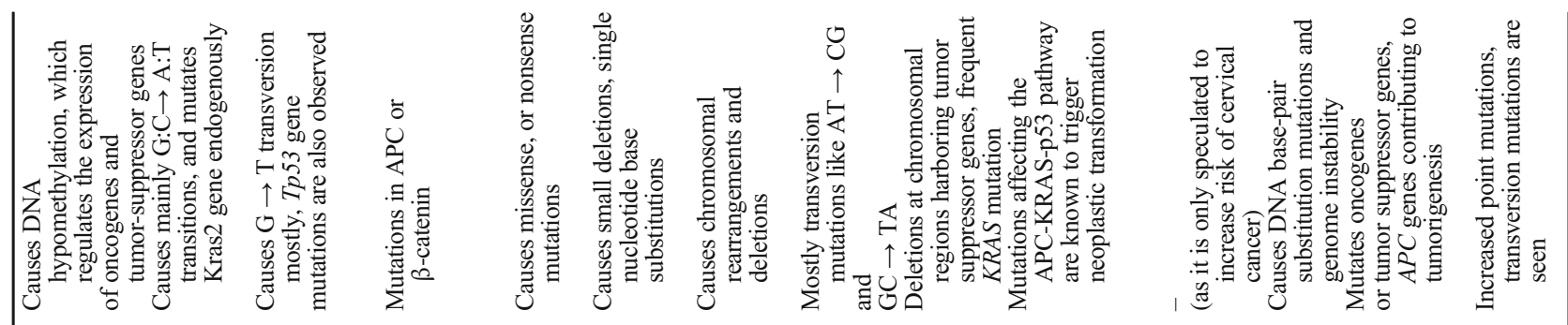

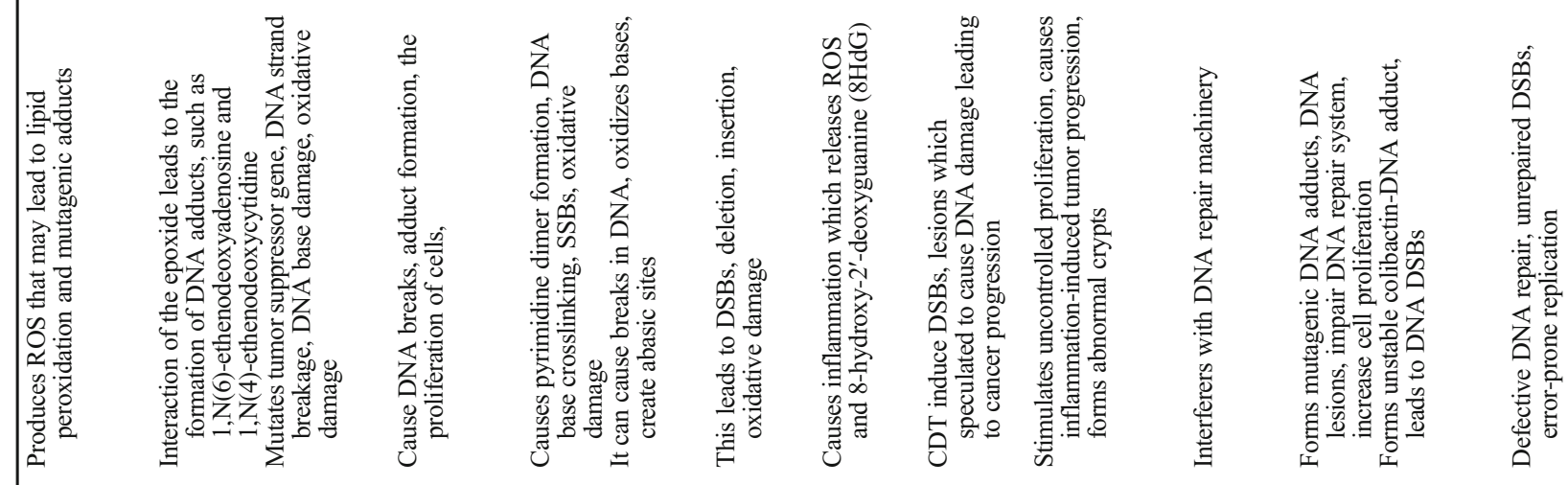

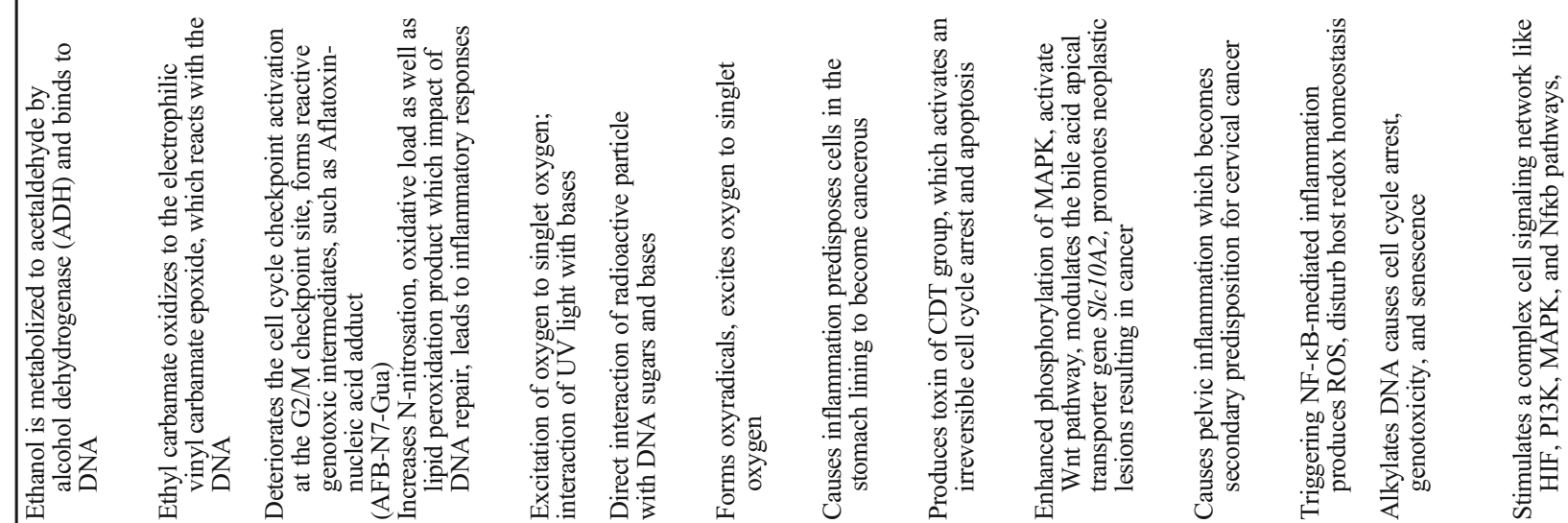

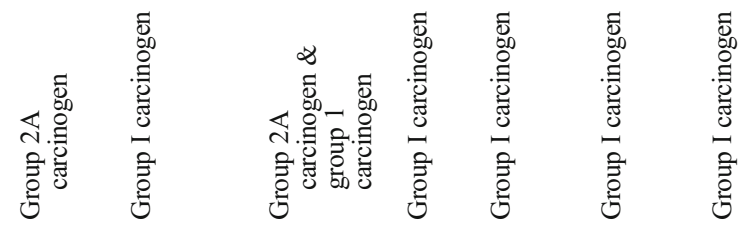
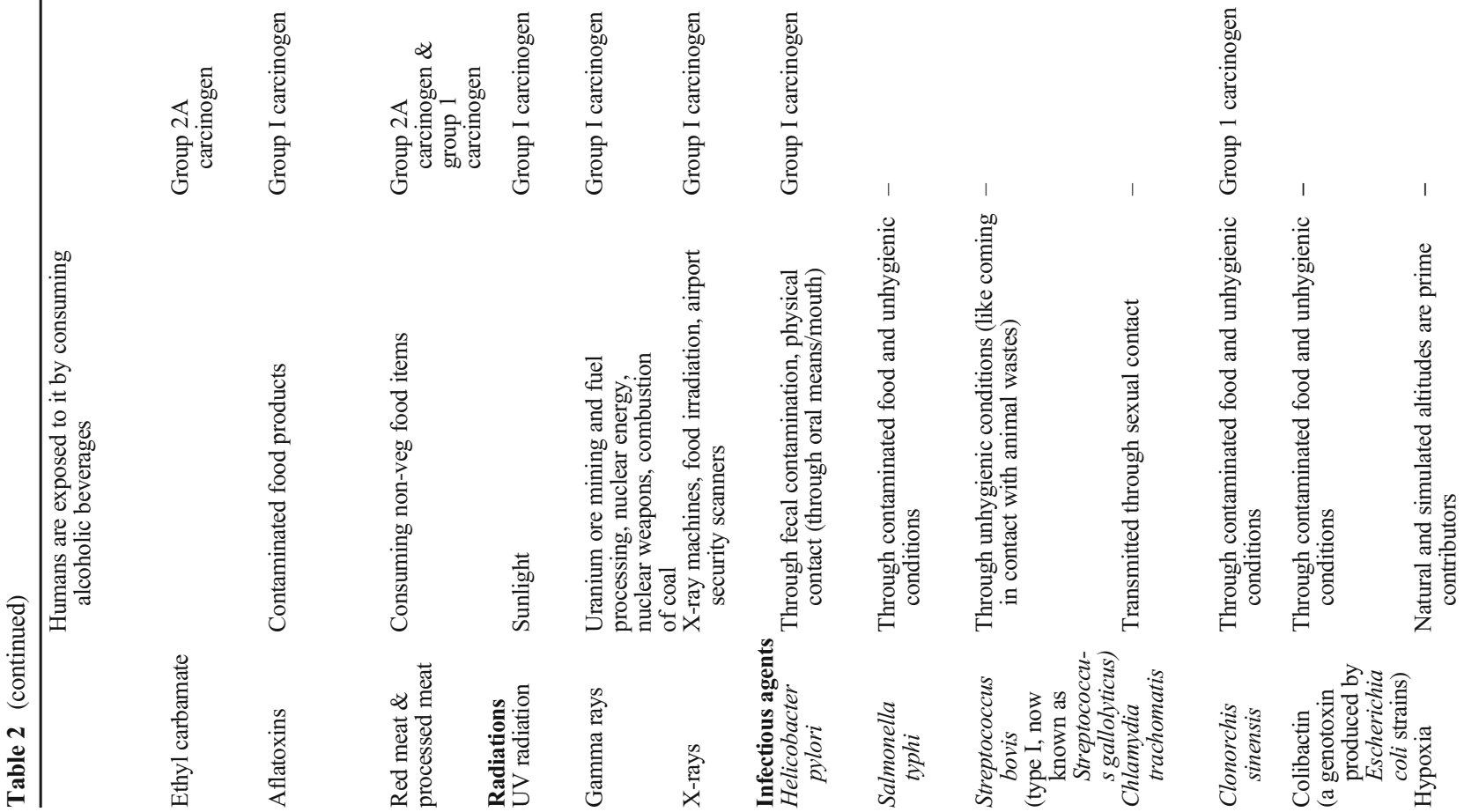

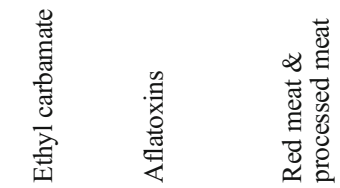
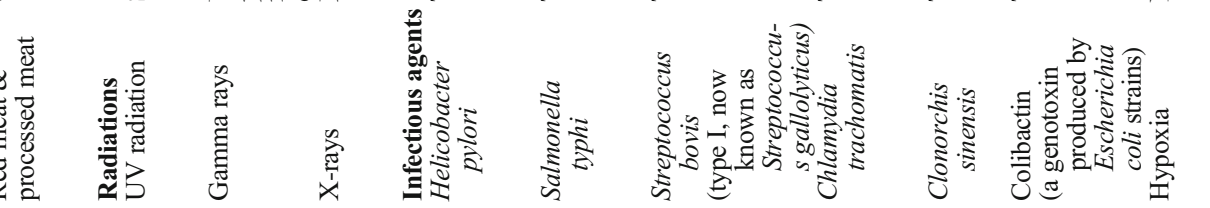


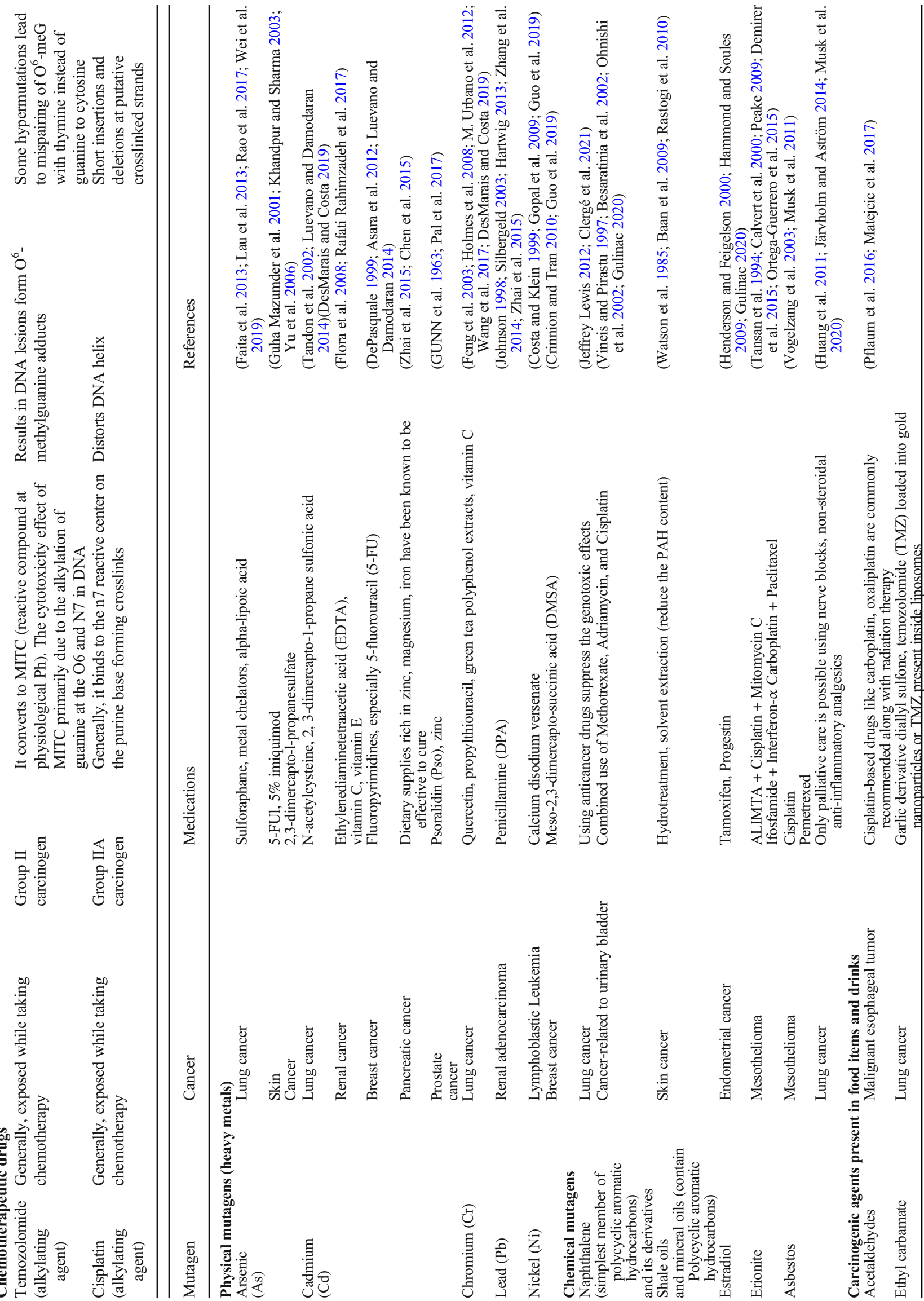




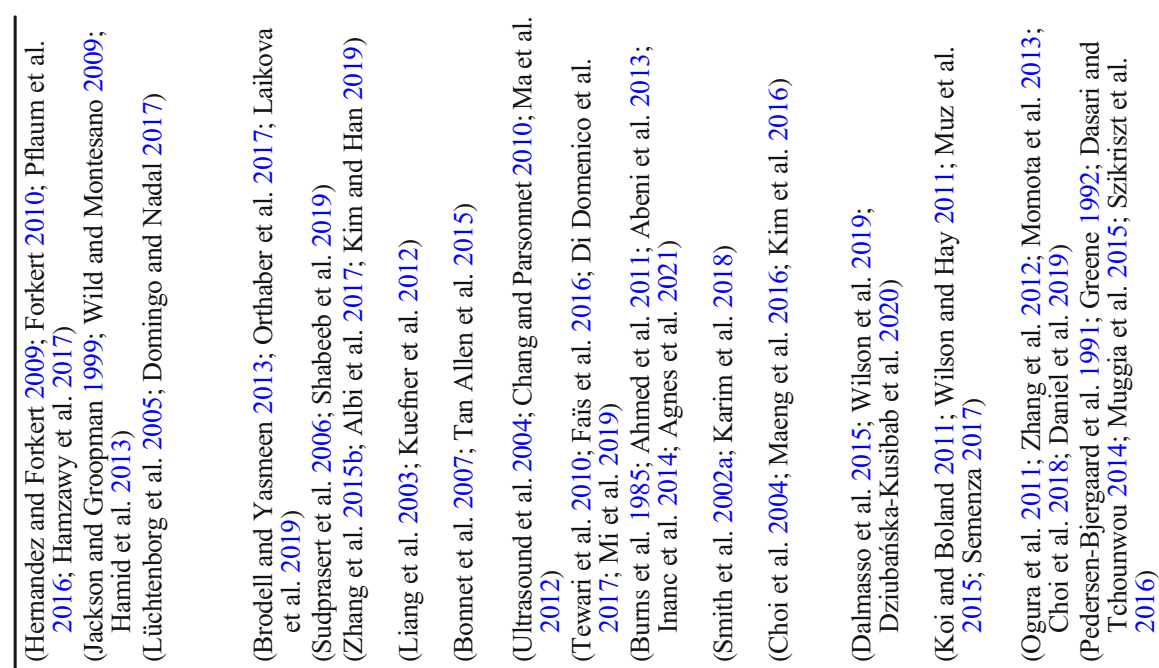

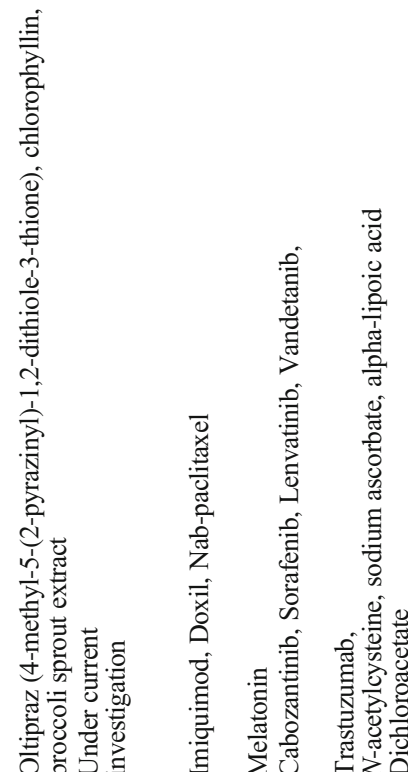

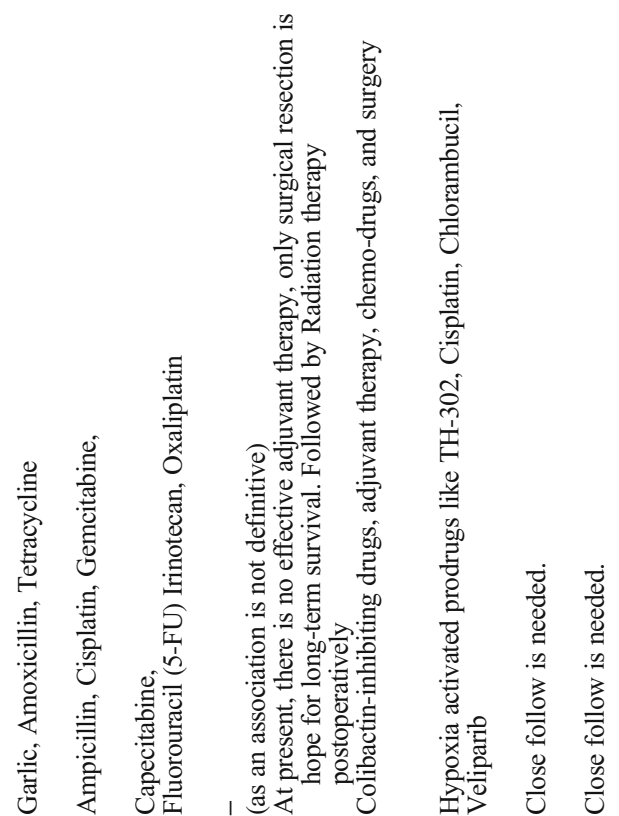
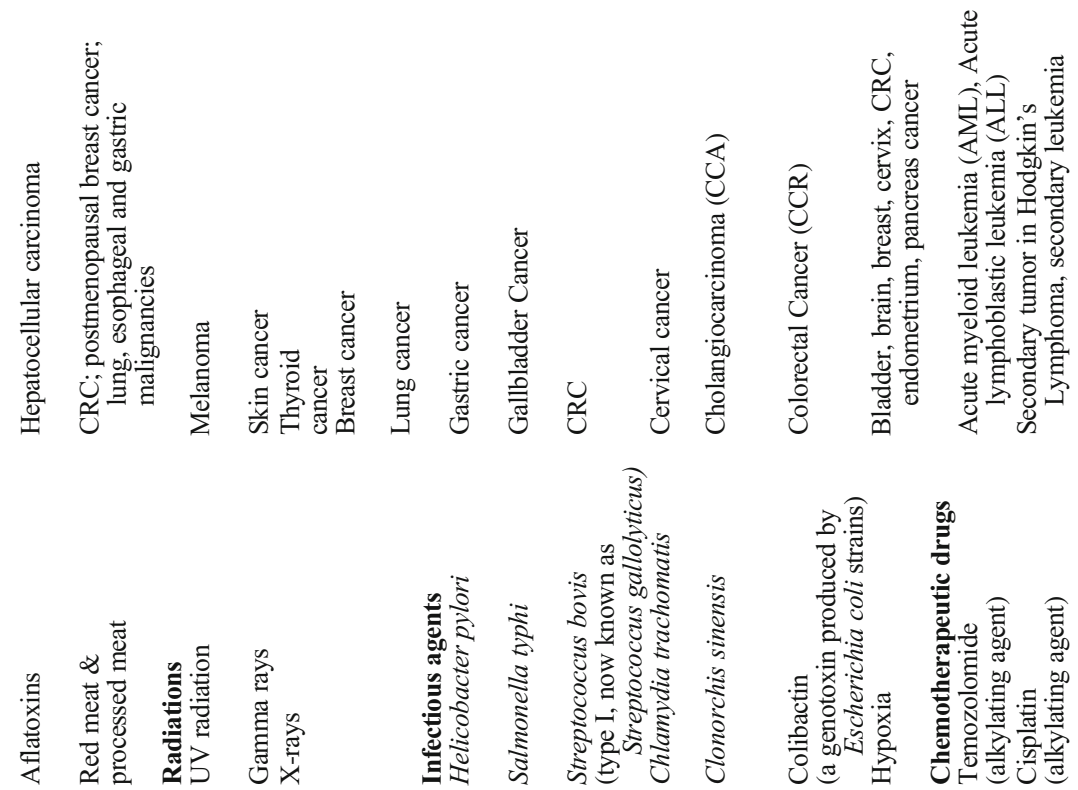
Defects in these pathways lead to genomic instability and hence cancer (Das et al. 2021). Scarbrough et al. identified three susceptibility DNA repair genes, RAD51B, MSH5, and BRCA2, and pleiotropic association of DNA repair mechanism with lung, ovary, prostate, breast, and colorectal cancer (Scarbrough et al. 2016). Research over the years has contributed substantially to our understanding of the importance of biomarkers as diagnostic, prognostic, and predictive markers regarding cancer and its treatment. More importantly, the generation of some biomarkers inside cells, namely micronuclei $(\mathrm{MN})$, nucleoplasmic bridges (NPB), and nuclear buds (NPB), can be utilized as an indicator of DNA damage due to exposure to cytotoxic or DNA damaging agents or any other environmental carcinogens (Alhmoud et al. 2020). For early detection of DNA damage, diagnostic biomarkers including phosphorylated histone $2 \mathrm{Ax}(\gamma \mathrm{H} 2 \mathrm{AX}), 8-\mathrm{OHdG}$ or 8-oxo-7,8-dihydro-2'-deoxyguanosine (8-oxodG) facilitation disease detection and prognosis. $\gamma \mathrm{H} 2 \mathrm{AX}$ is proven to be one of the most promising markers for DSB in precision medicine (Ivashkevich et al. 2012; Reddig et al. 2018). Besides, $\gamma \mathrm{H} 2 \mathrm{AX}$ foci levels have also been used as predictive markers where they predict the pathological complete response (pCR) in TNBC patients and cervical Cancer (Vici et al. 2015, 2016) and monitor cancer progression and treatment because therapeutic agents either induce DSBs directly (such as radiation, other environmental factors) or produce diverse DNA damage that causes DSBs formation (such as PARP inhibitors, gemcitabine, platinum drugs) (Sedelnikova and Bonner 2006). Evidence and understanding of DNA repair function and its correlation with drug response in individual tumors will be critical to patient selection for DNA repair targeted therapies.

Genomic and functional assays of DNA repair pathway activity are being explored extensively as potential prognostic or predictive biomarkers for targeted therapies. These biomarkers consider specific alterations in DDR pathways or genomic signatures resulting from the aberrant repair. For example, germline BRCA1 or BRCA2 (BRCA1/2) mutations (HRR deficiency) and somatic ERCC2 mutations (NER pathway) in epithelial ovarian cancer patients and urothelial cancer patients respectively enhance platinum drug sensitivity because it decreases the capacity to repair platinum-induced DNA damage (Van Allen et al. 2014; Mylavarapu et al. 2018; Palacios et al. 2020). On a similar note, HRR and BER deficiencies in cancer cells sensitize them to topoisomerase-I inhibitors (e.g., topotecan). In contrast, HRR and NHEJ deficiencies sensitize to topoisomerase-II inhibitors (e.g., doxorubicin and etoposide) (Maede et al. 2013). In addition, BRCA1/2 mutations (HRR deficiency) serve as an essential biomarker for PARP inhibitors' sensitivity (PARPi) response. PARPi is selectively lethal to HRRdeficient cells. Olaparib was the first FDA-approved drug for ovarian cancer with BRCA mutation (Farmer et al. 2005;
Matulonis et al. 2016; Golan et al. 2019). Aurora A, a mitotic kinase, is involved in cell cycle control and has been overexpressed in many cancers. Aurora A prevents RAD51 from being recruited to DNA DSBs via a process that requires the checkpoint kinase CHK1 to be inhibited. As a result, HR's DSB repair is hampered, and cells are more vulnerable to PARP inhibitors. More importantly, overexpression of Aurora A is a potential predictive biomarker of PARP inhibitor sensitivity (Michels et al. 2014).

Abundant published evidence suggested that alteration in tumor DNA repair can be the therapeutic target, and its deficiency is linked with clinical biomarkers (Li et al. 2021)S. For instance, the most excellent and well-characterized link allying specific DNA repair alteration and response to a DNAdamaging alkylating agent is the correlation between $\mathrm{O}^{6}$ methylguanine MGMT promoter methylation and response to temozolomide in glioblastoma multiforme (GBM) (Hegi et al. 2005). Recent studies using next-generation sequencing next-generation sequencing (NGS)-based methods to expand the association between specific DNA repair-deficient states and specific DNA-damaging agents (Nesic et al. 2018). For example, DNA adducts are created because of DNAdamaging agents (such as UV light and platinum chemotherapies) repairs by NER pathways that involve ERCC2 (DNA helicase). Research by Allen et al. and other groups showed that somatic ERCC2 missense mutations correspond to muscle-invasive bladder cancers (MIBC), and alteration (loss of function) in ERCC2 in tumors reveal improved sensitivity to cisplatin-based chemotherapy (Van Allen et al. 2014; Liu et al. 2016).

Moreover, defects in the DDR pathway have been studies concerning tumor immunogenicity as delayed repair can alter the tumor genome, which causes an imbalance in the immune system in the TME (Mouw et al. 2017). Wang et al. data allude that comutations (defined as co-mut+) in DDR pathways of homologous recombination repair and mismatch repair (HRR-MMR) or HRR and BER (HRR-BER) correlates with biomarkers (such as enhanced tumor mutational burden (TMB) and neo-antigen load (NAL) and greater levels of immune gene expression signatures) which all together predict the efficacy of ICB. Other biomarkers such as PD-L1 expression, high microsatellite instability also predict the response of ICB in patients with cancer (Wang et al. 2018; Zhang et al. 2020; Jiang et al. 2021). Also recently, new anti-cancer drugs have been produced that blocks the regulatory pathways governing the DDR response are (a) PARP inhibitors (e.g., Niraparib, Olaparib, Talazoparib, Rucaparib, Veliparib); (b) CHK1 Inhibitors (e.g., GDC-0575, MK-8776, Prexasertib, SRA-737); (c) ATR inhibitors (e.g ., Ceralasertib, BAY1895344, Berzosertib, M4344); (d) ATM inhibitors (e.g., AZD0156, M3541); (e) DNA-PK inhibitors (e.g., AZD7648, CC-115, Nedisertib, M9831); (f) WEE1 inhibitor (e.g., Adavosertib) (Cleary et al. 2020). 
Melanoma patients with BRCA2 mutation respond well to ICB (Lemery et al. 2017). Thus, DNA repair deficiency has been explored as biomarkers and also as therapeutic targets for understanding oncology. Further, in the future, NGS-based studies will continue to uncover links between DNA damage, biomarkers, DNA repair pathway function, and response to chemotherapeutics therapy. Table 3 describes DNA repair pathways and biomarkers in cancer.

\section{Anti-viral therapy used in combating cancer}

Human viruses have been extensively studied over the past 60 years and are responsible for $10-15 \%$ of the total world human cancer burden. According to International Agency for Research on Cancer (IARC), in 2002 (Parkin 2006) estimated total of infection-attributable cancer is 1.9 million $(17.8 \%$ of the global cancer burden), and in 2018 approximate 2.2 million infection-attributable cancer cases were diagnosed worldwide (13\% of global cancer incidence). Currently, eight viruses are known to cause chronic infection and also have been associated with cancer in humans, including DNA viruses: Hepatitis B virus (HBV), human papillomavirus (HPV), Epstein-Barr virus (EBV), Kaposi's sarcoma-associated herpesvirus (KSHV) and Merkel cell polyomavirus (MCV) and the simian virus 40 (SV40) and RNA viruses: hepatitis C virus (HCV), human T cell lymphotropic virus type 1 (HTLV-1), (Shah 2007; de Martel et al. 2020; Rositch 2020). Data and results from different laboratories across globes have shown that viral load (a marker of virus replication activity in the human body) and cancer risk are often akin for virusassociated cancers, for example, HBV and HCV for hepatocellular carcinoma (HCC), EBV for nasopharyngeal carcinoma (NPC), HPV for cervical cancer, MCC for Merkel cell carcinoma and SV40 for brain cancer and mesothelioma, and non-Hodgkin's lymphoma (Vilchez and Butel 2004; Shih et al. 2014; Carbone et al. 2020). Each virus has a unique mechanism for promoting carcinogenesis and develops a tumor (Moore and Chang 2010). The viral factor of HPV, EBV, KSHV, SV40, HCV, and HTLV encodes oncoproteins that induce genomic instability by inactivating the $\mathrm{p} 53$ and retinoblastoma proteins (pRB), the two important regulators play a central role in the initiation of human cancers via both somatic and germline mutations (Levine 2009). Moreover, it also accumulates mutations, dysregulated cell cycle, DNA damage, and viral DNA integration into the human genome (Weitzman et al. 2010). Currently, anti-viral therapy, including therapeutic drugs and vaccines, immunotherapy, RNA -interferencebased therapies, which have been applied on these seven viruses-associated cancers, have yielded promising results in cancer prevention and treatment (Table 4). Studies also support that viral infection also generates free radicals such as ROS and RNS, which induces oxidative and nitrative DNA damage that often occurs during inflammation can contribute to carcinogenesis (Georgakilas et al. 2010; Chen et al. 2014). Increased concentration of ROS can directly influence NF- $\kappa \mathrm{B}$ activation. Hagen and colleagues demonstrated a connection between Oxidative stress, DNA damage with HCC (Hagen et al. 1994). Interestingly, Cerimele and co-workers showed increased ROS levels and altered NF- $\mathrm{KB}$ activation in EBVpositive Burkitt's lymphoma cells compared to EBV-negative Burkitt's lymphoma cells (Cerimele et al. 2005).

Some viruses are known as oncolytic viruses that include both naturally occurring viruses and laboratory modified viruses. These viruses have been used directly to target and kill cancer cells. In addition, some of these viruses infect tumor cells and cause oncolysis producing and releasing new virus progeny to kill nearby tumor cells. It also releases tumor antigen (danger signals) like DAMPS and PAMPS, which will stimulate an immune response in the body against cancer by (a) activating and encouraging maturation of dendritic cells (DCs) in nearby TME by upregulating co-stimulatory markers, such as CD80, CD83, and CD86; (b) tumor antigens or debris processed by professional antigen processing cells (such as mature DC, macrophages, and B cells) which subsequent $\mathrm{T}$ cell priming; (c) activated B cells produces neutralizing antibodies, that tag with infected tumor cells for ADCC and phagocytosis by NK cells and M1 macrophage respectively; (d) direct killing of infected and non-infected tumor cells by $\mathrm{CD}^{+} \mathrm{T}$ cells and $\mathrm{NK}$ cells via releasing INFg/GranzB and GranzB/Perforins in TME. In 2015, an oncolytic virus Talimogene laherparepvec (T-VEC; Imlygic $\left.{ }^{\circledR}\right)$, a genetically engineered second-generation oncolytic herpes simplex virus type 1 (HSV-1), had been approved by FDA for treating the patient with melanoma (Fukuhara et al. 2016; U.S. Food and Drug Administration 2017). This works by infecting cancer cells to produce the immune-stimulating GM-CSF protein but does not infect healthy cells. Although many viruses are being evaluated as potential cancer treatments in clinical trials, only one has been approved to date (Hemminki et al. 2020). It appears anti-viral therapy, including oncolytic viruses, will be part of future multimodality approaches and data, yielding promising results in cancer prevention and treatment.

\section{Anti-inflammatory nonsteroidal anti-inflammatory drugs as chemical cancer prevention}

Inflammation is one among the hallmark of cancer (Hanahan and Weinberg 2011). Therefore, in recent years, extensive research has focused on using nonsteroidal antiinflammatory drugs (NSAIDs) to target inflammation in cancer prevention and treatment (Wong 2019; Iovoli et al. 2020). Few examples of NSAIDs include ibuprofen, mefenamic acid, celecoxib, aspirin, valdecoxib, and diclofenac, have been used as cancer therapy. These drugs have the potential to block cyclooxygenase $(\mathrm{COX})$ or prostaglandin endoperoxide $\mathrm{H}$ 


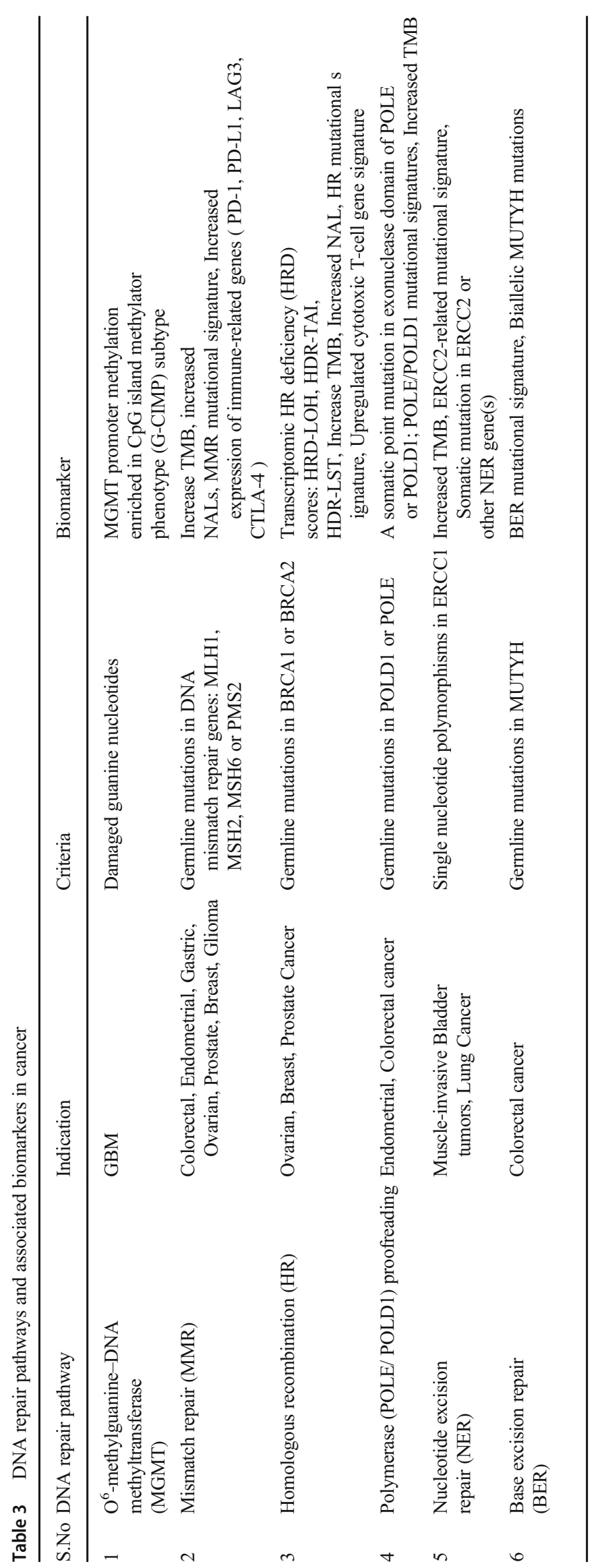




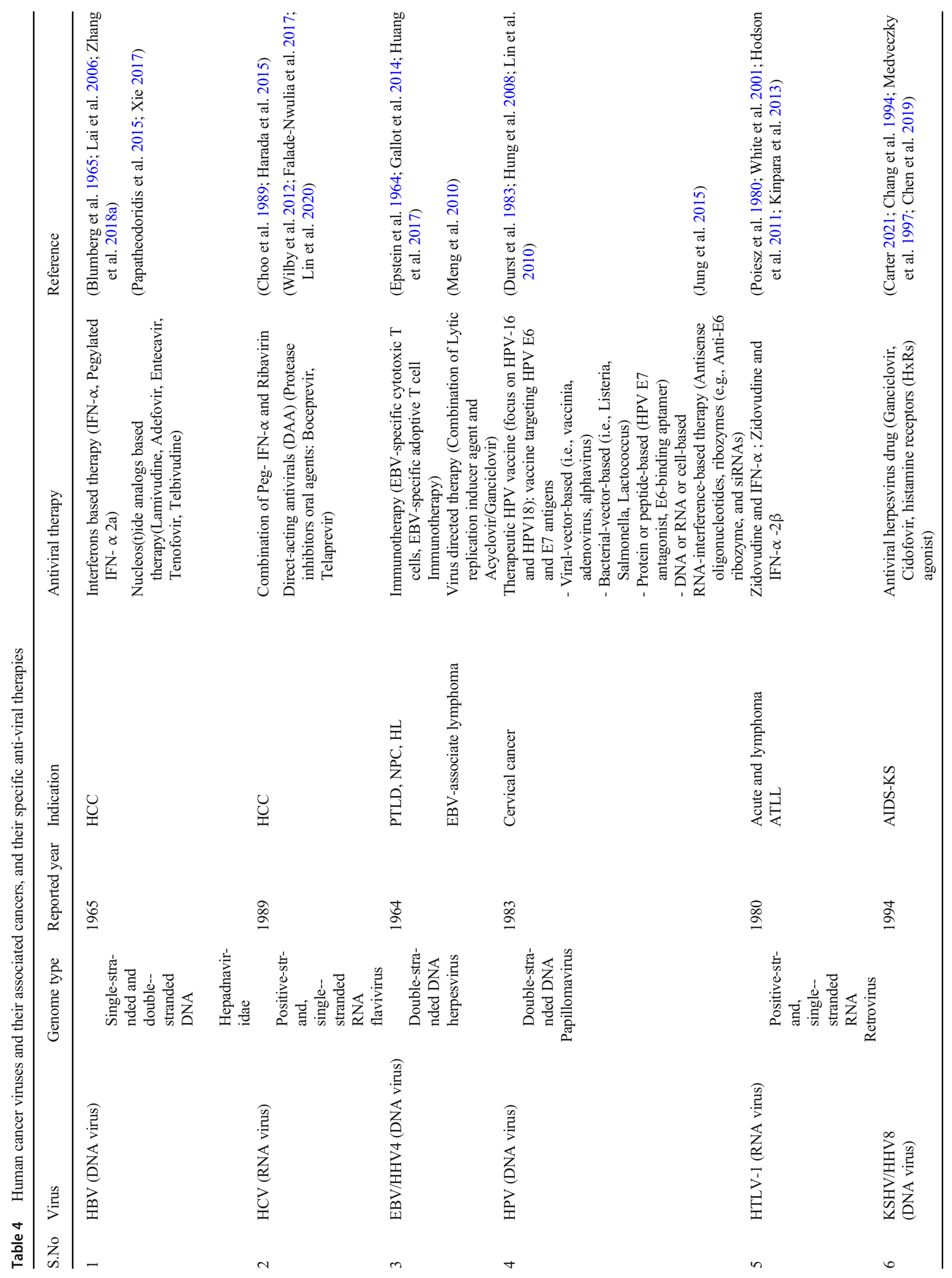




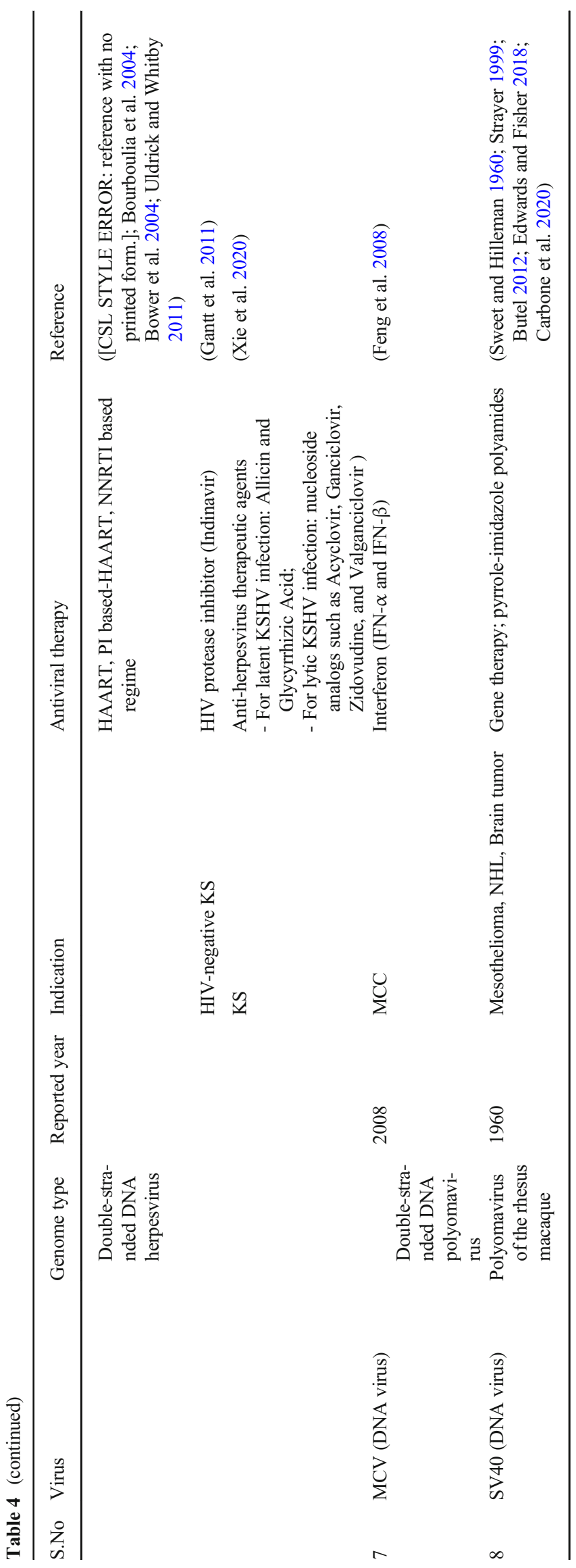




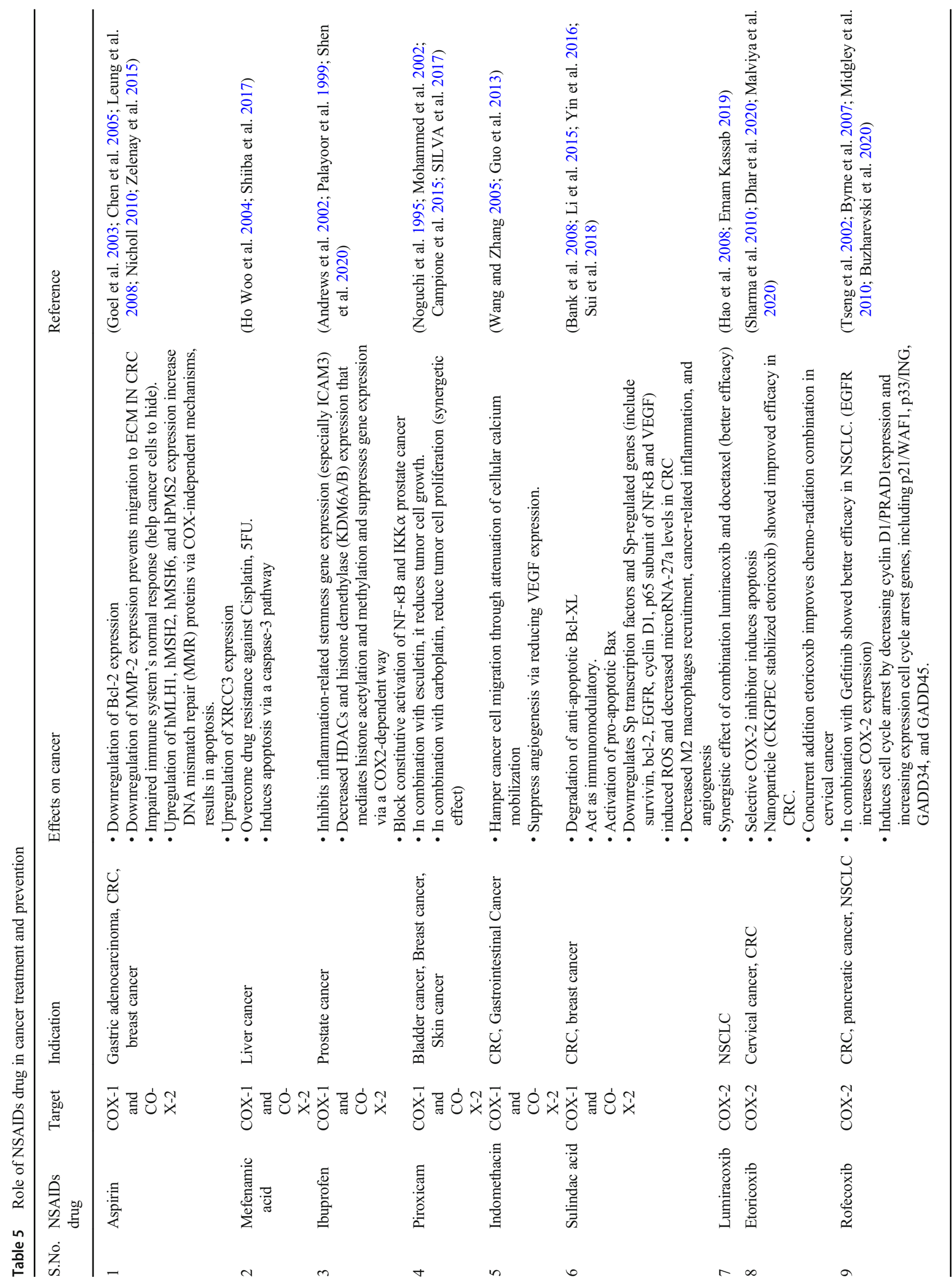


synthase (PGHS) enzymes and hence have the ability to inhibit tumorigenesis (Zappavigna et al. 2020). In 1971, Vane was the first to establish a relationship between the mechanism of inhibition of COX activity by aspirin and NSAIDs (Vane 1971). Research data suggest that NSAIDs may prove effective chemoprophylaxis agents in patients with hereditary colorectal cancer syndromes and sporadic colorectal Cancer (Sangha et al. 2005). In colorectal cancer, the COX-2/PGE2 signaling pathway has been played a vital role (Roberts et al. 2011).

Similarly, Lichtenberger and his team in colorectal cancer showed that modified NSAIDs Aspirin and Indomethacin with phosphatidylcholine showed higher efficacy when used in combination. The use of phosphatidylcholine modifies these drugs gastrointestinal (GI) -safer NSAIDs (Lichtenberger et al. 2018). In 2020, Cairat and co-workers reported the use of aspirin or any other selective COX-2 inhibitors along with proton pump inhibitor (PPI) in reducing breast cancer risk in postmenopausal women (Cairat et al. 2020). Few inflammation targets have been studied in combating inflammation linked with cancer are COX, NF-kB, cytokines/chemokines and their receptors, FGF and its receptor, and VEGF. These targets are seen overexpressed in many cancers, including breast, colorectal, lung, prostate, head and neck, cervical cancer. The study by Leahy and et al. mentioned overexpressed COX-2, an isoform of COX linked with angiogenesis, and the use of the drug celecoxib to block COX2 reduces angiogenesis, hence proliferation and invasion (Leahy et al. 2002). NSAIDs drugs and their effects have been summarized in Table 5. Kostadinov et al. suggest that aspirin slows down somatic evaluation by lowering DNA mutation accumulation, thus preventing esophageal adenocarcinoma (Kostadinov et al. 2013). Liu et al. summarized results from meta-analysis, where they have found no significant link between the use of aspirin and other NSAIDs with brain cancer (Liu et al. 2014). In contrast, new breakthrough studies result found that liquid aspirin can cross the blood-brain barrier (BBB) and destroy brain cancer cells with tenfold higher efficacy compared with other chemotherapy drugs (unable to cross BBB).

Also, some NSAIDs enhance chemotherapeutics' sensitivity to tumors. For example, indomethacin (NSAIDs drug) produces a synergetic efficacy effect in combination with Adriamycin and cisplatin in glioblastoma and colorectal cancer (Hattori et al. 2001). Recently, a combination of aspirin and clopidogrel (antiplatelet drugs) enhanced immunotherapy (adoptive $\mathrm{T}$ cell therapy) for melanoma treatment (Rachidi et al. 2017). Moreover, existing literature recommends that NSAIDs prevents cancer from escaping immune surveillance. Data supported this that aspirin being a COX inhibitor inhibits the synthesis of PGE2 (increase amount of PGE2 aids cancer cells to hid by attenuating the immune system), which results in rejuvenation (re-activation) immune system (Wong 2019). 
Hence, the application of NSAIDs has been a boom in the prevention and treatment of cancer. Recent studies also showed that early use of NSAIDs obstruct and inhibit the SARS CoV-2 produced inflammation produced by SARS CoV-2, resulting in the prevention of COVID-19 complications. In contrast, early use of glucocorticoids (steroids) might encourage the development of COVID-19 complications (Kelleni 2021).

\section{Conclusion and future perspectives}

A plethora of environmental mutagens, including physical, chemical, radiations, infectious agents, and endogenous agents such as hypoxia, free radicals, etc., are capable of inducing DNA lesions in the genome, which results in DNA damage followed by mutation and consequentially lead to carcinogenesis. Even though cells have evolved repair systems and cell cycle checkpoints to combat the detrimental outcomes of chemical modifications, chromosomal breakage, and genome instability to restore to a normal state. However, genetic and epigenetic changes affect many physiological processes because of dysfunctional DNA repair mechanisms and checkpoints' failure (including cell cycle checkpoints and immune checkpoints).

At present, only mutator genes have been recognized on the basis of the role they have in human diseases that are inherited. As numeral genes are involved in the replication, recombination, and repair process, and thus in the future, it is likely that many more such genes will be discovered, and that can further provide some future directives in the pathogenesis of specific cancers. Also, many new treatment modalities at present aim at sequencing the DNA which can serve to act as an influential tool. Moreover, a promising new time of malignancy therapeutics with specialists that repress explicit development stimulatory pathways is tracking down another specialty in our armamentarium in the conflict against disease. Designated malignancy therapeutics, like cytotoxic chemotherapies, refined monoclonal antibodies (mAbs), and tyrosine kinase inhibitors (TKIs), are among the significant therapy choices for the disease today as well as future. Designated treatments are more specific for malignancy cells and work on the personal satisfaction of disease patients going through treatment. A considerable lot of these medications have been supported by the FDA, and a few more are being concentrated in clinical preliminaries. In spite of the fact that the advancement of designated therapeutics has further developed malignant growth therapy altogether, the brutal truth is that the "Battle on Cancer" actually exists. Significant difficulties actually exist with the presently advertised inhibitors, incorporating constraints related to mAbs and TKIs drug types, gained instruments of medication obstruction that cause patient to backslide, and cancer heterogeneity. Today, there is a dire requirement for the advancement of the novel enemies of growth specialists that are less expensive, stable, can specifically target disease subordinate pathways without influencing ordinary cells, and in particular, stay away from the improvement of opposition instruments. Peptide impersonates have the likely advantages of being exceptionally specific, steady, modest, and non-harmful. The focal point of this audit is to talk about the drawbacks related to the utilization of monoclonal antibodies and tyrosine kinase inhibitors. An exceptional accentuation will be set on endeavors taken in our research facility to (1) plan peptide antibodies and therapeutics that target subordinate disease pathways and (2) utilize a blended approach that will close down elective instruments that lead to obstruction.

Herein, we have summarized the various sources and types of DNA damage caused by different mutagenic agents that are carcinogenic in nature and how they lead to DNA replication errors, DNA adduct formations, oxidative stress, inflammation, as well as the failure of immune surveillance. All these eventually contribute and result in a different type of cancer. Moreover, we have also explained the genetic and epigenetic effects caused due to damaged DNA and its association with immunotherapy. Using these damaged DNA biomarkers as a tool for diagnosis and prognosis would greatly facilitate and enhance our capacity to identify the most crucial risk factors causing cancer. Indeed, to facilitate the development of new and contemporary preventive and therapeutic approaches, future more in-depth research is still necessary continue in order to enhance our understanding and compact cancer. Advance studies are needed to fully elucidate which lesions or cell types are more responsive to cancer prevention or treatment with anti-inflammatory agents, anti-viral therapies, and other chemotherapies. Also, additional focus is required to expand the horizon of Therapeutics Avenue including immune therapies, viral-related therapies, NSAIDs drugs, and other chemotherapeutics drugs and inhibitors.

\footnotetext{
Abbreviations AST, advanced solid tumor; ATR, ATR serine/threonine kinase; CRPC, castrate-resistant prostate cancer; CTLA-4, cytotoxic Tlymphocyte-associated protein 4; DDR, DNA damage repair; ICI, immunocheckpoint inhibitor; NSCLC, non-small cell lung cancer; OC, ovarian cancer; PARP, poly [ADP-ribose] polymerase 1; PD-1, programmed cell death-1; TNBC, triple-negative breast cancer; HBV, hepatitis B virus; $\mathrm{HCV}$, hepatitis C virus; EBV, Epstein-Barr virus; HPV, human papillomavirus; HTLV-1, human T cell lymphotropic virus type 1; KSHV, Kaposi's associated sarcoma virus; MCV, Merkel cell polyomavirus; HHV4, human herpesvirus 4; HHV8, human herpesvirus 8; SV 40, simian virus 40; HCC, hepatocellular carcinoma; AIDS-KS, AIDS-Kaposi's sarcoma; ATL, adult T cell lymphoma; PTLD, posttransplant lymphoproliferative disorder; NPC, nasopharyngeal carcinoma; HL, Hodgkin's lymphoma; MCC, Merkel cell carcinoma; NHL, non-Hodgkin lymphoma; GBM, glioblastoma multiforme; CRC, colorectal cancer; HAART, highly active antiretroviral therapy; PI-based HAART, protease inhibitor (PI)-based HAART; NNRTI, non-nucleoside
} 
reverse transcriptase inhibitor; PGs, prostaglandins; CKGPEC, chitosanKheri gum polyelectrolyte complex; ATM, ataxia telangiectasia mutated; ATR, Ataxia telangiectasia and RAD3-related; HMGB1, high mobility group box 1; MITC, 5-(3-methyltriazen-1-yl)-imidazole-4-carboxamide

Acknowledgements We would like to thank the senior management of Delhi Technological University for their constant support and infrastructure.

Author contribution All authors have read the paper and agreed to submit. RKA conceived the idea. SK, SS, DA, and AK arranged the data. Art work is done by SK, SS, DA, and AK. RKA and PK given their critical comments and structured this paper. Paper is written by SK, SS, DA, AK, and RKA.

Data availability Not applicable.

\section{Declarations}

Ethics approval Not applicable.

Consent to participate All authors read and agreed.

Consent for publication All authors have given their consent to publish without any reservation.

Conflict of interest The authors declare no competing interests.

\section{References}

Aarnio M, Sankila R, Pukkala E et al (1999) Cancer risk in mutation carriers of DNA-mismatch-repair genes. Int J Cancer 81:214-218. https://doi.org/10.1002/(sici)1097-0215(19990412)81:2<214::aidijc8>3.0.co;2-1

Abbotts R, Jewell R, Nsengimana J et al (2014) Targeting human apurinic/apyrimidinic endonuclease 1 (APE1) in phosphatase and tensin homolog (PTEN) deficient melanoma cells for personalized therapy. Oncotarget 5:3273-3286. https://doi.org/10.18632/ oncotarget.1926

Abeni C, Rota L, Ogliosi C et al (2013) Correlation among Streptococcus bovis, endocarditis and septicemia in a patient with advanced colon cancer: a case report. J Med Case Rep 7:185. https://doi.org/10. 1186/1752-1947-7-185

Adeola H, Bano A, Vats R, et al (2021) Bioactive compounds and their libraries: an insight into prospective phytotherapeutics approach for oral mucocutaneous cancers. Elsevier

Aggarwal BB, Shishodia S, Sandur SK et al (2006) Inflammation and cancer: how hot is the link? Biochem Pharmacol. https://doi.org/10. 1016/j.bcp.2006.06.029

Agnes A, Biondi A, Belia F et al (2021) Association between colorectal cancer and streptococcus gallolyticus subsp. pasteuranus (former s. bovis) endocarditis: clinical relevance and cues for microbiota science. case report and review of the literature. Eur Rev Med Pharmacol Sci 25:480-486. https://doi.org/10.26355/eurrev 20210124417

Ahmed SA, Rand RH, Fatimah Abu B (2011) The association of Streptococcus bovis/gallolyticus with colorectal tumors: the nature and the underlying mechanisms of its etiological role. J Exp Clin Cancer Res 30:1-13

Ajay Goel, Dong Kyung Chang, Luigi Ricciardiello, Christoph Gasche and $\mathrm{C}$.
Richard Boland (2003) A novel mechanism for aspirin-mediated growth inhibition of human colon cancer cells (2021) Clin Cancer Res (9) (1) 383390. https://clincancerres.aacrjournals.org/content/ 9/1/383.long. Accessed 28 Mar 2021c

Alard E, Butnariu A-B, Grillo M et al (2020) Advances in anti-cancer immunotherapy: car-T cell, checkpoint inhibitors, dendritic cell vaccines, and oncolytic viruses, and emerging cellular and molecular targets. Cancers (Basel) 12:1-38. https://doi.org/10.3390/ CANCERS12071826

Albi E, Cataldi S, Lazzarini A et al (2017) Radiation and thyroid cancer. Int J Mol Sci 18:911. https://doi.org/10.3390/ijms18050911

Alhmoud JF, Woolley JF, Al Moustafa AE, Malki MI (2020) DNA damage/repair management in cancers. Cancers (Basel) 12

Al-Nimer MSM, Hameed HG, Mahmood MM (2015) Antiproliferative effects of aspirin and diclofenac against the growth of cancer and fibroblast cells: in vitro comparative study. Saudi Pharm J 23:483486. https://doi.org/10.1016/j.jsps.2015.01.002

Alsaud A, Mohamed S, Yassin MA et al (2020) Acute myeloid leukemia after low-dose radioiodine therapy for papillary thyroid carcinoma. Case Rep Oncol 13:207. https://doi.org/10.1159/000505686

Andrews J, Djakiew D, Krygier S et al (2002) Superior effectiveness of ibuprofen compared with other NSAIDs for reducing the survival of human prostate cancer cells. Cancer Chemother Pharmacol. https:// doi.org/10.1007/s00280-002-0485-8

Androutsos G (2006) The outstanding British surgeon Percivall Pott (1714-1789) and the first description of an occupational cancer. J Buon 11:533-539

Anna B, Blazej Z, Jacqueline G et al (2007) Mechanism of UV-related carcinogenesis and its contribution to nevi/melanoma. Expert Rev Dermatol 2:451-469

Anwar SL, Wulaningsih W, Lehmann U (2017) Transposable elements in human cancer: causes and consequences of deregulation. Int J Mol Sci 18:974. https://doi.org/10.3390/ijms18050974

Aoshiba K, Tsuji T, Yamaguchi K et al (2013) The danger signal plus DNA damage two-hit hypothesis for chronic inflammation in COPD. Eur Respir J 42:1689-1695

Apetoh L, Ghiringhelli F, Tesniere A et al (2007) Toll-like receptor 4dependent contribution of the immune system to anticancer chemotherapy and radiotherapy. Nat Med. https://doi.org/10.1038/nm1622

Arlt V, Stiborova M, Henderson C, et al (2005) Environmental pollutant and potent mutagen 3-nitrobenzanthrone forms DNA adducts after reduction by $\mathrm{NAD}(\mathrm{P}) \mathrm{H}$ : quinone oxidoreductase and conjugation by. AACR

Arun B, Zhang H, Mirza NQ et al (2001) Growth inhibition of breast cancer cells by celecoxib. Breast Cancer Res Treat 69:234

Asara Y, Marchal JA, Bandiera P et al (2012) Cadmium influences the 5Fluorouracil cytotoxic effects on breast cancer cells. Eur J Histochem 56:e1-e1. https://doi.org/10.4081/ejh.2012.e1

Baan R, Grosse Y, Straif K et al (2009) A review of human carcinogensPart F: chemical agents and related occupations. Lancet Oncol 10: 1143-1144. https://doi.org/10.1016/s1470-2045(09)70358-4

Bank A, Yu J, Zhang L (2008) NSAIDs downregulate Bcl-XL and dissociate BAX and Bcl-X L to induce apoptosis in colon cancer cells. In: Nutrition and Cancer. Nutr Cancer, pp 98-103

Bao Y (2011) Chromatin response to DNA double-strand break damage. Epigenomics 3:307-321

Barnes JL, Zubair M, John K et al (2018) Carcinogens and DNA damage. Biochem Soc Trans

Barrak NH, Khajah MA, Luqmani YA (2020) Hypoxic environment may enhance migration/penetration of endocrine resistant MCF7- derived breast cancer cells through monolayers of other non-invasive cancer cells in vitro. Sci Rep 10:1-14. https://doi.org/10.1038/ s41598-020-58055-x 
Bartek J, Bartkova J, Lukas J (2007) DNA damage signalling guards against activated oncogenes and tumour progression. Oncogene 26:7773-7779

Begg K, Tavassoli M (2020) Inside the hypoxic tumour: reprogramming of the DDR and radioresistance. Cell Death Discov.

Belhassen H, Jiménez-Díaz I, Arrebola JP et al (2015) Zearalenone and its metabolites in urine and breast cancer risk: a case-control study in Tunisia. Chemosphere 128:1-6. https://doi.org/10.1016/j. chemosphere.2014.12.055

Besaratinia A, Bates SE, Pfeifer GP (2002) Mutational signature of the proximate bladder carcinogen $\mathrm{N}$-hydroxy-4-acetylaminobiphenyl: inconsistency with the p53 mutational spectrum in bladder cancer. Cancer Res 62:4331-4338

Beyersmann D (2002) Effects of carcinogenic metals on gene expression. In: Toxicology Letters

Bhattacharya T, Maishu S, ... RA-CT in, (2021) undefined A review on natural sources derived protein nanoparticles as anticancer agents. https://www.ingentaconnect.com. Accessed 26 Aug 2021

Bindra RS, Schaffer PJ, Meng A et al (2004) Down-regulation of Rad51 and decreased homologous recombination in hypoxic cancer cells. Mol Cell Biol. https://doi.org/10.1128/mcb.24.19.8504-8518.2004

Bindra RS, Gibson SL, Meng A et al (2005) Hypoxia-induced downregulation of BRCA1 expression by E2Fs. Cancer Res. https://doi. org/10.1158/0008-5472.CAN-05-2119

Biswas S, Das R, Banerjee ER (2017) Role of free radicals in human inflammatory diseases. AIMS Biophys.

Blumberg BS, Alter HJ, Visnich S (1965) A "new" antigen in leukemia sera. JAMA J Am Med Assoc 191:541-546. https://doi.org/10. 1001/jama.1965.03080070025007

Bonnet S, Archer SL, Allalunis-Turner J et al (2007) A mitochondria-K+ channel axis is suppressed in cancer and its normalization promotes apoptosis and inhibits cancer growth. Cancer Cell 11:37-51. https:// doi.org/10.1016/j.ccr.2006.10.020

Botelho MC, Teixeira JP, Oliveira PA (2014) Carcinogenesis. Encycl Toxicol 3rd Ed 1:713-729. https://doi.org/10.1016/B978-0-12386454-3.00371-7

Bourboulia D, Aldam D, Lagos D et al (2004) Short- and long-term effects of highly active antiretroviral therapy on Kaposi sarcomaassociated herpesvirus immune responses and viraemia. AIDS 18: 485-493. https://doi.org/10.1097/00002030-200402200-00015

Bower M, McCall-Peat N, Ryan N et al (2004) Protease inhibitors potentiate chemotherapy-induced neutropenia. Blood 104:2943-2946. https://doi.org/10.1182/blood-2004-05-1747

Bristow RG (2008) Hypoxia, DNA repair, and genetic instability. AACR Educ B. https://doi.org/10.1158/aacr.edb-08-8388

Brodell R, Yasmeen T (2013) Local reactions to imiquimod in the treatment of basal cell carcinoma; UC Davis. Dermatol Online J 18(9):196

Brown K (2012) Methods for the detection of DNA adducts. Methods Mol Biol. https://doi.org/10.1007/978-1-61779-421-6 11

Brown JS, Sundar R, Lopez J (2018) Combining DNA damaging therapeutics with immunotherapy: More haste, less speed. Br J Cancer

Brzostek-Racine S, Gordon C, Van Scoy S, Reich NC (2011) The DNA damage response induces IFN. J Immunol. https://doi.org/10.4049/ jimmunol.1100040

Burns CA, McCaughey R, Lauter CB (1985) The association of Streptococcus bovis fecal carriage and colon neoplasia: possible relationship with polyps and their premalignant potential. Am J Gastroenterol 80:42-46

Butel JS (2012) Patterns of polyomavirus SV40 infections and associated cancers in humans: A model. Curr Opin Virol 2:508-514

Buzharevski A, Paskaš S, Sárosi MB et al (2020) Carboranyl derivatives of rofecoxib with cytostatic activity against human melanoma and colon cancer cells. Sci Rep 10:1-13. https://doi.org/10.1038/ s41598-020-59059-3
Buzun K, Bielawska A, Bielawski K, Gornowicz A (2020) DNA topoisomerases as molecular targets for anticancer drugs. J Enzyme Inhib Med Chem 35:1781-1799. https://doi.org/10.1080/ 14756366.2020 .1821676

Byrne KJO, O'byrne KJ, Danson S et al (2007) Combination therapy with gefitinib and rofecoxib in patients with platinum-pretreated relapsed non small-cell lung cancer article. J Clin Oncol. https:// doi.org/10.1200/JCO.2006.09.2791

Cadet J, Douki T (2018) Formation of UV-induced DNA damage contributing to skin cancer development. Photochem Photobiol Sci 17: 1816-1841. https://doi.org/10.1039/C7PP00395A

Cairat M, Al Rahmoun M, Gunter MJ et al (2020) Use of nonsteroidal anti-inflammatory drugs and breast cancer risk in a prospective cohort of postmenopausal women. Breast Cancer Res 22:118. https:// doi.org/10.1186/s13058-020-01343-1

Califf RM (2018) Biomarker definitions and their applications. Exp Biol Med 243:213. https://doi.org/10.1177/1535370217750088

Calvert A, Hughes AN, Calvert PM et al (2000) ALIMTATM in combination with carboplatin demonstrates clinical activity against malignant mesothelioma in a phase I trial. Lung Cancer 29:19-20. https:// doi.org/10.1016/S0169-5002(00)80059-8

Calvino-Fernández M, Benito-Martínez S, Parra-Cid T (2008) Oxidative stress by Helicobacter pylori causes apoptosis through mitochondrial pathway in gastric epithelial cells. Apoptosis. https://doi.org/10. 1007/s10495-008-0255-0

Campione E, Paternò EJ, Candi E et al (2015) The relevance of piroxicam for the prevention and treatment of nonmelanoma skin cancer and its precursors. Drug Des Devel Ther 9:5843-5850

Cannan WJ, Pederson DS (2016) Mechanisms and consequences of double-strand DNA break formation in chromatin. J Cell Physiol 231:3-14

Carbone M, Gazdar A, Butel JS (2020) SV40 and human mesothelioma. Transl Lung Cancer Res 9:S47-S59

Carhill AA, Vassilopoulou-Sellin R (2012) Durable effect of radioactive iodine in a patient with metastatic follicular thyroid carcinoma. Case Rep Endocrinol 2012:1-5. https://doi.org/10.1155/2012/231912

Carter M (2021) DNA damage response as a candidate anti-cancer barrier.

Caspari E, Muth W, Pohley HJ (1965) Effects of DNA base analogues on the scales of the WI[1] E. CASPARI, W. MUTH, and H. J. POHLEY, "EFFECTS OF DNA BASE ANALOGUES ON THE SCALES OF THE WING OF EPHESTIA," Genetics, vol. 51, no. 5, pp. 771-794, May 1965, [Online]. Available: https://pubmed.ncb. Genetics 51:771-794. Accessed 03 Apr 2021

Cerimele F, Battle T, Lynch R et al (2005) Reactive oxygen signaling and MAPK activation distinguish Epstein-Barr Virus (EBV)-positive versus EBV-negative Burkitt's lymphoma. Proc Natl Acad Sci U S A 102:175-179. https://doi.org/10.1073/pnas.0408381102

Chakravarthi BVSK, Nepal S, Varambally S (2016) Genomic and epigenomic alterations in cancer. Am J Pathol 186:1724-1735

Chan N, Koch C, Bristow R (2009) Tumor hypoxia as a Modifier of DNA strand break and cross-link repair. Curr Mol Med. https://doi.org/10. 2174/156652409788167050

Chang AH, Parsonnet J (2010) Role of bacteria in oncogenesis. Clin Microbiol Rev 23:837-857. https://doi.org/10.1128/CMR.0001210

Chang Y, Cesarman E, Pessin MS et al (1994) Identification of herpesvirus-like DNA sequences in AIDS-associated Kaposi's sarcoma. Science (80-) 266:1865-1869. https://doi.org/10.1126/ science.7997879

Chang HHY, Pannunzio NR, Adachi N, Lieber MR (2017) Nonhomologous DNA end joining and alternative pathways to doublestrand break repair. Nat Rev Mol Cell Biol 18:495-506

Chatterjee N, Walker GC (2017) Mechanisms of DNA damage, repair, and mutagenesis. Environ Mol Mutagen 58:235-263 
Chen CBE-C (2013) Aspects of DNA damage from internal radionuclides. IntechOpen, Rijeka, p Ch. 22

Chen XL, Su BS, Sun RQ et al (2005) Relationship between expression and distribution of cyclooxygenase-2 and bcl-2 in human gastric adenocarcinoma. World J Gastroenterol 11:1228-1231. https://doi. org/10.3748/wjg.v11.i8.1228

Chen CH, Dickman KG, Moriya M et al (2012) Aristolochic acidassociated urothelial cancer in Taiwan. Proc Natl Acad Sci U S A. https://doi.org/10.1073/pnas.1119920109

Chen Y, Williams V, Filippova M et al (2014) Viral carcinogenesis: factors inducing DNA damage and virus integration. Cancers (Basel) 6:2155-2186

Chen C, Xun P, Nishijo M et al (2015) Cadmium exposure and risk of pancreatic cancer: a meta-analysis of prospective cohort studies and case-control studies among individuals without occupational exposure history. Environ Sci Pollut Res Int 22:17465-17474. https:// doi.org/10.1007/s11356-015-5464-9

Chen J, Dai L, Goldstein A et al (2019) Identification of new antiviral agents against Kaposi's sarcoma-associated herpesvirus (KSHV) by high-throughput drug screening reveals the role of histamine-related signaling in promoting viral lytic reactivation. PLoS Pathog 15: e1008156. https://doi.org/10.1371/journal.ppat.1008156

Cheng KC, Cahill DS, Kasai H et al (1992) 8-Hydroxyguanine, an abundant form of oxidative DNA damage, causes $\mathrm{G} \rightarrow \mathrm{T}$ and $\mathrm{A} \rightarrow \mathrm{C}$ substitutions. J Biol Chem. https://doi.org/10.1016/s0021-9258(18) 48474-8

Chenmala K, Hari B, Rahman H et al (2021) Multiple strategies with the synergistic approach for addressing colorectal cancer. Biomed Pharmacother 140:111704. https://doi.org/10.1016/J.BIOPHA. 2021.111704

Cheung-Ong K, Giaever G, Nislow C (2013) DNA-damaging agents in cancer chemotherapy: serendipity and chemical biology. Chem Biol 20:648-659

Cho M, Gwak J, Park S et al (2005) Diclofenac attenuates Wnt/ $\beta$-catenin signaling in colon cancer cells by activation of NF-KB. FEBS Lett 579:4213-4218. https://doi.org/10.1016/j.febslet.2005.06.049

Choi BI, Han JK, Hong ST, Lee KH (2004) Clonorchiasis and cholangiocarcinoma: etiologic relationship and imaging diagnosis. Clin Microbiol Rev 17:540-552. https://doi.org/10.1128/CMR.17.3. 540-552.2004

Choi S, Yu Y, Grimmer MR et al (2018) Temozolomide-associated hypermutation in gliomas. Neuro-Oncology 20:1300-1309. https:// doi.org/10.1093/neuonc/noy016

Choo QL, Kuo G, Weiner AJ et al (1989) Isolation of a cDNA clone derived from a blood-borne non-A, non-B viral hepatitis genome. Science (80-) 244:359-362. https://doi.org/10.1126/science. 2523562

Chow TY-K, Alaoui-Jamali MA, Yeh C et al (2004) The DNA doublestranded break repair protein endo-exonuclease as a therapeutic target for cancer. Mol Cancer Ther 3:911-919

Ciccia A, Ling C, Coulthard R, Yan Z (2010) cell SE-M undefined The DNA damage response: making it safe to play with knives. Elsevier

Claeys L, Romano C, De Ruyck K et al (2020) Mycotoxin exposure and human cancer risk: a systematic review of epidemiological studies. Compr Rev Food Sci Food Saf 19:1449-1464. https://doi.org/10. 1111/1541-4337.12567

Cleary JM, Aguirre AJ, Shapiro GI, D'Andrea AD (2020) Biomarkerguided development of DNA repair inhibitors. Mol Cell 78:10701085

Clergé A, Le Goff J, Lopez-Piffet C et al (2021) Investigation by mass spectrometry and (32)P post-labelling of DNA adducts formation from 1,2-naphthoquinone, an oxydated metabolite of naphthalene. Chemosphere 263:128079. https://doi.org/10.1016/j.chemosphere. 2020.128079

Coquelle A, Toledo F, Stern S et al (1998) A new role for hypoxia in tumor progression: Induction of fragile site triggering genomic rearrangements and formation of complex DMs and HSRs. Mol Cell. https://doi.org/10.1016/S1097-2765(00)80137-9

Costa M, Klein CB (1999) Nickel carcinogenesis, mutation, epigenetics, or selection. Environ Health Perspect 107:A438-A439. https://doi. org/10.1289/ehp.99107a438

Coussens LM, Werb Z (2002) Inflammation and cancer. Nature 420:860867

Crinnion WJ, Tran JQ (2010) Case report: heavy metal burden presenting as Bartter syndrome. Altern Med Rev 15:303-310

Curtin NJ (2013) Inhibiting the DNA damage response as a therapeutic manoeuvre in cancer. Br J Pharmacol 169:1745-1765. https://doi. org/10.1111/bph.12244

D'Souza C, Peretiatko R (2002) The nexus between industrialization and environment. Environ Manag Health 13:80-97. https://doi.org/10. $1108 / 09566160210417859$

Dalmasso G, Cougnoux A, Delmas J et al (2015) The bacterial genotoxin colibactin promotes colon tumor growth by modifying the tumor microenvironment. Gut Microbes 5:675-680. https://doi.org/10. 4161/19490976.2014.969989

Daniel P, Sabri S, Chaddad A et al (2019) Temozolomide induced hypermutation in glioma: evolutionary mechanisms and therapeutic opportunities. Front Oncol 9:41. https://doi.org/10.3389/fonc.2019. 00041

Das B, Choudhury B, Kumar A, Jyoti Baruah V (2021) Genome instability and DNA repair in cancer. In: DNA Repair [Working Title]. IntechOpen

Dasari S, Tchounwou PB (2014) Cisplatin in cancer therapy: molecular mechanisms of action. Eur J Pharmacol 740:364-378. https://doi. org/10.1016/j.ejphar.2014.07.025

de Martel C, Georges D, Bray F et al (2020) Global burden of cancer attributable to infections in 2018: a worldwide incidence analysis. Lancet Glob Health 8:e180-e190. https://doi.org/10.1016/S2214109X(19)30488-7

De Zio D, Cianfanelli V, Cecconi F (2013) New insights into the link between DNA damage and apoptosis. Antioxid Redox Signal 19: 559. https://doi.org/10.1089/ARS.2012.4938

Demirer E, Ghattas CF, Radwan MO, Elamin EM (2015) Clinical and prognostic features of erionite-induced malignant mesothelioma. Yonsei Med J 56:311-323. https://doi.org/10.3349/ymj.2015.56.2. 311

DePasquale JA (1999) Rearrangement of the F-actin cytoskeleton in estradiol-treated MCF-7 breast carcinoma cells. Histochem Cell Biol 112:341-350. https://doi.org/10.1007/s004180050415

DesMarais TL, Costa M (2019) Mechanisms of chromium-induced toxicity. Curr Opin Toxicol 14:1-7. https://doi.org/10.1016/j.cotox. 2019.05.003

Dhar SS, Shahi UP, Kumar D et al (2020) Addition of etoricoxib during concurrent chemo-radiation of cervical cancer patients could result in faster resolution of gross disease: a prospective single-institution study. Indian J Gynecol Oncol 18:1-6. https://doi.org/10.1007/ s40944-019-0331-0

Di Domenico EG, Cavallo I, Pontone M et al (2017) Biofilm producing Salmonella Typhi: chronic colonization and development of gallbladder cancer. Int J Mol Sci 18:1887. https://doi.org/10.3390/ ijms 18091887

Dianov GL (2011) Base excision repair targets for cancer therapy. Am J Cancer Res 1:845-851

DNA damage response as a candidate anti-cancer barrier, (2021)... Google Scholar PI and NNRTI based regimens equally effective in treating KS, says study | aidsmap. https:/www.aidsmap.com/news/ nov-2002/pi-and-nnrti-based-regimens-equally-effective-treatingks-says-study. Accessed 25 Mar 2021b

Dolan ME, Moschel RC, Pegg AE (1990) Depletion of mammalian O6alkylguanine-DNA alkyltransferase activity by O6-benzylguanine provides a means to evaluate the role of this protein in protection against carcinogenic and therapeutic alkylating agents. Proc Natl 
Acad Sci U S A 87:5368-5372. https://doi.org/10.1073/pnas.87.14. 5368

Domingo JL, Nadal M (2017) Carcinogenicity of consumption of red meat and processed meat: a review of scientific news since the IARC decision. Food Chem Toxicol 105:256-261. https://doi.org/ 10.1016/j.fct.2017.04.028

Dudley RE, Gammal LM, Klaassen CD (1985) Cadmium-induced hepatic and renal injury in chronically exposed rats: likely role of hepatic cadmium-metallothionein in nephrotoxicity. Toxicol Appl Pharmacol 77:414-426. https://doi.org/10.1016/0041-008x(85) 90181-4

Durkacz BW, Omidiji O, Gray DA, Shall S (1980) (ADP-ribose)n participates in DNA excision repair. Nature 283:593-596. https://doi. org $/ 10.1038 / 283593 \mathrm{a} 0$

Durst M, Gissmann L, Ikenberg H, Zur Hausen H (1983) A papillomavirus DNA from a cervical carcinoma and its prevalence in cancer biopsy samples from different geographic regions. Proc Natl Acad Sci U S A 80:3812-3815. https://doi.org/10.1073/pnas.80.12.3812

Dzantiev L, Constantin N, Genschel J, et al (2004) A defined human system that supports bidirectional mismatch-provoked excision. Elsevier

Dziubańska-Kusibab PJ, Berger H, Battistini F et al (2020) Colibactin DNA-damage signature indicates mutational impact in colorectal cancer. Nat Med 26:1063-1069. https://doi.org/10.1038/s41591020-0908-2

Economopoulou M, Langer HF, Celeste A et al (2009) Histone H2AX is integral to hypoxia-driven neovascularization. Nat Med 15:553558. https://doi.org/10.1038/nm.1947

Edwards TG, Fisher C (2018) Antiviral activity of pyrrole-imidazole polyamides against SV40 and BK polyomaviruses. Antivir Res 152:68-75. https://doi.org/10.1016/j.antiviral.2018.02.012

El Ghissassi F, Baan R, Straif K et al (2009) A review of human carcinogens-part D: radiation. Lancet Oncol 10:751-752. https:// doi.org/10.1016/s1470-2045(09)70213-x

Emam Kassab S (2019) Indomethacin from Anti-Inflammatory to Anticancer Agent. In: Medicinal Chemistry. IntechOpen

Engin AB, Engin A (2019) DNA damage checkpoint response to aflatoxin B1. Environ Toxicol Pharmacol 65:90-96. https://doi.org/10. 1016/j.etap.2018.12.006

Englander EW, Greeley GH, Wang G et al (1999) Hypoxia-induced mitochondrial and nuclear DNA damage in the rat brain. J Neurosci Res. https://doi.org/10.1002/(SICI)1097-4547(19991015) 58:2<262::AID-JNR6>3.0.CO;2-W

Epstein MA, Achong BG, Barr YM (1964) Virus particles in cultured lymphoblasts from Burkitt's lymphoma. Lancet 283:702-703. https://doi.org/10.1016/S0140-6736(64)91524-7

Errol Z (2001) Mutagens that are not carcinogens: faulty theory or faulty tests? Mutat Res 492:29-38. https://doi.org/10.1016/S13835718(01)00153-X

Fadriquela A, Sharma S, Thi TT et al (2021) Redox effects of molecular hydrogen and its therapeutic efficacy in the treatment of neurodegenerative diseases. Processes 9:308. mdpi.com. https://doi.org/10. 3390/pr9020308

Faïs T, Delmas J, Serres A et al (2016) Impact of CDT toxin on human diseases. Toxins (Basel) 8:220. https://doi.org/10.3390/ toxins 8070220

Faita F, Cori L, Bianchi F, Andreassi MG (2013) Arsenic-induced genotoxicity and genetic susceptibility to arsenic-related pathologies. Int J Environ Res Public Health 10:1527-1546. https://doi. org/10.3390/ijerph10041527

Falade-Nwulia O, Suarez-Cuervo C, Nelson DR et al (2017) Oral directacting agent therapy for hepatitis $\mathrm{c}$ virus infection: a systematic review. Ann Intern Med 166:637-648

Farmer H, McCabe H, Lord CJ et al (2005) Targeting the DNA repair defect in BRCA mutant cells as a therapeutic strategy. Nature 434: 917-921. https://doi.org/10.1038/nature03445
Fayyad N, Kobaisi F, Fayyad-Kazan M, et al (2021) Link between base excision repair (BER), reactive oxygen species (ROS), and cancer

Feng Z, Hu W, Rom WN et al (2003) Chromium(VI) exposure enhances polycyclic aromatic hydrocarbon-DNA binding at the p53 gene in human lung cells. Carcinogenesis 24:771-778. https://doi.org/10. 1093/carcin/bgg012

Feng H, Shuda M, Chang Y, Moore PS (2008) Clonal integration of a polyomavirus in human Merkel cell carcinoma. Science (80-) 319: 1096-1100. https://doi.org/10.1126/science.1152586

Ferrante M, Sciacca S, Oliveri G (2012) Carcinogen role of food by mycotoxins and knowledge gap. Carcinogen. https://doi.org/10. $5772 / 46123$

Ferrer M, de Winter JP, Jeroen Mastenbroek DC et al (2004) Chemosensitizing tumor cells by targeting the Fanconi anemia pathway with an adenovirus overexpressing dominant-negative FANCA. Cancer Gene Ther 11:539-546. https://doi.org/10.1038/ sj.cgt. 7700734

Flora SJS, Mittal M, Mehta A (2008) Heavy metal induced oxidative stress \& its possible reversal by chelation therapy. Indian J Med Res 128:501-523

Forkert P-G (2010) Mechanisms of lung tumorigenesis by ethyl carbamate and vinyl carbamate. Drug Metab Rev 42:355-378. https://doi. org/10.3109/03602531003611915

Fujiwara Y, Masutani C, Mizukoshi T, et al (1999) Characterization of DNA recognition by the human UV-damaged DNA-binding protein. Elsevier

Fukuda T, Sumiyoshi T, Takahashi M, et al (2001) Alterations of the double-strand break repair gene MRE11 in cancer. Cancer Res

Fukuhara H, Ino Y, Todo T (2016) Oncolytic virus therapy: a new era of cancer treatment at dawn. Cancer Sci 107:1373-1379

Fukushima S, Endo M, Matsumoto Y et al (2017) Hypoxia-inducible factor 1 alpha is a poor prognostic factor and potential therapeutic target in malignant peripheral nerve sheath tumor. PLoS One. https://doi.org/10.1371/journal.pone.0178064

Gallot G, Vollant S, Saïagh S et al (2014) T-cell therapy using a bank of EBV-specific Cytotoxic T cells: lessons from a phase I/II feasibility and safety study. J Immunother 37:170-179. https://doi.org/10. 1097/CJI.0000000000000031

Gantt S, Carlsson J, Ikoma M et al (2011) The HIV protease inhibitor nelfinavir inhibits Kaposi's sarcoma-associated herpesvirus replication in vitro. Antimicrob Agents Chemother 55:2696-2703. https:// doi.org/10.1128/AAC.01295-10

Garner RC (1998) The role of DNA adducts in chemical carcinogenesis. In: Mutation Research - Fundamental and Molecular Mechanisms of Mutagenesis

Gavande NS, Vandervere-Carozza PS, Hinshaw HD et al (2016) DNA repair targeted therapy: the past or future of cancer treatment? Pharmacol Ther 160:65-83. https://doi.org/10.1016/j.pharmthera. 2016.02.003

Gavina JMA, Yao C, Feng YL (2014) Recent developments in DNA adduct analysis by mass spectrometry: a tool for exposure biomonitoring and identification of hazard for environmental pollutants. Talanta

Georgakilas AG, Mosley WG, Georgakila S et al (2010) Viral-induced human carcinogenesis: An oxidative stress perspective. Mol BioSyst 6:1162-1172

Gilabert M, Prebet T (2012) Acute leukemia arising after radioiodine treatment for thyroid cancer. Haematologica 97:e28-e30. https:// doi.org/10.3324/haematol.2012.067454

Gillet LCJ, Schärer OD (2006) Molecular mechanisms of mammalian global genome nucleotide excision repair. Chem Rev 106:253-276

Goel A, Chang DK, Ricciardiello L, Gasche C, Boland CR (2003) A novel mechanism for aspirin-mediated growth inhibition of human colon cancer cells (2021) Clin Cancer Res 9(1):383-390. https:// www.clincancerres.aacrjournals.org/content/9/1/383.long. Accessed 28 Mar 2021c 
Golan T, Hammel P, Reni M et al (2019) Maintenance olaparib for germline BRCA-mutated metastatic pancreatic cancer. N Engl J Med. https://doi.org/10.1056/NEJMoa1903387

Gopal R, Narmada S, Vijayakumar R, Jaleel CA (2009) Chelating efficacy of $\mathrm{CaNa}(2)$ EDTA on nickel-induced toxicity in Cirrhinus mrigala (Ham.) through its effects on glutathione peroxidase, reduced glutathione and lipid peroxidation. C R Biol 332:685-696. https://doi.org/10.1016/j.crvi.2009.03.004

Grabosch S, Bulatovic M, Zeng F et al (2019) Cisplatin-induced immune modulation in ovarian cancer mouse models with distinct inflammation profiles. Oncogene. https://doi.org/10.1038/s41388-018-0581-

Graf F, Fahrer J, Maus S et al (2014) DNA double strand breaks as predictor of efficacy of the alpha-particle emitter Ac-225 and the electron emitter Lu-177 for somatostatin receptor targeted radiotherapy. PLoS One 9:e88239-e88239. https://doi.org/10.1371/journal. pone. 0088239

Greene MH (1992) Is cisplatin a human carcinogen? J Natl Cancer Inst 84:306-312. https://doi.org/10.1093/jnci/84.5.306

Greten FR, Grivennikov SI (2019) Inflammation and cancer: triggers, mechanisms, and consequences. Immunity

Griffiths AJ, Miller JH, Suzuki DT, et al (2000) Relation between mutagens and carcinogens

Grivennikov SI, Greten FR, Karin M (2010) Immunity, Inflammation, and Cancer. Cell

Grover M, Behl T, Virmani T (2021) Phytochemical screening, antioxidant assay and cytotoxic profile for different extracts of chrysopogon zizanioides roots. Chem Biodivers Wiley Online Libr 18:e2100012. https://doi.org/10.1002/cbdv.202100012

Grundy GJ, Parsons JL (2020) Base excision repair and its implications to cancer therapy. Essays Biochem 64:831-843. https://doi.org/10. 1042/EBC20200013

Guha Mazumder DN, De BK, Santra A et al (2001) Randomized placebocontrolled trial of 2,3-dimercapto-1-propanesulfonate (DMPS) in therapy of chronic arsenicosis due to drinking arseniccontaminated water. J Toxicol Clin Toxicol 39:665-674. https:// doi.org/10.1081/clt-100108507

Guidolin V, Carlson ES, Carrà A et al (2021) Identification of new markers of alcohol-derived DNA damage in humans. Biomolecules 11:366. https://doi.org/10.3390/biom11030366

Gulinac M (2020) A review on the evolution of immunotherapy in bladder carcinoma. J Med 2(04):374-376

Gunn SA, Gould TC, Anderson WA (1963) Cadmium-induced interstitial cell tumors in rats and mice and their prevention by zinc. J Natl Cancer Inst 31:745-759

Guo YC, Chang CM, Hsu WL et al (2013) Indomethacin inhibits cancer cell migration via attenuation of cellular calcium mobilization. Molecules 18:6584-6596. https://doi.org/10.3390/ molecules 18066584

Guo H, Liu H, Wu H et al (2019) Nickel carcinogenesis mechanism: DNA damage. Int J Mol Sci

Gupta A, Shah K, Oza M, et al (2019) Reactivation of p53 gene by MDM2 inhibitors: a novel therapy for cancer treatment. Elsevier

Hagen TM, Huang S, Curnutte J et al (1994) Extensive oxidative DNA damage in hepatocytes of transgenic mice with chronic active hepatitis destined to develop hepatocellular carcinoma. Proc Natl Acad Sci U S A 91:12808-12812. https://doi.org/10.1073/pnas.91.26. 12808

Halbrook CJ, Pontious C, Kovalenko I et al (2019) Macrophage-released pyrimidines inhibit gemcitabine therapy in pancreatic cancer. Cell Metab. https://doi.org/10.1016/j.cmet.2019.02.001

Hamanaka RB, Chandel NS (2009) Mitochondrial reactive oxygen species regulate hypoxic signaling. Curr. Opin. Cell Biol.

Hamid AS, Tesfamariam SG, Zhang Y, Zhang ZG (2013) Aflatoxin B1induced hepatocellular carcinoma in developing countries: geographical distribution, mechanism of action and prevention
(Review). Oncol Lett 5:1087-1092. https://doi.org/10.3892/ol. 2013.1169

Hammond CB, Soules MR (2009) Endocrine aspects of adenocarcinoma of the endometrium. Glob Libr Women's Med. https://doi.org/10. 3843/glowm. 10237

Hammond EM, Dorie MJ, Giaccia AJ (2003) ATR/ATM targets are phosphorylated by ATR in response to hypoxia and ATM in response to reoxygenation. J Biol Chem. https://doi.org/10.1074/jbc. M212360200

Hamzawy MA, Abo-Youssef AM, Salem HF, Mohammed SA (2017) Antitumor activity of intratracheal inhalation of temozolomide (TMZ) loaded into gold nanoparticles and/or liposomes against urethane-induced lung cancer in BALB/c mice. Drug Deliv 24: 599-607. https://doi.org/10.1080/10717544.2016.1247924

Han S, Huang T, Hou F et al (2019) The prognostic value of hypoxiainducible factor- $1 \alpha$ in advanced cancer survivors: a meta-analysis with trial sequential analysis. Ther Adv Med Oncol. https://doi.org/ $10.1177 / 1758835919875851$

Hanahan D, Weinberg RA (2011) Hallmarks of cancer: The next generation. Cell

Hao JQ, Li Q, Xu SP et al (2008) Effect of lumiracoxib on proliferation and apoptosis of human nonsmall cell lung cancer cells in vitro. Chin Med J 121:602-607. https://doi.org/10.1097/00029330200804010-00006

Harada N, Hiramatsu N, Oze T et al (2015) Efficacy of pegylated interferon and ribavirin combination therapy for patients with hepatitis $\mathrm{C}$ virus infection after curative resection or ablation for hepatocellular carcinoma - a retrospective multicenter study. J Med Virol 87: 1199-1206. https://doi.org/10.1002/jmv.24173

Hart RW, Hall KY, Daniel FB (1978) DNA repair and mutagenesis in mammalian cells. Photochem Photobiol 28:131-155. https://doi. org/10.1111/j.1751-1097.1978.tb07689.x

Hartman Z, Henrikson EN, Hartman PE, Cebula TA (1994) Molecular models that may account for nitrous acid mutagenesis in organisms containing double-stranded DNA. Environ Mol Mutagen 24:168 175. https://doi.org/10.1002/em.2850240305

Hartwig A (2013) Cadmium and cancer. Met Ions Life Sci 11:491-507. https://doi.org/10.1007/978-94-007-5179-8_15

Hassen S, Ali AA, Kilaparty SP et al (2016) Interdependence of DNA mismatch repair proteins MLH1 and MSH2 in apoptosis in human colorectal carcinoma cell lines. Mol Cell Biochem 412:297-305. https://doi.org/10.1007/S11010-015-2636-3

Hato SV, Khong A, De Vries IJM, Lesterhuis WJ (2014) Molecular pathways: the immunogenic effects of platinum-based chemotherapeutics. Clin Cancer Res. https://doi.org/10.1158/1078-0432.CCR13-3141

Hattori Y, Nishigori C, Tanaka T et al (1996) 8-Hydroxy-2'deoxyguanosine is increased in epidermal cells of hairless mice after chronic ultraviolet B exposure. J Invest Dermatol 107:733-737. https://doi.org/10.1111/1523-1747.ep12365625

Hattori K, Matsushita R, Kimura K et al (2001) Synergistic effect of indomethacin and adriamycin and cisplatin on tumor growth. Biol Pharm Bull 24:1214-1217. https://doi.org/10.1248/bpb.24.1214

Heeke AL, Pishvaian MJ, Lynce F et al (2018) Prevalence of homologous recombination-related gene mutations across multiple cancer types. JCO Precis Oncol. https://doi.org/10.1200/po.17.00286

Hegi ME, Diserens AC, Gorlia T et al (2005) MGMT gene silencing and benefit from temozolomide in glioblastoma. N Engl J Med. https:// doi.org/10.1056/NEJMoa043331

Helleday T, Lo J, Gent D van, et al (2007) DNA double-strand break repair: from mechanistic understanding to cancer treatment. Elsevier

Hemeryck LY, Vanhaecke L (2016) Diet-related DNA adduct formation in relation to carcinogenesis. Nutr Rev. https://doi.org/10.1093/ nutrit/nuw017

Hemminki O, Dos Santos JM, Hemminki A (2020) Oncolytic viruses for cancer immunotherapy. J Hematol Oncol 13:84 
Henderson BE, Feigelson HS (2000) Hormonal carcinogenesis the number of cell divisions and the opportunity for random. Carcinogenesis $21: 427-433$

Hernandez LG, Forkert PG (2009) Inhibition of vinyl carbamate-induced lung tumors and Kras2 mutations by the garlic derivative diallyl sulfone. Mutat Res Fundam Mol Mech Mutagen 662:16-21. https://doi.org/10.1016/j.mrfmmm.2008.11.013

Ho Woo D, Han IS, Jung G (2004) Mefenamic acid-induced apoptosis in human liver cancer cell-lines through caspase-3 pathway. Life Sci 75:2439-2449. https://doi.org/10.1016/j.lfs.2004.04.042

Hodge WH (1973) Fern foods of Japan and the problem of toxicity. Am Fern J. https://doi.org/10.2307/1546182

Hodson A, Crichton S, Montoto S et al (2011) Use of zidovudine and interferon alfa with chemotherapy improves survival in both acute and lymphoma subtypes of adult T-cell leukemia/lymphoma. J Clin Oncol 29:4696-4701. https://doi.org/10.1200/JCO.2011.35.5578

Hoffmann GR, Calciano MA, Lawless BM, Mahoney KM (2003) Frameshift mutations induced by three classes of acridines in the lacZ reversion assay in Escherichia coli: potency of responses and relationship to slipped mispairing models. Environ Mol Mutagen 42:111-121. https://doi.org/10.1002/em.10182

Hoki Y, Murata M, Hiraku Y et al (2007) 8-Nitroguanine as a potential biomarker for progression of malignant fibrous histiocytoma, a model of inflammation-related cancer. Oncol Rep. https://doi.org/ 10.3892/or.18.5.1165

Holmes AL, Wise SS, Wise JP (2008) Carcinogenicity of hexavalent chromium. Indian J Med Res 128:353-372

Hong Z, Jiang J, Hashiguchi K et al (2008) Recruitment of mismatch repair proteins to the site of DNA damage in human cells. J Cell Sci 121:3146-3154. https://doi.org/10.1242/jcs.026393

Hu J, Mao Y, White K et al (2002) Renal cell carcinoma and occupational exposure to chemicals in Canada. Occup Med (Chic Ill) 52:157164. https://doi.org/10.1093/occmed/52.3.157

Huang L-C, Clarkin KC, Wahl GM (1996) Sensitivity and selectivity of the DNA damage sensor responsible for activating p53-dependent G1 arrest

Huang SXL, Jaurand MC, Kamp DW et al (2011) Role of mutagenicity in asbestos fiber-induced carcinogenicity and other diseases. J Toxicol Environ Heal - Part B Crit Rev 14:179-245. https://doi.org/10.1080/ 10937404.2011.556051

Huang J, Fogg M, Wirth LJ et al (2017) Epstein-Barr virus-specific adoptive immunotherapy for recurrent, metastatic nasopharyngeal carcinoma. Cancer 123:2642-2650. https://doi.org/10.1002/cncr.30541

Hughes VS, Wiggins JM, Siemann DW (2019) Tumor oxygenation and cancer therapy-then and now. Br J Radiol

Hung CF, Ma B, Monie A et al (2008) Therapeutic human papillomavirus vaccines: current clinical trials and future directions. Expert Opin Biol Ther 8:421-439

Ibrahim ZA, Cheng KJ, Fakaruzi NA et al (2019) HMGB1 and sRAGE: what are their links to acute myeloid leukemia? Int J Hum Heal Sci. https://doi.org/10.31344/ijhhs.v0i0.177

Inanc M, Duran A, Karaca H et al (2014) Haematologic parameters in metastatic colorectal cancer patients treated with capecitabine combination therapy. Asian Pac J Cancer Prev 15:253-256. https://doi. org/10.7314/APJCP.2014.15.1.253

Iovoli AJ, Hermann GM, Ma SJ et al (2020) Association of nonsteroidal anti-inflammatory drug use with survival in patients with squamous cell carcinoma of the head and neck treated with chemoradiation therapy. JAMA Netw Open 3:e207199. https://doi.org/10.1001/ jamanetworkopen.2020.7199

Itoh $\mathrm{H}$, Iwasaki M, Sawada $\mathrm{N}$ et al (2014) Dietary cadmium intake and breast cancer risk in Japanese women: a case-control study. Int J Hyg Environ Health 217:70-77. https://doi.org/10.1016/j.ijheh. 2013.03.010
Ivashkevich A, Redon CE, Nakamura AJ et al (2012) Use of the $\gamma$-H2AX assay to monitor DNA damage and repair in translational cancer research. Cancer Lett 327:123-133

Jackson PE, Groopman JD (1999) Alfatoxin and liver cancer. Best Pract Res Clin Gastroenterol 13:545-555

Jadoon S, Malik A (2017) DNA Damage by heavy metals in animals and human beings: an overview. Biochem Pharmacol Open Access. https://doi.org/10.4172/2167-0501.1000235

Jaiswal M, LaRusso NF, Burgart LJ, Gores GJ (2000) Inflammatory cytokines induce DNA damage and inhibit DNA repair in cholangiocarcinoma cells by a nitric oxide-dependent mechanism. Cancer Res

Jang HG, Park M, Wishnok JS et al (2006) Hydroxyl-specific fluorescence labeling of ABP-deoxyguanosine, PhIP-deoxyguanosine, and AFB1-formamidopyrimidine with BODIPY-FL. Anal Biochem. https://doi.org/10.1016/j.ab.2006.08.030

Janssens S, Tschopp J (2006) Signals from within: the DNA-damageinduced NF-kB response. Cell Death Differ 135(13):773-784. https://doi.org/10.1038/sj.cdd.4401843

Järvholm B, Aström E (2014) The risk of lung cancer after cessation of asbestos exposure in construction workers using pleural malignant mesothelioma as a marker of exposure. J Occup Environ Med 56: 1297-1301. https://doi.org/10.1097/JOM.0000000000000258

Jeffrey Lewis R (2012) Naphthalene animal carcinogenicity and human relevancy: overview of industries with naphthalene-containing streams. Regul Toxicol Pharmacol 62:131-137. https://doi.org/10. 1016/j.yrtph.2011.12.004

Ji W, Yang L, Yu L et al (2008) Epigenetic silencing of O6methylguanine DNA methyltransferase gene in NiS-transformed cells. Carcinogenesis. https://doi.org/10.1093/carcin/bgn012

Jiang M, Jia K, Wang L et al (2021) Alterations of DNA damage response pathway: biomarker and therapeutic strategy for cancer immunotherapy. Acta Pharm Sin B. https://doi.org/10.1016/j.apsb.2021.01. 003

Jing Y, Han Z, Zhang S, et al (2011) Epithelial-mesenchymal transition in tumor microenvironment. Cell Biosci.

Johnson FM (1998) The genetic effects of environmental lead. Mutat Res Rev Mutat Res 410:123-140. https://doi.org/10.1016/S13835742(97)00032-X

Jones PA, Baylin SB (2007) The epigenomics of cancer. Cell

Jones GDD, Le Pla RC, Farmer PB (2010) Phosphotriester adducts (PTEs): DNA's overlooked lesion. Mutagenesis 25:3-16. https:// doi.org/10.1093/mutage/gep038

Joon Hwang B, Ford JM, Hanawalt PC, Chu G (1999) Expression of the $\mathrm{p} 48$ xeroderma pigmentosum gene is $\mathrm{p} 53$-dependent and is involved in global genomic repair

Jun JC, Rathore A, Younas H, et al (2017) Hypoxia-Inducible Factors and Cancer. Curr. Sleep Med. Rep

Jung H, Rajasekaran N, Ju W, Shin Y (2015) Human papillomavirus: current and future RNAi therapeutic strategies for cervical cancer. J Clin Med 4:1126-1155. https://doi.org/10.3390/jcm4051126

Kabir MT, Rahman MH, Akter R et al (2021) Potential role of curcumin and its nanoformulations to treat various types of cancers. Biomol 392(11):392. https://doi.org/10.3390/BIOM11030392

Kang R, Zhang Q, Zeh HJ et al (2013) HMGB1 in cancer: good, bad, or both? Clin Cancer Res. https://doi.org/10.1158/1078-0432.CCR$13-0495$

Kaoru S (2016) Molecular mechanisms of DNA damage recognition for mammalian nucleotide excision repair. DNA Repair (Amst) 44: 110-117. https://doi.org/10.1016/J.DNAREP.2016.05.015

Kaplan AR, Glazer PM (2020) Impact of hypoxia on DNA repair and genome integrity. Mutagenesis 35:61-68. https://doi.org/10.1093/ mutage/gez019

Karakasilioti I, Kamileri I, Chatzinikolaou G et al (2013) DNA damage triggers a chronic autoinflammatory response, leading to fat 
depletion in NER progeria. Cell Metab. https://doi.org/10.1016/j. cmet.2013.08.011

Karanam K, Kafri R, Loewer A, et al (2012) Quantitative live cell imaging reveals a gradual shift between DNA repair mechanisms and a maximal use of $\mathrm{HR}$ in mid $\mathrm{S}$ phase. Elsevier

Karim S, Souho T, Benlemlih M, Bennani B (2018) Cervical cancer induction enhancement potential of chlamydia trachomatis: a systematic review. Curr Microbiol 75:1667-1674. https://doi.org/10. 1007/s00284-018-1439-7

Karthika C, Hari B, Mano V, et al (2021) Curcumin as a great contributor for the treatment and mitigation of colorectal cancer. Elsevier

Kaur I, Behl T, Aleya L et al (2021) Role of metallic pollutants in neurodegeneration: effects of aluminum, lead, mercury, and arsenic in mediating brain impairment events and autism spectrum disorder. Environ Sci Pollut Res 28:8989-9001. https://doi.org/10.1007/ S11356-020-12255-0

Kawanishi S, Ohnishi S, Ma N, et al (2017) Crosstalk between DNA damage and inflammation in the multiple steps of carcinogenesis. Int J Mol Sci

Kay J, Thadhani E, Samson L, Engelward B (2019) Inflammationinduced DNA damage, mutations and cancer. DNA Repair (Amst).

Kefford RF, Thomas NPB, Corrie PG et al (2009) A phase I study of extended dosing with lomeguatrib with temozolomide in patients with advanced melanoma. Br J Cancer 100:1245-1249. https://doi. org/10.1038/sj.bjc.6605016

Kelleni MT (2021) Early use of non-steroidal anti-inflammatory drugs in COVID-19 might reverse pathogenesis, prevent complications and improve clinical outcomes. Biomed Pharmacother 133:110982. https://doi.org/10.1016/j.biopha.2020.110982

Khan OA, Ranson M, Michael M et al (2008) A phase II trial of lomeguatrib and temozolomide in metastatic colorectal cancer. $\mathrm{Br}$ J Cancer 98:1614-1618. https://doi.org/10.1038/sj.bjc.6604366

Khandpur S, Sharma VK (2003) Successful treatment of multiple premalignant and malignant lesions in arsenical keratosis with a combination of acitretin and intralesional 5-fluorouracil. J Dermatol 30:730 734. https://doi.org/10.1111/j.1346-8138.2003.tb00468.x

Kidane D, Chae WJ, Czochor J, et al (2014) Interplay between DNA repair and inflammation, and the link to cancer. Crit Rev Biochem Mol Biol

Kim D, Guengerich FP (2005) Cytochrome P450 activation of arylamines and heterocyclic amines. Annu Rev Pharmacol Toxicol

Kim H-H, Han S-Y (2019) Vandetanib and lenvatinib for the treatment of thyroid cancers. J Adv Med Med Res 28:1-5. https://doi.org/10. 9734/jammr/2018/46474

Kim T-S, Pak JH, Kim J-B, Bahk YY (2016) Clonorchis sinensis, an oriental liver fluke, as a human biological agent of cholangiocarcinoma: a brief review. BMB Rep 49:590-597. https://doi.org/10. 5483/bmbrep.2016.49.11.109

Kinpara S, Kijiyama M, Takamori A et al (2013) Interferon- $\alpha$ (IFN- $\alpha$ ) suppresses HTLV-1 gene expression and cell cycling, while IFN- $\alpha$ combined with zidovudin induces $\mathrm{p} 53$ signaling and apoptosis in HTLV-1-infected cells. Retrovirology 10:1-15. https://doi.org/10. 1186/1742-4690-10-52

Kirby-Smith JS, Daniels DS (1953) The relative effects of X-Rays, gamma rays and beta rays on chromosomal breakage in tradescantia. Genetics 38:375-388. https://doi.org/10.1093/genetics/38.4.375

Klutstein M, Nejman D, Greenfield R, Cedar H (2016) DNA methylation in cancer and aging. Cancer Res

Knijnenburg TA, Wang L, Zimmermann MT et al (2018) Genomic and molecular landscape of DNA damage repair deficiency across the Cancer Genome Atlas. Cell Rep. https://doi.org/10.1016/j.celrep. 2018.03.076

Koi M, Boland CR (2011) Tumor hypoxia and genetic alterations in sporadic cancers. J Obstet Gynaecol Res 37:85-98. https://doi.org/ 10.1111/j.1447-0756.2010.01377.x
Kojima Y, Machida YJ (2020) DNA-protein crosslinks from environmental exposure: mechanisms of formation and repair. Environ $\mathrm{Mol}$ Mutagen

Kolodner R, 1999 undefined Eukaryotic DNA mismatch repair. development GM-C opinion in genetics. Elsevier

Kostadinov RL, Kuhner MK, Li X et al (2013) NSAIDs Modulate clonal evolution in Barrett's esophagus. PLoS Genet 9:e1003553. https:// doi.org/10.1371/journal.pgen.1003553

Koturbash I, Scherhag A, Sorrentino J et al (2011) Epigenetic mechanisms of mouse interstrain variability in genotoxicity of the environmental toxicant 1,3-butadiene. Toxicol Sci. https://doi.org/10.1093/ toxsci/kfr133

Kryston TB, Georgiev AB, Pissis P, Georgakilas AG (2011) Role of oxidative stress and DNA damage in human carcinogenesis. Mutat Res-Fundam Mol Mech Mutagen.

Kuefner MA, Brand M, Ehrlich J et al (2012) Effect of antioxidants on Xray-induced $\gamma-\mathrm{H} 2 \mathrm{AX}$ foci in human blood lymphocytes: Preliminary observations. Radiology 264:59-67. https://doi.org/10. 1148/radiol.12111730

Kumar R (2020) A new insight into base excision repair (BER) in targeted cancer therapy. Genome Instab Dis 1:310-317. https:// doi.org/10.1007/s42764-020-00024-9

Kumareswaran R, Ludkovski O, Meng A et al (2012) Chronic hypoxia compromises repair of DNA double-strand breaks to drive genetic instability. J Cell Sci 125:189-199. https://doi.org/10.1242/jcs. 092262

Kumawat S, Rana N, Bansal R, Vishwakarma G (2019) Expanding avenue of fast neutron mediated. Mutagenesis for Crop Improvement. Plants (Basel). https://doi.org/10.20944/preprints201905.0130.v1

Kurdistani SK (2007) Histone modifications as markers of cancer prognosis: A cellular view. Br J Cancer

Labelle M, Begum S, Hynes RO (2011) Direct signaling between platelets and cancer cells induces an epithelial-mesenchymal-like transition and promotes metastasis. Cancer Cell. https://doi.org/10.1016/j. ccr.2011.09.009

LaFargue CJ, Dal Molin GZ, Sood AK, Coleman RL (2019) Exploring and comparing adverse events between PARP inhibitors. Lancet Oncol 20:e15-e28. https://doi.org/10.1016/S1470-2045(18)30786-

Lai L, Hui CK, Leung N, Lau GK (2006) Pegylated interferon alpha-2a $(40 \mathrm{kDa})$ in the treatment of chronic hepatitis B. Int J Nanomed 1: 255-262

Lai V, George J, Richey L et al (2008) Results of a pilot study of the effects of celecoxib on cancer cachexia in patients with cancer of the head, neck, and gastrointestinal tract. Head Neck 30:67-74. https:// doi.org/10.1002/hed.20662

Laikova KV, Oberemok VV, Krasnodubets AM et al (2019) Advances in the understanding of skin cancer: ultraviolet radiation, mutations, and antisense oligonucleotides as anticancer drugs. Molecules 24: E1516. https://doi.org/10.3390/molecules24081516

Lama-Sherpa D, Shevde LA (2020) An emerging regulatory role for the tumor microenvironment in the DNA damage response to doublestrand breaks. Mol Cancer Res 18:185-93. https://doi.org/10.1158/ 1541-7786.MCR-19-0665

Lamberti G, Andrini E, Sisi M, et al (2020) Targeting DNA damage response and repair genes to enhance anticancer immunotherapy: rationale and clinical implication. Futur. Oncol.

Langård S, Vigander T (1983) Occurrence of lung cancer in workers producing chromium pigments. Br J Ind Med 40:71-74. https:// doi.org/10.1136/oem.40.1.71

Lau A, Zheng Y, Tao S et al (2013) Arsenic inhibits autophagic flux, activating the Nrf2-Keap1 pathway in a p62-dependent manner. Mol Cell Biol 33:2436-2446. https://doi.org/10.1128/MCB.01748-12

Lauwerys RR, Bernard AM (1986) Cadmium and the kidney. Br J Ind Med 43:433-435. https://doi.org/10.1136/oem.43.7.433 
Le QT, Courter D (2008) Clinical biomarkers for hypoxia targeting. Cancer Metastasis Rev.

Le DT, Durham JN, Smith KN et al (2017) Mismatch repair deficiency predicts response of solid tumors to PD-1 blockade. Science (80-). https://doi.org/10.1126/science.aan6733

Leahy KM, Ornberg RL, Wang Y et al (2002) Cyclooxygenase-2 Inhibition by Celecoxib Reduces Proliferation and Induces Apoptosis in Angiogenic Endothelial Cells in Vivo. Cancer Res 62:625-631

Lee KJ, Piett CG, Andrews JF et al (2019) Defective base excision repair in the response to DNA damaging agents in triple negative breast cancer. PLoS One 14:e0223725. https://doi.org/10.1371/journal. pone. 0223725

Lemery S, Keegan P, Pazdur R (2017) First FDA approval agnostic of cancer site - when a biomarker defines the indication. N Engl J Med 377:1409-1412. https://doi.org/10.1056/nejmp1709968

Lempiäinen H, Müller A, Brasa S et al (2011) Phenobarbital mediates an epigenetic switch at the constitutive androstane receptor (CAR) target gene Cyp2b10 in the liver of B6C3F1 mice. PLoS One. https:// doi.org/10.1371/journal.pone.0018216

Leung E, McArthur D, Morris A, Williams N (2008) Cyclooxygenase-2 inhibition prevents migration of colorectal cancer cells to extracellular matrix by down-regulation of matrix metalloproteinase- 2 expression. Dis Colon Rectum 51:342-347. https://doi.org/10.1007/ s10350-007-9120-4

Levine AJ (2009) The common mechanisms of transformation by the small DNA tumor viruses: The inactivation of tumor suppressor gene products: p53. Virology 384:285-293

Lewis JG, Adams DO (1987) Inflammation, oxidative DNA damage, and carcinogenesis. Environ Health Perspect. https://doi.org/10.1289/ ehp. 877619

Li W, Wu B, Zeng Y, et al (2004) Epstein-Barr virus in hepatocellular carcinogenesis. World J Gastroenterol 10(23):3409-13. https://doi. org/10.3748/wjg.v10.i23.3409

Li J, Fan R, Zhao S et al (2011) Reactive oxygen species released from hypoxic hepatocytes regulates MMP-2 expression in hepatic stellate cells. Int J Mol Sci. https://doi.org/10.3390/ijms12042434

Li X, Pathi SS, Safe S (2015) Sulindac sulfide inhibits colon cancer cell growth and downregulates specificity protein transcription factors. BMC Cancer 15:1. https://doi.org/10.1186/s12885-015-1956-8

Li Y, He M, Chen B, Hu B (2019) Inhibition of arsenite methylation induces synergistic genotoxicity of arsenite and benzo(a)pyrene diol epoxide in SCC-7 cells. Metallomics 11:176-182. https://doi.org/ $10.1039 / \mathrm{c} 8 \mathrm{mt} 00217 \mathrm{~g}$

Li Y, Sun XX, Qian DZ, Dai MS (2020) Molecular crosstalk between MYC and HIF in cancer. Front Cell Dev Biol.

Li LY, Di Guan Y, Chen XS et al (2021) DNA repair pathways in cancer therapy and resistance. Front Pharmacol 11:2520

Liang K, Lu Y, Jin W et al (2003) Sensitization of breast cancer cells to radiation by trastuzumab. Mol Cancer Ther 2:1113-1120

Lichtenberger LM, Phan T, Fang D, Dial EJ (2018) Chemoprevention with phosphatidylcholine non-steroidal anti-inflammatory drugs in vivo and in vitro. Oncol Lett 15:6688-6694. https://doi.org/10. 3892/ol.2018.8098

Lin K, Doolan K, Hung CF, Wu TC (2010) Perspectives for preventive and therapeutic HPV vaccines. J Formos Med Assoc 109:4-24

Lin YC, Lin JF, Tsai TF et al (2017) Acridine orange exhibits photodamage in human bladder cancer cells under blue light exposure. Sci Rep 7:1-11. https://doi.org/10.1038/s41598-017-13904-0

Lin W-C, Lin Y-S, Chang C-W et al (2020) Impact of direct-acting antiviral therapy for hepatitis C-related hepatocellular carcinoma. PLoS One 15:e0233212. https://doi.org/10.1371/JOURNAL. PONE.0233212

Lindahl T (1979) undefined DNA glycosylases, endonucleases for apurinic/apyrimidinic sites, and base excision-repair. Progress Nucl Acid Res Mol Biol. Elsevier
Little MP, Wakeford R, Tawn EJ et al (2009) Risks associated with low doses and low dose rates of ionizing radiation: why linearity may be (almost) the best we can do. Radiology 251:6-12. https://doi.org/10. 1148/radiol.2511081686

Liu HF, Hsiao PW, Chao JI (2008) Celecoxib induces p53-PUMA pathway for apoptosis in human colorectal cancer cells. Chem Biol Interact 176:48-57. https://doi.org/10.1016/j.cbi.2008.07.012

Liu Y, Lu Y, Wang J et al (2014) Association between nonsteroidal antiinflammatory drug use and brain tumour risk: a meta-analysis. Br J Clin Pharmacol 78:58-68

Liu D, Plimack ER, Hoffman-Censits J et al (2016) Clinical validation of chemotherapy response biomarker ERCC2 in muscle-invasive urothelial bladder carcinoma. JAMA Oncol 2:1094-1096

Ljungkvist ASE, Bussink J, Kaanders JHAM, Van Der Kogel AJ (2007) Dynamics of tumor hypoxia measured with bioreductive hypoxic cell markers. Radiat Res

Lonkar P, Dedon PC (2011) Reactive species and DNA damage in chronic inflammation: reconciling chemical mechanisms and biological fates. Int J Cancer

Loucas BD, Durante M, Bailey SM, Cornforth MN (2013) Chromosome damage in human cells by $\gamma$ rays, $\alpha$ particles and heavy ions: track interactions in basic dose-response relationships. Radiat Res 179:9 20. https://doi.org/10.1667/RR3089.1

Lüchtenborg M, Weijenberg MP, de Goeij AFPM et al (2005) Meat and fish consumption, APCGene mutations and hMLH1 expression in colon and rectal cancer: a prospective cohort study (The Netherlands). Cancer Causes Control 16:1041-1054. https:// doi.org/10.1007/s10552-005-0239-0

Luevano J, Damodaran C (2014) A review of molecular events of cadmium-induced carcinogenesis. J Environ Pathol Toxicol Oncol 33:183-194. https://doi.org/10.1615/jenvironpatholtoxicoloncol. 2014011075

Luoto KR, Kumareswaran R, Bristow RG (2013) Tumor hypoxia as a driving force in genetic instability. Genome Integr.

Ma N, Kawanishi M, Hiraku Y et al (2008) Reactive nitrogen speciesdependent DNA damage in EBV-associated nasopharyngeal carcinoma: the relation to STAT3 activation and EGFR expression. Int $\mathrm{J}$ Cancer. https://doi.org/10.1002/ijc.23415

Ma J-L, Zhang L, Brown LM et al (2012) Fifteen-year effects of Helicobacter pylori, garlic, and vitamin treatments on gastric cancer incidence and mortality. J Natl Cancer Inst 104:488-492. https://doi. org/10.1093/jnci/djs003

Ma F, Wang T, Jiang L et al (2017) Ultrasensitive detection of telomerase activity in lung cancer cells with quencher-free molecular beaconassisted quadratic signal amplification. Elsevier

Madhusudan S, Hickson ID (2005) DNA repair inhibition: a selective tumour targeting strategy. Trends Mol Med 11:503-511. https:// doi.org/10.1016/j.molmed.2005.09.004

Madhusudan S, Smart F, Shrimpton P et al (2005) Isolation of a small molecule inhibitor of DNA base excision repair. Nucleic Acids Res 33:4711-4724. https://doi.org/10.1093/nar/gki781

Maede Y, Shimizu H, Fukushima T et al (2013) Differential and common DNA repair pathways for topoisomerase I- and II-targeted drugs in a genetic DT40 repair cell screen panel. Mol Cancer Ther 13:214220. https://doi.org/10.1158/1535-7163.MCT-13-0551

Maeng S, Lee HW, Bashir Q et al (2016) Oxidative stress-mediated mouse liver lesions caused by Clonorchis sinensis infection. Int $\mathrm{J}$ Parasitol 46:195-204. https://doi.org/10.1016/j.ijpara.2015.11.003

Mager DL (2006) Bacteria and cancer: cause, coincidence or cure? A review. J Transl Med 4:14. https://doi.org/10.1186/1479-5876-4-14

Maher VM, Justin McCormick J (1984) Role of DNA lesions and repair in the transformation of human cells. Pharmacol Ther. https://doi. org/10.1016/0163-7258(84)90006-8

Malviya R, Sharma PK, Dubey SK (2020) Efficiency of self-assembled etoricoxib containing polyelectrolyte complex stabilized cubic 
nanoparticles against human cancer cells. Precis Med Sci 9:9-22. https://doi.org/10.1002/prm2.12004

Mamlouk S, Wielockx B (2013) Hypoxia-inducible factors as key regulators of tumor inflammation. Int $\mathrm{J}$ Cancer

Mandrioli D, Belpoggi F, Silbergeld EK, Perry MJ (2016) Aneuploidy: a common and early evidence-based biomarker for carcinogens and reproductive toxicants. Environ Health A Glob Access Sci. Source

Mantovani A (2005) Cancer: Inflammation by remote control. Nature

Martinez VD, Vucic EA, Becker-Santos DD et al (2011) Arsenic exposure and the induction of human cancers. J Toxicol 2011:431287. https://doi.org/10.1155/2011/431287

Martín-Sanz P, Casado M, Boscá L (2017) Cyclooxygenase 2 in liver dysfunction and carcinogenesis: Facts and perspectives. World J Gastroenterol 23:3572. https://doi.org/10.3748/WJG.V23.I20.3572

Marusawa H, Takai A, Chiba T (2011) Role of activation-induced cytidine deaminase in inflammation-associated cancer development. In: Advances in Immunology

Matejcic M, Gunter MJ, Ferrari P (2017) Alcohol metabolism and oesophageal cancer: a systematic review of the evidence. Carcinogenesis 38:859-872. https://doi.org/10.1093/carcin/bgx067

Matulonis UA, Harter P, Gourley C et al (2016) Olaparib maintenance therapy in patients with platinum-sensitive, relapsed serous ovarian cancer and a BRCA mutation: Overall survival adjusted for postprogression poly(adenosine diphosphate ribose) polymerase inhibitor therapy. Cancer 122:1844-1852. https://doi.org/10.1002/ cncr. 29995

Maynard S, Schurman SH, Harboe C et al (2009) Base excision repair of oxidative DNA damage and association with cancer and aging. Carcinogenesis 30:2-10

Mayorek N, Naftali-Shani N, Grunewald M (2010) Diclofenac inhibits tumor growth in a murine model of pancreatic cancer by modulation of VEGF levels and arginase activity. PLoS One 5:e12715. https:// doi.org/10.1371/journal.pone.0012715

McCool KW, Miyamoto S (2012) DNA damage-dependent NF-kB activation: NEMO turns nuclear signaling inside out. Immunol Rev. https://doi.org/10.1111/j.1600-065X.2012.01101.x

Medveczky MM, Horvath E, Lund T, Medveczky PG (1997) In vitro antiviral drug sensitivity of the Kaposi's sarcoma-associated herpesvirus. AIDS 11:1327-1332. https://doi.org/10.1097/00002030199711000-00006

Melo SA, Esteller M (2011) Dysregulation of microRNAs in cancer: playing with fire. FEBS Lett

Meng AX, Jalali F, Cuddihy A, et al (2005) Hypoxia down-regulates DNA double strand break repair gene expression in prostate cancer cells. In: Radiotherapy and Oncology

Meng Q, Hagemeier SR, Fingeroth JD et al (2010) The Epstein-Barr virus (EBV)-encoded protein kinase, EBV-PK, but not the thymidine kinase (EBV-TK), is required for ganciclovir and acyclovir inhibition of lytic viral production. J Virol 84:4534 4542. https://doi.org/10. 1128/jvi.02487-09

Mi Z, Feng Z-C, Li C et al (2019) Salmonella-mediated cancer therapy: an innovative therapeutic strategy. J Cancer 10:4765-4776. https:// doi.org/10.7150/jca.32650

Michels J, Vitale I, Saparbaev M et al (2014) Predictive biomarkers for cancer therapy with PARP inhibitors. Oncogene 33:3894-3907

Midgley RS, Mcconkey CC, Johnstone EC et al (2010) Phase III Randomized Trial assessing rofecoxib in the adjuvant setting of colorectal cancer: final results of the VICTOR Trial. J Clin Oncol 28:4575-4580. https://doi.org/10.1200/JCO.2010.29.6244

Miki Y, Nishisho I, Horii A et al (1992) Disruption of the APC gene by a retrotransposal insertion of $\mathrm{L} 1$ sequence in a colon cancer. Cancer Res 52:643-645

Mimitou EP, Symington LS (2009) Nucleases and helicases take center stage in homologous recombination. Trends Biochem Sci
Min J, (2007) undefined Recognition of DNA damage by the Rad4 nucleotide excision repair protein. Nature (7162):570-575. https://doi. org/10.1038/nature06155

Mishima M (2017) Chromosomal aberrations, clastogens vs aneugens. Front Biosci - Sch. https://doi.org/10.2741/S468

Mitra S, Hazra T, Roy R, et al (1997) Complexities of DNA base excision repair in mammalian cells. Mol Cells 7(3):305-12.

Mittal M, Siddiqui MR, Tran K et al (2014) Reactive oxygen species in inflammation and tissue injury. Antioxid Redox Signal 20:11261167

Mohammed SI, Bennett PF, Craig BA et al (2002) Effects of the cyclooxygenase inhibitor, piroxicam, on tumor response, apoptosis, and angiogenesis in a canine model of human invasive urinary bladder cancer. Cancer Res 62:356-358

Mohiuddin IS, Kang MH (2019) DNA-PK as an emerging therapeutic target in cancer. Front Oncol 9:635. https://doi.org/10.3389/fonc. 2019.00635

Momota H, Narita Y, Miyakita Y, Shibui S (2013) Secondary hematological malignancies associated with temozolomide in patients with glioma. Neuro-Oncology 15:1445-1450. https://doi.org/10.1093/ neuonc/not036

Moore PS, Chang Y (2010) Why do viruses cause cancer?Highlights of the first century of human tumour virology. Nat Rev Cancer 10: 878-889

Mouw KW, Goldberg MS, Konstantinopoulos PA, D'Andrea AD (2017) DNA damage and repair biomarkers of immunotherapy response. Cancer Discov 7:675-693

Muenyi CS, Ljungman M, States JC (2015) Arsenic disruption of DNA damage responses - potential role in carcinogenesis and chemotherapy. Biomolecules

Muggia FM, Bonetti A, Hoeschele JD et al (2015) Platinum antitumor complexes: 50 years since Barnett Rosenberg's discovery. J Clin Oncol Off J Am Soc Clin Oncol 33:4219-4226. https://doi.org/10. 1200/JCO.2015.60.7481

Murata M (2018) Inflammation and cancer. Environ Health Prev Med.

Musk AW, Olsen N, Alfonso $\mathrm{H}$ et al (2011) Predicting survival in malignant mesothelioma. Eur Respir J 38:1420-1424. https://doi.org/ 10.1183/09031936.00000811

Musk AW, Klerk N De, Reid A, et al (2020) State of the art asbestosrelated diseases 24:562-567

Muz B, de la Puente P, Azab F, Azab AK (2015) The role of hypoxia in cancer progression, angiogenesis, metastasis, and resistance to therapy. Hypoxia (Auckland, NZ) 3:83-92. https://doi.org/10.2147/HP. S93413

Mylavarapu S, Das A, Roy M (2018) Role of BRCA mutations in the modulation of response to platinum therapy. Front Oncol 8:1

Nakajima T, Yamashita S, Maekita T et al (2009) The presence of a methylation fingerprint of Helicobacter pylori Infection in human gastric mucosae. Int J Cancer. https://doi.org/10.1002/ijc.24018

Nature EF, (2003) undefined DNA damage and repair. nature.com. Accessed 04 Apr 2021

Nawrot T, Plusquin M, Hogervorst J et al (2006) Environmental exposure to cadmium and risk of cancer: a prospective population-based study. Lancet Oncol 7:119-126. https://doi.org/10.1016/S14702045(06)70545-9

Negrini S, Gorgoulis VG, Halazonetis TD (2010) Genomic instability an evolving hallmark of cancer. Nat Rev Mol Cell Biol.

Nesic K, Wakefield M, Kondrashova O et al (2018) Targeting DNA repair: the genome as a potential biomarker. J Pathol 244:586597. https://doi.org/10.1002/path.5025

Nicholl (2010) Aspirin and alterations in DNA repair proteins in the SW480 colorectal cancer cell line. Oncol Rep 24:37-46. https:// doi.org/10.3892/or_00000826

Nikiforova M, Stringer J, ..., Blough R, (2000) undefined Proximity of chromosomal loci that participate in radiation-induced 
rearrangements in human cells. science.sciencemag.org. Accessed 26 Aug 2021

Nikolova T, Roos WP, Krämer OH, Strik HM et al (2017) Chloroethylating nitrosoureas in cancer therapy: DNA damage, repair and cell death signaling. Biochim Biophys Acta Rev Cancer 1868:29-39. https://doi.org/10.1016/J.BBCAN.2017.01.004

Noguchi M, Earashi M, Minami M et al (1995) Effects of piroxicam and esculetin on the MDA-MB-231 human breast cancer cell line. Prostaglandins Leukot Essent Fat Acids 53:325-329. https://doi. org/10.1016/0952-3278(95)90051-9

Nordberg GF, Goyer R, Nordberg M (1975) Comparative toxicity of cadmium-metallothionein and cadmium chloride on mouse kidney. Arch Pathol 99:192-197

Ogura M, Todo T, Tanaka M et al (2011) Temozolomide may induce therapy-related acute lymphoblastic leukaemia. Br J Haematol 154: 663-665

Ohnishi S, Murata M, Kawanishi S (2002) Oxidative DNA damage induced by a metabolite of 2-naphthylamine, a smoking-related bladder carcinogen. Jpn J Cancer Res 93:736-743. https://doi.org/10. 1111/j.1349-7006.2002.tb01314.x

Oishi K, Hofmann S, Diaz GA et al (2002) Biallelic germline mutations in $\mathrm{MYH}$ predispose to multiple colorectal adenoma and somatic G: $\mathrm{C} \rightarrow \mathrm{T}:$ A mutations. Hum Mol Genet 11:2961-2967. https://doi.org/ 10.1093/hmg/11.23.2961

Oksenych V, De Jesus BB, Zhovmer A et al (2009) Molecular insights into the recruitment of TFIIH to sites of DNA damage. EMBO J 28: 2971-2980. https://doi.org/10.1038/emboj.2009.230

Okuyama H, Endo H, Akashika T et al (2010) Downregulation of c-MYC protein levels contributes to cancer cell survival under dual deficiency of oxygen and glucose. Cancer Res. https://doi.org/10.1158/ 0008-5472.CAN-10-2720

Olcina M, Lecane PS, Hammond EM (2010) Targeting hypoxic cells through the DNA damage response. Clin Cancer Res

Ortega-Guerrero MA, Carrasco-Núñez G, Barragán-Campos H, Ortega MR (2015) High incidence of lung cancer and malignant mesothelioma linked to erionite fibre exposure in a rural community in Central Mexico. Occup Environ Med 72:216 LP-216218. https:// doi.org/10.1136/oemed-2013-101957

Orthaber K, Pristovnik M, Skok K et al (2017) Skin cancer and its treatment: novel treatment approaches with emphasis on nanotechnology. J Nanomater 2017:2606271. https://doi.org/10.1155/2017/ 2606271

Paini A, Punt A, Scholz G et al (2012) In vivo validation of DNA adduct formation by estragole in rats predicted by physiologically based biodynamic modelling. Mutagenesis. https://doi.org/10.1093/ mutage/ges031

Pal D, Suman S, Kolluru V et al (2017) Inhibition of autophagy prevents cadmium-induced prostate carcinogenesis. Br J Cancer 117:56-64. https://doi.org/10.1038/bjc.2017.143

Palacios J, de la Hoya M, Bellosillo B et al (2020) Mutational screening of BRCA1/2 genes as a predictive factor for therapeutic response in epithelial ovarian cancer: a consensus guide from the Spanish Society of Pathology (SEAP-IAP) and the Spanish Society of Human Genetics (AEGH). Virchows Arch 476:195-207

Palayoor ST, Youmell MY, Calderwood SK et al (1999) Constitutive activation of IKB kinase $\alpha$ and NF- $\mathrm{KB}$ in prostate cancer cells is inhibited by ibuprofen. Oncogene 18:7389-7394. https://doi.org/ 10.1038/sj.onc. 1203160

Pálmai-Pallag T, Bachrati CZ (2014) Inflammation-induced DNA damage and damage-induced inflammation: a vicious cycle. Microbes Infect. https://doi.org/10.1016/j.micinf.2014.10.001

Pantziarka P, Sukhatme V, Bouche G et al (2016) Repurposing drugs in oncology (ReDO) - Diclofenac as an anti-cancer agent. Ecancermedicalscience 10. https://doi.org/10.3332/ecancer.2016. 610
Papatheodoridis GV, Chan HLY, Hansen BE et al (2015) Risk of hepatocellular carcinoma in chronic hepatitis B: assessment and modification with current antiviral therapy. J Hepatol 62:956-967

Parker KH, Sinha P, Horn LA et al (2014) HMGB1 enhances immune suppression by facilitating the differentiation and suppressive activity of myeloid-derived suppressor cells. Cancer Res. https://doi.org/ 10.1158/0008-5472.CAN-13-2347

Parkes EE, Walker SM, Taggart LE et al (2017) Activation of STINGdependent innate immune signaling by s-phase-specific DNA damage in breast cancer. J Natl Cancer Inst. https://doi.org/10.1093/jnci/ djw199

Parkin DM (2006) The global health burden of infection-associated cancers in the year 2002. Int J Cancer 118:3030-3044. https://doi.org/ $10.1002 /$ ijc. 21731

Peake MD (2009) Pemetrexed in the treatment of malignant pleural mesothelioma. Therapy 6:569-575. https://doi.org/10.2217/thy.09.30

Pedersen-Bjergaard J, Daugaard G, Hansen SW et al (1991) Increased risk of myelodysplasia and leukaemia after etoposide, cisplatin, and bleomycin for germ-cell tumours. Lancet 338:359-363. https://doi. org/10.1016/0140-6736(91)90490-G

Pegg AE (1990) Mammalian O6-alkylguanine-DNA alkyltransferase: regulation and importance in response to alkylating carcinogenic and therapeutic agents. Cancer Res 50:6119-6129

Pelland-St-Pierre L, Sernoskie SC, Verner M-A, Ho V (2021) Genotoxic effect of meat consumption: a mini review. Mutat Res Toxicol Environ Mutagen 863-864:503311. https://doi.org/10.1016/j. mrgentox.2021.503311

Peltomäki P (2016) Role of DNA mismatch repair defects in the pathogenesis of human cancer. J Clin Oncol 21:1174-1179. https://doi. org/10.1200/JCO.2003.04.060

Perera FP, Weinstein IB (2000) Molecular epidemiology: recent advances and future directions. Carcinogenesis 21:517-524. https:// doi.org/10.1093/CARCIN/21.3.517

Persing DH, McGinty L, Adams CW, Fowler RG (1981) Mutational specificity of the base analogue, 2-aminopurine, in Escherichia coli. Mutat Res 83:25-37. https://doi.org/10.1016/0027-5107(81)900683

Pflaum T, Hausler T, Baumung C et al (2016) Carcinogenic compounds in alcoholic beverages: an update. Arch Toxicol 90:2349-2367. https://doi.org/10.1007/s00204-016-1770-3

Pham-Huy LA, He H, Pham-Huy C (2008) Free radicals, antioxidants in disease and health. Int J Biomed Sci 4:89-96

Pillay D, Chuturgoon AA, Nevines E et al (2002) The quantitative analysis of zearalenone and its derivatives in plasma of patients with breast and cervical cancer. Clin Chem Lab Med 40:946-951. https://doi.org/10.1515/CCLM.2002.166

Piotrowski I, Kulcenty K, Suchorska W (2020) Interplay between inflammation and cancer. Rep Pract Oncol Radiother 25:422-427

Pogribny IP, Rusyn I (2013) Environmental toxicants, epigeneticas, and cancer. Adv Exp Med Biol

Poiesz BJ, Ruscetti FW, Gazdar AF et al (1980) Detection and isolation of type $\mathrm{C}$ retrovirus particles from fresh and cultured lymphocytes of a patient with cutaneous T-cell lymphoma. Proc Natl Acad Sci U S A 77:7415-7419. https://doi.org/10.1073/pnas.77.12.7415

Poirier MC, Lair S, Michaud R et al (2019) Intestinal polycyclic aromatic hydrocarbon-DNA adducts in a population of beluga whales with high levels of gastrointestinal cancers. Environ Mol Mutagen 60: 29-41. https://doi.org/10.1002/em.22251

Preventive (2018) MM-E health and undefined Inflammation and cancer. environhealthprevmed.

Rachidi S, Metelli A, Riesenberg B et al (2017) Platelets subvert T cell immunity against cancer via GARP-TGF axis. Sci Immunol 2: eaai7911. https://doi.org/10.1126/sciimmunol.aai7911

Rafati Rahimzadeh M, Rafati Rahimzadeh M, Kazemi S, Moghadamnia A-A (2017) Cadmium toxicity and treatment: An update. Casp J Intern Med 8:135-145. https://doi.org/10.22088/cjim.8.3.135 
Rahman M, Bajgai J, Fadriquela A, et al (2019) Characteristics and antibacterial effects of mineral supplement-hypochlorous acid water on human pathogenic bacteria. researchgate.net

Rahman M, Rahman H, Hossain M et al (2020) Molecular insights into the multifunctional role of natural compounds: autophagy modulation and cancer prevention. Biomedicines. https://doi.org/10.31219/ OSF.IO/AHC58

Rahman M, Hannan M, Raju Dash, (2021) undefined Phytochemicals as a complement to cancer chemotherapy: pharmacological modulation of the autophagy-apoptosis pathway. ncbi.nlm.nih.gov. Accessed 26 Aug 2021

Rajalakshmi TR, Aravindhababu N, Shanmugam KT, Masthan KMK (2015) DNA adducts-chemical addons. J Pharm Bioallied Sci

Ramilo C, Gu L, Guo S et al (2002) Partial reconstitution of human DNA mismatch repair in vitro: characterization of the role of human replication protein A. Mol Cell Biol 22:2037-2046. https://doi.org/10. 1128/MCB.22.7.2037-2046.2002

Rana C, Piplani H, Vaish V et al (2015) Downregulation of PI3-K/Akt/ PTEN pathway and activation of mitochondrial intrinsic apoptosis by Diclofenac and Curcumin in colon cancer. Mol Cell Biochem 402:225-241. https://doi.org/10.1007/s11010-015-2330-5

Rao C V., Pal S, Mohammed A, et al (2017) Biological effects and epidemiological consequences of arsenic exposure, and reagents that can ameliorate arsenic damage in vivo. Oncotarget 8:5760557621. 10.18632/oncotarget. 17745

Rastogi RP, Richa KA et al (2010) Molecular mechanisms of ultraviolet radiation-induced DNA damage and repair. J Nucleic Acids 2010: 592980. https://doi.org/10.4061/2010/592980

Reddig A, Rödiger S, Schierack P (2018) DNA damage assessment and potential applications in laboratory diagnostics and precision medicine Emerging assay technologies for celiac disease diganostics View project Glycoprotein 2-a novel serological marker for acute pancreatitis View project. https://doi.org/10.21037/jlpm.2018.03.06

Repair KS-D, 2016 undefined Molecular mechanisms of DNA damage recognition for mammalian nucleotide excision repair. Elsevier

Ricciardi M, Zanotto M, Malpeli G et al (2015) Epithelial-tomesenchymal transition (EMT) induced by inflammatory priming elicits mesenchymal stromal cell-like immune-modulatory properties in cancer cells. Br J Cancer. https://doi.org/10.1038/bjc.2015.29

Richards EJ, Elgin SCR (2002) Epigenetic codes for heterochromatin formation and silencing: Rounding up the usual suspects. Cell

Richardson C, Jasin, M.(2000) undefined Frequent chromosomal translocations induced by DNA double-strand breaks. Nature nature. com. Accessed 25 Aug 2021

Riffle S, Pandey RN, Albert M, Hegde RS (2017) Linking hypoxia, DNA damage and proliferation in multicellular tumor spheroids. BMC Cancer 17:338. https://doi.org/10.1186/s12885-017-3319-0

Ripley LS (2013) Mutation. In: Brenner's Encyclopedia of Genetics: 2nd Edition

Roberts HR, Smartt HJM, Greenhough A et al (2011) Colon tumour cells increase PGE2 by regulating COX-2 and $15-\mathrm{PGDH}$ to promote survival during the microenvironmental stress of glucose deprivation. Carcinogenesis 32:1741-1747. https://doi.org/10.1093/carcin/ bgr 210

Rositch AF (2020) Global burden of cancer attributable to infections: the critical role of implementation science. Lancet Glob Health 8:e153e154

Rossman TG, Uddin AN, Burns FJ (2004) Evidence that arsenite acts as a cocarcinogen in skin cancer. Toxicol Appl Pharmacol 198:394-404. https://doi.org/10.1016/j.taap.2003.10.016

Roychowdhury R, Tah J (2013) Mutagenesis - a potential approach for crop improvement. In: Crop Improvement: New Approaches and Modern Techniques. pp 149-187

Saito Y, Suzuki H, Imaeda H et al (2013) The tumor suppressor microRNA-29c is downregulated and restored by celecoxib in human gastric cancer cells. Int J Cancer 132:1751-1760. https:// doi.org/10.1002/ijc.27862

Salazar AM, Miller HL, McNeely SC et al (2010) Suppression of p53 and p21CIP1/WAF1 reduces arsenite-induced aneuploidy. Chem Res Toxicol 23:357-364. https://doi.org/10.1021/tx900353v

Sanchez AB, Garcia CCM, Di Mascio P, Medeiros MHG (2021b) Detection of DNA adduct formation in rat lungs by a microHPLC/MS/MS approach. Methods Mol Biol 2279:225-239. https://doi.org/10.1007/978-1-0716-1278-1_18

Sandhir R, Halder A, Sunkaria A (2017) Mitochondria as a centrally positioned hub in the innate immune response. Biochim Biophys Acta - Mol Basis Dis.

Sangha S, Yao M, Wolfe MM (2005) Non-steroidal anti-inflammatory drugs and colorectal cancer prevention. Postgrad Med J 81:223-227

Santella RM (2018) Immunological techniques for the detection and quantitation of 8-methoxypsoralen-DNA adducts. In: Psoralen DNA Photobiology

Sato H, Niimi A, Yasuhara T et al (2017) DNA double-strand break repair pathway regulates PD-L1 expression in cancer cells. Nat Commun. https://doi.org/10.1038/s41467-017-01883-9

Saxena P, Sharma PK, Purohit P (2020) A journey of celecoxib from pain to cancer. Prostaglandins Other Lipid Mediat 147:106379

Scarbrough PM, Weber RP, Iversen ES et al (2016) A cross-cancer genetic association analysis of the DNA repair and DNA damage signaling pathways for lung, ovary, prostate, breast, and colorectal cancer. Cancer Epidemiol Biomark Prev 25:193-200. https://doi. org/10.1158/1055-9965.EPI-15-0649

Schoental R (1968) Toxicology and carcinogenic action of pyrrolizidine alkaloids. Cancer Res 28:2237-2246

Sedelnikova OA, Bonner WM (2006) $\gamma \mathrm{H} 2 \mathrm{AX}$ in cancer cells: a potential biomarker for cancer diagnostics, prediction and recurrence. Cell Cycle 5:2909-2913. https://doi.org/10.4161/cc.5.24.3569

Selvakumaran M, Pisarcik DA, Bao R et al (2003) Enhanced cisplatin cytotoxicity by disturbing the nucleotide excision repair pathway in ovarian cancer cell lines. Cancer Res 63:1311-1316

Semenza GL (2010) Defining the role of hypoxia-inducible factor 1 in cancer biology and therapeutics. Oncogene

Semenza GL (2017) Hypoxia-inducible factors: coupling glucose metabolism and redox regulation with induction of the breast cancer stem cell phenotype. EMBO J 36:252-259. https://doi.org/10.15252/ embj.201695204

Shabeeb D, Najafi M, Musa AE et al (2019) Biochemical and histopathological evaluation of the radioprotective effects of melatonin against Gamma ray-induced skin damage. Curr Radiopharm 12: 72-81. https://doi.org/10.2174/1874471012666181120163250

Shah KV (2007) SV40 and human cancer: a review of recent data. Int J Cancer 120:215-223

Shapiro NI, Marshak MI, Varshaver NB (1984) Mutagenic effects of DNA-containing oncogenic viruses and malignant transformation of mammalian cells. Cancer Genet Cytogenet 13:167-179. https:// doi.org/10.1016/0165-4608(84)90058-x

Sharma P, Kaur J, Sanyal SN, Professor SNS (2010) Effect of etoricoxib, a cyclooxygenase- 2 selective inhibitor on aberrant crypt formation and apoptosis in 1,2 dimethyl hydrazine induced colon carcinogenesis in rat model. Nutr Hosp 25:39-48. https://doi.org/10.3305/nh. 2010.25.1.4603

Sheh A, Lee CW, Masumura K et al (2010) Mutagenic potency of Helicobacter pylori in the gastric mucosa of mice is determined by sex and duration of infection. Proc Natl Acad Sci 107:15217 LP15215222. https://doi.org/10.1073/pnas.1009017107

Shen W, Zhang X, Du R et al (2020) Ibuprofen mediates histone modification to diminish cancer cell stemness properties via a COX2dependent manner. Br J Cancer 123:730-741. https://doi.org/10. 1038/s41416-020-0906-7 
Shih WL, Fang CT, Chen PJ (2014) Anti-viral treatment and cancer control. Recent Results Cancer Res 193:269-290. https://doi.org/ 10.1007/978-3-642-38965-8 14

Shiiba M, Yamagami H, Yamamoto A et al (2017) Mefenamic acid enhances anticancer drug sensitivity via inhibition of aldo-keto reductase 1C enzyme activity. Oncol Rep 37:2025-2032. https://doi. org/10.3892/or.2017.5480

Siddiqui BA, Khan S (1999) Mutagenesis: Tools and techniques - a practical view. Breed Crop Plants Mutat Vitr Mutat Breed 20-32

Silbergeld EK (2003) Facilitative mechanisms of lead as a carcinogen. Mutat Res Fundam Mol Mech Mutagen 533:121-133. https://doi. org/10.1016/j.mrfmmm.2003.07.010

Silva J, Arantes-Rodrigues R, Pinto-Leite R et al (2017) Synergistic Effect of carboplatin and piroxicam on two bladder cancer cell lines. Anticancer Res 37:1737-1745

Singh N, Baby D, Rajguru J et al (2019) Inflammation and cancer. Ann Afr Med. https://doi.org/10.4103/aam.aam_56_18

Singh V, Kumar K, Purohit D, et al (2021) Exploration of therapeutic applicability and different signaling mechanism of various phytopharmacological agents for treatment of breast cancer. Elsevier

Sistigu A, Di Modugno F, Manic G, Nisticò P (2017) Deciphering the loop of epithelial-mesenchymal transition, inflammatory cytokines and cancer immunoediting. Cytokine Growth Factor Rev.

Smith JS, Munñoz N, Herrero R et al (2002a) Evidence for Chlamydia trachomatis as a human papillomavirus cofactor in the etiology of invasive cervical cancer in Brazil and the Philippines. J Infect Dis 185:324-331. https://doi.org/10.1086/338569

Smith RL, Adams TB, Doull J et al (2002b) Safety assessment of allylalkoxybenzene derivatives used as flavouring substances methyl eugenol and estragole. Food Chem Toxicol

Sokolova O, Naumann M (2019) Crosstalk between DNA damage and inflammation in the multiple steps of gastric carcinogenesis. In: Current Topics in Microbiology and Immunology

Srivastava M, Nambiar M, Sharma S et al (2012) An inhibitor of nonhomologous end-joining abrogates double-strand break repair and impedes cancer progression. Cell 151:1474-1487. https://doi.org/10. 1016/j.cell.2012.11.054

Srivatsa S, Paul MC, Cardone C et al (2017) EGFR in tumor-associated myeloid cells promotes development of colorectal cancer in mice and associates with outcomes of patients. Gastroenterology. https:// doi.org/10.1053/j.gastro.2017.03.053

Steenken S, Jovanovic SV (1997) How easily oxidizable is DNA? Oneelectron reduction potentials of adenosine and guanosine radicals in aqueous solution. J Am Chem Soc. https://doi.org/10.1021/ ja962255b

Strayer DS (1999) Gene therapy using SV40-derived vectors: what does the future hold? J Cell Physiol 181:375-384. https://doi.org/10. 1002/(SICI)1097-4652(199912)181:3<375::AID-JCP1>3.0.CO;2-

Strickland KC, Howitt BE, Shukla SA et al (2016) Association and prognostic significance of BRCA1/2-mutation status with neoantigen load, number of tumor-infiltrating lymphocytes and expression of PD-1/PD-L1 in high grade serous ovarian cancer. Oncotarget. https://doi.org/10.18632/oncotarget.7277

Suarez-Carmona M, Lesage J, Cataldo D, Gilles C (2017) EMT and inflammation: inseparable actors of cancer progression. Mol. Oncol.

Sudprasert W, Navasumrit P, Ruchirawat M (2006) Effects of low-dose gamma radiation on DNA damage, chromosomal aberration and expression of repair genes in human blood cells. Int J Hyg Environ Health 209:503-511. https://doi.org/10.1016/j.ijheh.2006. 06.004

Sugasawa K, Akagi J, Nishi R, et al (2009) Two-step recognition of DNA damage for mammalian nucleotide excision repair: directional binding of the XPC complex and DNA strand scanning. Elsevier
Sui HH, Zhou YJ, Wang H et al (2018) Effects of sulindac sulfide on proliferation and apoptosis of human breast cancer cell. Oncol Lett 15:7981-7986. https://doi.org/10.3892/ol.2018.8331

Sweet BH, Hilleman MR (1960) The Vacuolating Virus, S.V.40. Proc Soc Exp Biol Med 105:420-427. https://doi.org/10.3181/ 00379727-105-26128

Szikriszt B, Póti Á, Pipek O et al (2016) A comprehensive survey of the mutagenic impact of common cancer cytotoxics. Genome Biol 17: 1-16. https://doi.org/10.1186/s13059-016-0963-7

Tachibana M (2018) The immunosuppressive function of myeloidderived suppressor cells is regulated by the HMGB1-TLR4 axis. Yakugaku Zasshi. https://doi.org/10.1248/yakushi.17-00158

Tafani M, Sansone L, Limana F, et al (2016) The interplay of reactive oxygen species, hypoxia, inflammation, and sirtuins in cancer initiation and progression. Oxid Med Cell. Longev.

Tan Allen K, Chin-Sinex H, DeLuca T et al (2015) Dichloroacetate alters Warburg metabolism, inhibits cell growth, and increases the X-ray sensitivity of human A549 and H1299 NSC lung cancer cells. Free Radic Biol Med 89:263-273. https://doi.org/10.1016/j. freeradbiomed.2015.08.006

Tandon SK, Prasad S, Singh S (2002) Chelation in metal intoxication: influence of cysteine or N-acetyl cysteine on the efficacy of 2,3dimercaptopropane-1-sulphonate in the treatment of cadmium toxicity. J Appl Toxicol 22:67-71. https://doi.org/10.1002/jat.827

Tansan S, Emri S, Selçuk T et al (1994) Treatment of malignant pleural mesothelioma with cisplatin, mitomycin $\mathrm{C}$ and alpha interferon. Oncology 51:348-351. https://doi.org/10.1159/000227363

Temko D, Tomlinson IPM, Severini S et al (2018) The effects of mutational processes and selection on driver mutations across cancer types. Nat Commun 9:1-10. https://doi.org/10.1038/s41467-01804208-6

Tewari M, Mishra RR, Shukla HS (2010) Salmonella typhi and gallbladder cancer: report from an endemic region. Hepatobiliary Pancreat Dis Int 9:524-530

Tiwari M (2012) Antimetabolites: established cancer therapy. J Cancer Res Ther 8:510-519. https://doi.org/10.4103/0973-1482.106526

Tokar EJ, Qu W, Liu J et al (2010) Arsenic-specific stem cell selection during malignant transformation. J Natl Cancer Inst 102:638-649. https://doi.org/10.1093/jnci/djq093

Tołoczko-Iwaniuk N, Dziemiańczyk-Pakieła D, Nowaszewska BK et al (2018) Celecoxib in cancer therapy and prevention - review. Curr Drug Targets 20:302-315. https://doi.org/10.2174/ 1389450119666180803121737

Torgovnick A, Schumacher B (2015) DNA repair mechanisms in cancer development and therapy. Front Genet 6:157

Totsuka Y, Watanabe M, Lin Y (2021) New horizons of DNA adductome for exploring environmental causes of cancer. Cancer Sci 112:7-15

Toxicology KS-MR in G, (1992) undefined Spontaneous mutagenesis: experimental, genetic and other factors. Elsevier

Triner D, Shah YM (2016) Hypoxia-inducible factors: a central link between inflammation and cancer. J Clin Invest

Tseng WW, Deganutti A, Chen MN et al (2002) Selective cyclooxygenase-2 inhibitor rofecoxib (Vioxx) induces expression of cell cycle arrest genes and slows tumor growth in human pancreatic cancer. J Gastrointest Surg 6:838-844. https://doi.org/10.1016/ S1091-255X(02)00061-6

Tu S, Bhagat G, Cui G et al (2008) Overexpression of interleukin-1beta induces gastric inflammation and cancer and mobilizes myeloidderived suppressor cells in mice. Cancer Cell 14:408-419. https:// doi.org/10.1016/j.ccr.2008.10.011

Tully DB, Collins BJ, Overstreet JD et al (2000) Effects of arsenic, cadmium, chromium, and lead on gene expression regulated by a battery of 13 different promoters in recombinant HepG2 cells. Toxicol Appl Pharmacol. https://doi.org/10.1006/taap.2000.9014 
Turanli B, Grøtli M, Boren J, et al (2018) Drug repositioning for effective prostate cancer treatment. Front Physiol 0:500. https://doi.org/10. 3389/FPHYS.2018.00500

U.S. Food and Drug Administration (2017) FDA approves first-of-itskind product for the treatment of melanoma. In: U.S. Food Drug Adm.

Uldrick TS, Whitby D (2011) Update on KSHV epidemiology, Kaposi Sarcoma pathogenesis, and treatment of Kaposi Sarcoma. Cancer Lett 305:150-162

Ultrasound D Of I, Venous S, et al (2004) Treatment of H. pylori infectionc. 158:55-58

Uppu RM, Cueto R, Squadrito GL et al (1996) Competitive reactions of peroxynitrite with 2'-deoxyguanosine and 7,8- dihydro-8-oxo-2'deoxyguanosine (8-oxodG): Relevance to the formation of 8oxodG in DNA exposed to peroxynitrite. Free Radic Biol Med. https://doi.org/10.1016/0891-5849(96)00220-1

Urbano AM, LMR F, Alpoim MC (2012) Molecular and cellular mechanisms of hexavalent chromium-induced lung cancer: an updated perspective. Curr Drug Metab 13:284-305. https://doi.org/10. 2174/138920012799320464

Van Allen EM, Mouw KW, Kim P et al (2014) Somatic ERCC2 mutations correlate with cisplatin sensitivity in muscle-invasive urothelial carcinoma. Cancer Discov 4:1140-1153. https://doi.org/10.1158/ 2159-8290.CD-14-0623

Heemst D van, Brugmans L, Verkaik N, et al (2004) End-joining of blunt DNA double-strand breaks in mammalian fibroblasts is precise and requires DNA-PK and XRCC4. Elsevier

van Tong H, Brindley PJ, Meyer CG, Velavan TP (2017) Parasite infection, carcinogenesis and human malignancy. EBioMedicine 15:1223. https://doi.org/10.1016/j.ebiom.2016.11.034

Vane JR (1971) Inhibition of prostaglandin synthesis as a mechanism of action for aspirin-like drugs. Nat New Biol 231:232-235. https:// doi.org/10.1038/newbio231232a0

Vasen H, Wijnen J, Menko F, et al (1996) Cancer risk in families with hereditary nonpolyposis colorectal cancer diagnosed by mutation analysis. Elsevier

Vaupel P, Harrison L (2004) Tumor hypoxia: causative factors, compensatory mechanisms, and cellular response. Oncologist. https://doi. org/10.1634/theoncologist.9-90005-4

Vega L, Gonsebatt ME, Ostrosky-Wegman P (1995) Aneugenic effect of sodium arsenite on human lymphocytes in vitro: an individual susceptibility effect detected. Mutat Res Mutagen Relat Subj 334:365373. https://doi.org/10.1016/0165-1161(95)90074-8

Vici P, Di Benedetto A, Ercolani C et al (2015) Predictive significance of DNA damage and repair biomarkers in triple-negative breast cancer patients treated with neoadjuvant chemotherapy: an exploratory analysis. Oncotarget 6:42773-42780. https://doi.org/10.18632/ oncotarget.6001

Vici P, Buglioni S, Sergi D et al (2016) DNA damage and repair biomarkers in cervical cancer patients treated with neoadjuvant chemotherapy: an exploratory analysis. PLoS One 11:e0149872. https:// doi.org/10.1371/journal.pone.0149872

Vilchez RA, Butel JS (2004) Emergent human pathogen simian virus 40 and its role in cancer. Clin Microbiol Rev 17:495-508

Vineis P, Pirastu R (1997) Aromatic amines and cancer. Cancer Causes Control 8:346-355. https://doi.org/10.1023/A:1018453104303

Vogelzang NJ, Rusthoven JJ, Symanowski J et al (2003) Phase III study of pemetrexed in combination with cisplatin versus cisplatin alone in patients with malignant pleural mesothelioma. J Clin Oncol Off J Am Soc Clin Oncol 21:2636-2644. https://doi.org/10.1200/JCO. 2003.11.136

Volker M, Moné M, Karmakar P, et al (2001) Sequential assembly of the nucleotide excision repair factors in vivo. Elsevier

Volkova N, Meier B, Víctor González-Huici, (2020) undefined Mutational signatures are jointly shaped by DNA damage and repair. nature.com. Accessed 26 Aug 2021
Waldvogel A-M, Pfenninger M (2020) Temperature-dependence of spontaneous mutation rates. bioRxiv 2020.11.03.366807. https:// doi.org/10.1101/2020.11.03.366807

Wang JS, Groopman JD (1999) DNA damage by mycotoxins. Mutat Res Fundam Mol Mech Mutagen. https://doi.org/10.1016/S00275107(99)00017-2

Wang HM, Zhang GY (2005) Indomethacin suppresses growth of colon cancer via inhibition of angiogenesis in vivo. World J Gastroenterol 11:340-343. https://doi.org/10.3748/wjg.v11.i3.340

Wang S, Zhang Y (2020) HMGB1 in inflammation and cancer. J Hematol Oncol

Wang L, Xue M, Chung DC (2016) c-Myc is regulated by HIF-2 $\alpha$ in chronic hypoxia and influences sensitivity to $5-\mathrm{FU}$ in colon cancer. Oncotarget. https://doi.org/10.18632/oncotarget.12911

Wang Y, Su H, Gu Y et al (2017) Carcinogenicity of chromium and chemoprevention: a brief update. Onco Targets Ther 10:40654079. https://doi.org/10.2147/OTT.S139262

Wang Z, Zhao J, Wang G et al (2018) Comutations in DNA damage response pathways serve as potential biomarkers for immune checkpoint blockade. Cancer Res 78:6486-6496. https://doi.org/10.1158/ 0008-5472.CAN-18-1814

Watson WP (1987) Post-radiolabelling for detecting DNA damage. Mutagenesis

Watson WP, Brooks TM, Gonzalez LP, Wright AS (1985) Genotoxicity studies with mineral oils; effects of oils on the microbial mutagenicity of precursor mutagens and genotoxic metabolites. Mutat Res 149:159-170. https://doi.org/10.1016/0027-5107(85)90022-3

Weber A, Tannapfel A, Wittekind C (2002) OR and undefined Carcinogen-induced site-specific mutagenesis and genetic susceptibility in squamous cell carcinoma of the head and neck. karger.com. Accessed 26 Aug 2021

Wei YD, Tepperman K, Huang MY et al (2004) Chromium inhibits transcription from polycyclic aromatic hydrocarbon-inducible promoters by blocking the release of histone deacetylase and preventing the binding of p300 to chromatin. J Biol Chem. https://doi.org/10. 1074/jbc.M310800200

Wei S, Zhang H, Tao S (2019) A review of arsenic exposure and lung cancer. Toxicol Res (Camb) 8:319-327. https://doi.org/10.1039/ c8tx00298c

Weitzman MD, Lilley CE, Chaurushiya MS (2010) Genomes in conflict: maintaining genome integrity during virus infection. Annu Rev Microbiol 64:61-81

Weterings E, Dik C. van Gen, (2004) undefined The mechanism of nonhomologous end-joining: a synopsis of synapsis. DNA Repair Elsevier

White JD, Wharfe G, Stewart DM et al (2001) The combination of zidovudine and interferon aipha-2B in the treatment of adult T-cell leukemia/lymphoma. Leuk Lymphoma 40:287-294. https://doi.org/10. 3109/10428190109057927

Wilby KJ, Partovi N, Ford JAE et al (2012) Review of boceprevir and telaprevir for the treatment of chronic hepatitis C. Can J Gastroenterol 26:205-210

Wild CP, Montesano R (2009) A model of interaction: aflatoxins and hepatitis viruses in liver cancer aetiology and prevention. Cancer Lett 286:22-28. https://doi.org/10.1016/j.canlet.2009.02.053

Willmore E, de Caux S, Sunter NJ et al (2004) A novel DNA-dependent protein kinase inhibitor, NU7026, potentiates the cytotoxicity of topoisomerase II poisons used in the treatment of leukemia. Blood 103:4659-4665. https://doi.org/10.1182/blood-2003-07-2527

Wilson WR, Hay MP (2011) Targeting hypoxia in cancer therapy. Nat Rev Cancer

Wilson MR, Jiang Y, Villalta PW et al (2019) The human gut bacterial genotoxin colibactin alkylates DNA. Science (80-) 363:eaar7785. https://doi.org/10.1126/science.aar7785 
Wogan GN, Hecht SS, Felton JS et al (2004) Environmental and chemical carcinogenesis. Semin Cancer Biol. https://doi.org/10.1016/j. semcancer.2004.06.010

Wong RSY (2019) Role of nonsteroidal anti-inflammatory drugs (NSAIDs) in cancer prevention and cancer promotion. Adv Pharmacol Sci 2019:3418975

Woodford N, Ellington MJ (2007) The emergence of antibiotic resistance by mutation. Clin Microbiol Infect Off Publ Eur Soc Clin Microbiol Infect Dis 13:5-18. https://doi.org/10.1111/j.1469-0691.2006. 01492.x

Wrann S, Kaufmann MR, Wirthner R et al (2013) HIF mediated and DNA damage independent histone $\mathrm{H} 2 \mathrm{AX}$ phosphorylation in chronic hypoxia. Biol Chem 394:519-528. https://doi.org/10.1515/ hsz-2012-0311

Xie Y (2017) Hepatitis B virus-associated hepatocellular carcinoma. In: Advances in Experimental Medicine and Biology. Springer New York LLC, pp 11-21

Xie Y, Liu J, Benbrahim-Tallaa L et al (2007) Aberrant DNA methylation and gene expression in livers of newborn mice transplacentally exposed to a hepatocarcinogenic dose of inorganic arsenic. Toxicology. https://doi.org/10.1016/j.tox.2007.03.021

Xie Y, Chen Y, Guo Y et al (2020) Allicin and glycyrrhizic acid display antiviral activity against latent and lytic Kaposi Sarcoma-associated herpesvirus. Infect Microbes Dis 2:30-34. https://doi.org/10.1097/ im9.0000000000000016

Yarchoan M, Johnson BA, Lutz ER, et al (2017) Targeting neoantigens to augment antitumour immunity. Nat. Rev. Cancer

Yasinska IM, Gonçalves Silva I, Sakhnevych SS et al (2018) High mobility group box 1 (HMGB1) acts as an "alarmin" to promote acute myeloid leukaemia progression. Oncoimmunology. https://doi.org/ 10.1080/2162402X.2018.1438109

Yin T, Wang G, Ye T, Wang Y (2016) Sulindac, a non-steroidal antiinflammatory drug, mediates breast cancer inhibition as an immune modulator. Sci Rep 6:1-8. https://doi.org/10.1038/srep19534

Young SD, Marshall RS, Hill RP (1988) Hypoxia induces DNA overreplication and enhances metastatic potential of murine tumor cells. Proc Natl Acad Sci USA. https://doi.org/10.1073/pnas.85.24. 9533

Yu H-S, Liao W-T, Chai C-Y (2006) Arsenic carcinogenesis in the skin. J Biomed Sci 13:657-666. https://doi.org/10.1007/s11373-006-9092-

Yu EY, Massard C, Retz M et al (2019) Keynote-365 cohort a: Pembrolizumab (pembro) plus olaparib in docetaxel-pretreated patients (pts) with metastatic castrate-resistant prostate cancer (mCRPC). J Clin Oncol. https://doi.org/10.1200/jco.2019.37.7 suppl.145

Yu H, Lin L, Zhang Z, et al (2020) Targeting NF-kB pathway for the therapy of diseases: mechanism and clinical study. Signal Transduct Target Ther

Yuan CL, He F, Ye JZ et al (2017) APE1 overexpression is associated with poor survival in patients with solid tumors: a meta-analysis. Oncotarget 8:59720-59728. https://doi.org/10.18632/oncotarget. 19814

Yuan S, Liu Z, Xu Z, et al (2020) High mobility group box 1 (HMGB1): a pivotal regulator of hematopoietic malignancies. J Hematol Oncol

Yun G, Huang M, Yao Y-m (2021) The effect and regulatory mechanism of high mobility group Box-1 protein on immune cells in inflammatory diseases. Cells 10:1044. https://doi.org/10.3390/ CELLS10051044

Yusuff O, Rafii M, Abdullah N et al (2015) Principle and application of plant mutagenesis in crop improvement: a review. Biotechnol Biotechnol Equip 30:1-16. https://doi.org/10.1080/13102818. 2015.1087333

Zappavigna S, Cossu AM, Grimaldi A et al (2020) Anti-inflammatory drugs as anticancer agents. Int J Mol Sci 21:1-29. https://doi.org/10. 3390/ijms21072605

Zelenay S, Van Der Veen AG, Böttcher JP et al (2015) Cyclooxygenasedependent tumor growth through evasion of immunity. Cell 162: 1257-1270. https://doi.org/10.1016/j.cell.2015.08.015

Zhai Q, Narbad A, Chen W (2015) Dietary strategies for the treatment of cadmium and lead toxicity. Nutrients 7:552-571. https://doi.org/10. 3390/nu7010552

Zhang YJ, Ahsan H, Chen Y et al (2002) High frequency of promoter hypermethylation of RASSF1A and p16 and its relationship to aflatoxin B1-DNA adduct levels in human hepatocellular carcinoma. Mol Carcinog. https://doi.org/10.1002/mc.10076

Zhang Y, Yuan F, Presnell SR et al (2005) Reconstitution of 5'-directed human mismatch repair in a purified system. Cell 122:693-705. https://doi.org/10.1016/j.cell.2005.06.027

Zhang J, Stevens MFG, Bradshaw TD (2012) Temozolomide: mechanisms of action, repair and resistance. Curr Mol Pharmacol 5:102 114. https://doi.org/10.2174/1874467211205010102

Zhang H, Wei K, Zhang M et al (2014) Assessing the mechanism of DNA damage induced by lead through direct and indirect interactions. J Photochem Photobiol B Biol 136:46-53. https://doi.org/10. 1016/j.jphotobiol.2014.04.020

Zhang MS, Niu FW, Li K (2015a) Proflavin suppresses the growth of human osteosarcoma MG63 cells through apoptosis and autophagy. Oncol Lett 10:463-468. https://doi.org/10.3892/ol.2015.3206

Zhang Y, Chen Y, Huang H et al (2015b) Diagnostic radiography exposure increases the risk for thyroid microcarcinoma: a populationbased case-control study. Eur J Cancer Prev 24:439-446. https:// doi.org/10.1097/CEJ.0000000000000169

Zhang W, Zhang D, Dou X et al (2018a) Consensus on pegylated interferon alpha in treatment of chronic hepatitis B. J Clin Transl Hepatol 6:1-10. https://doi.org/10.14218/JCTH.2017.00073

Zhang Z, Chen F, Shang L (2018b) Advances in antitumor effects of NSAIDs. Cancer Manag Res 10:4631. https://doi.org/10.2147/ CMAR.S175212

Zhang J, Shih DJH, Lin SY (2020) Role of DNA repair defects in predicting immunotherapy response. Biomark Res 8:23

Zhou X, Zhang X, Xie Y et al (2013) DNA-PKcs inhibition sensitizes cancer cells to carbon-ion irradiation via telomere capping disruption. PLoS One 8:e72641. https://doi.org/10.1371/journal.pone. 0072641

Zhou W, Guo S, Liu M et al (2017) Targeting CXCL12/CXCR4 axis in tumor immunotherapy. Curr Med Chem. https://doi.org/10.2174/ 0929867324666170830111531

Zur Hausen H (1991) Viruses in human cancers. Science (80-) 254:1167 LP-1161173. https://doi.org/10.1126/science.1659743

Publisher's note Springer Nature remains neutral with regard to jurisdictional claims in published maps and institutional affiliations. 